University of New Hampshire

University of New Hampshire Scholars' Repository

Master's Theses and Capstones

Student Scholarship

Spring 2018

\title{
A wideband acoustic method for direct assessment of bubble- mediated methane flux
}

Elizabeth Frances Weidner

University of New Hampshire, Durham

Follow this and additional works at: https://scholars.unh.edu/thesis

\section{Recommended Citation}

Weidner, Elizabeth Frances, "A wideband acoustic method for direct assessment of bubble-mediated methane flux" (2018). Master's Theses and Capstones. 1177.

https://scholars.unh.edu/thesis/1177

This Thesis is brought to you for free and open access by the Student Scholarship at University of New Hampshire Scholars' Repository. It has been accepted for inclusion in Master's Theses and Capstones by an authorized administrator of University of New Hampshire Scholars' Repository. For more information, please contact Scholarly.Communication@unh.edu. 


\title{
A WIDEBAND ACOUSTIC METHOD FOR DIRECT ASSESSMENT OF BUBBLE- MEDIATED METHANE FLUX
}

\author{
BY \\ ELIZABETH WEIDNER \\ Oceanography (BS), University of Washington, 2012
}

THESIS

Submitted to the University of New Hampshire

In Partial Fulfillment of

The Requirements for the Degree of

Master of Science

In

Earth Science: Ocean Mapping

May, 2018 
This thesis has been examined and approved in partial fulfillment of the requirements for the degree of Master of Science in Earth Science by:

Thesis Director, Thomas C. Weber, Associate Professor of Mechanical Engineering

Layer Mayer, Director, Center for Coastal and Ocean Mapping

Joel Johnson, Associate Professor of Geology

April 19, 2018

Date

Original approval signatures are on file with the University of New Hampshire Graduate School. 


\section{ACKNOWLEDGEMENTS}

This research was supported under a series of grants: NSF grant 1417789, NSF grant 1352301, and NOAA grant NA15NOS4000200. The authors would likely to thank Captain Erik Andersson and crew of icebreaker Oden, as well as the science party of the SWERUS-C3 program for their work. Additionally, we would like to thank Anthony Lyons, Alexandra Padilla, Kevin Jerram, and Samuel Reed for their support on this research and manuscript. 


\section{TABLE OF CONTENTS}

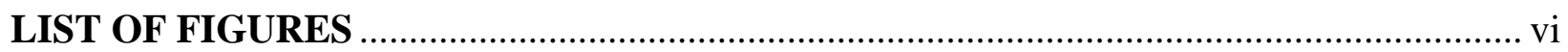

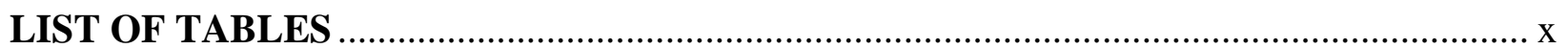

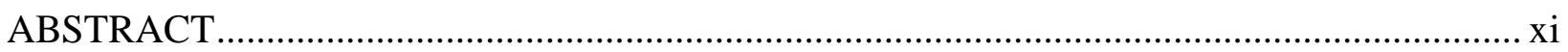

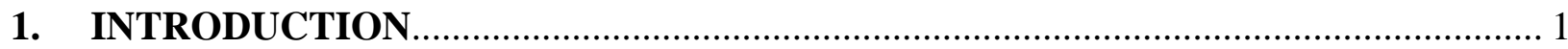

2. WIDEBAND, SPLIT-BEAM ACOUSTIC OBSERVATIONS OF INDIVIDUAL

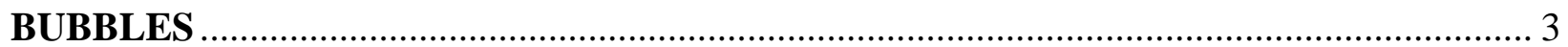

3. DATA COLLECTION AND IDENTIFICATION OF GAS SEEPS ……....................... 7

4. INDIVIDUAL BUBBLE SAMPLING AND PARAMETER ESTIMATION................ 10

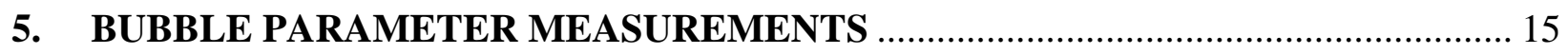

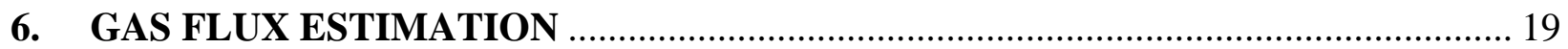

6.1 Instantaneous gas flux estimation ....................................................................... 19

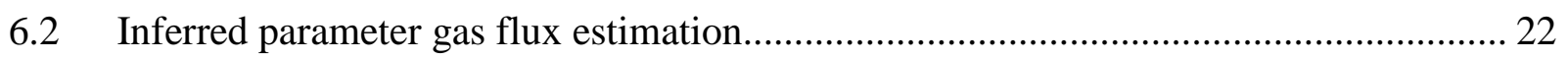

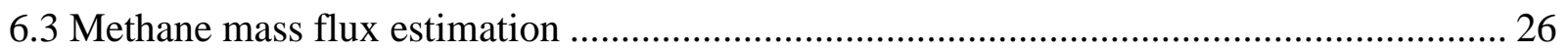

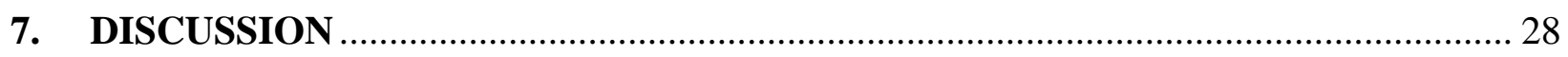

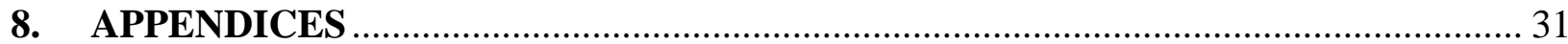

8.1 Acoustic scattering from single vs multiple bubble scatterers ....................................... 31

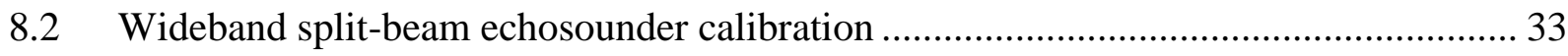

8.3 Acoustic background noise intensity ....................................................................... 36

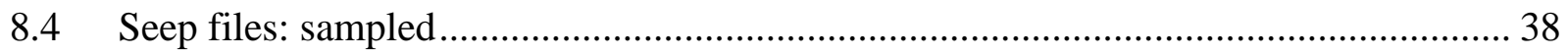

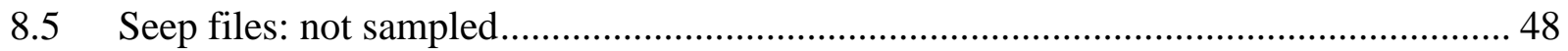

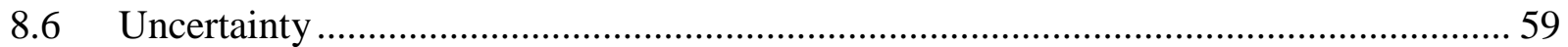

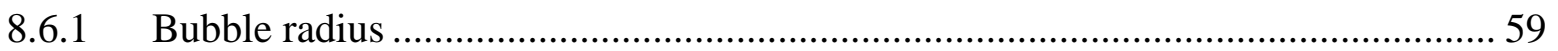

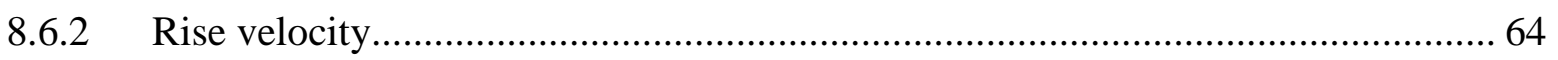

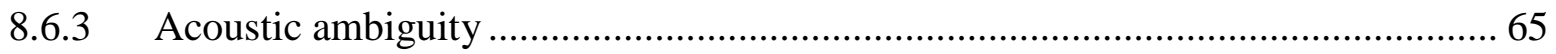

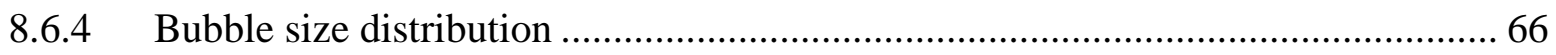

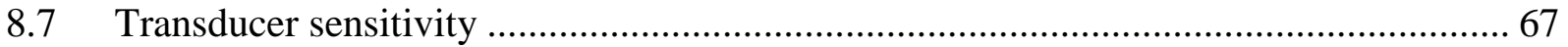

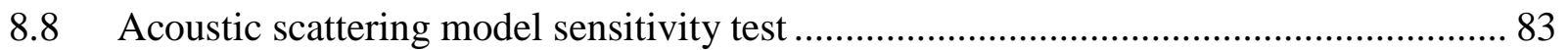

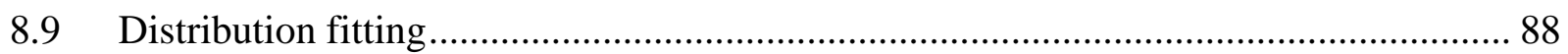

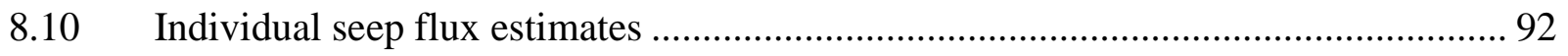

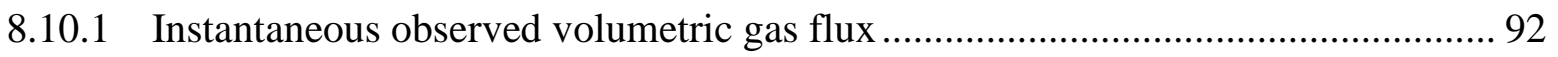

8.10.2 Inferred parameter volumetric gas flux............................................................ 93 


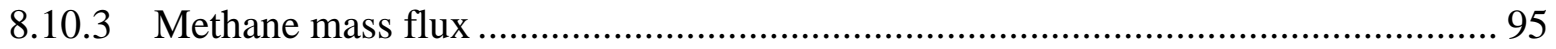

8.11 Herald Canyon oceanographic measurements .................................................... 97

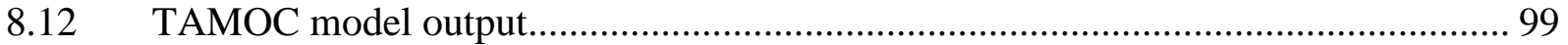

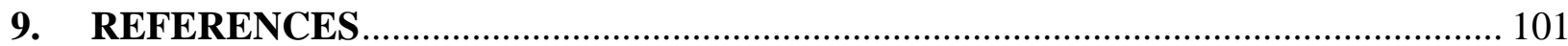




\section{LIST OF FIGURES}

Figure 1. Modeled frequency modulated TS curves for typical seep sized bubbles in typical Arctic Ocean conditions (temperature of $6^{\circ}$ and salinity of $30 \mathrm{PSU}$ ) at $50 \mathrm{~m}$ depth, assuming bubble composition of $100 \%$ methane gas. Shaded box indicates the study frequency band (16$26 \mathrm{kHz})$.

Figure 2. An overview of Icebreaker Oden's vessel track (black line) through the Arctic Ocean during SWERUS-C3 Leg 2. Cut-out box shows the vessel track from August 24-26, 2014 during operations in the Herald Canyon region of the ESAS. All identified 89 seep features are marked (blue markers), with areas of high seep density identified by additional boxes and total seep counts listed. IBCAO grid from: https://www.ngdc.noaa.gov/mgg/bathymetry/arctic/images/IBCAO_ver1map_letter.jpg. 7 Figure 3. EK80 echograms showing acoustic anomalies associated with gas seep and other scatterers (e.g. fish and biological scattering). Each echogram is displayed as a series of vertical time series, colored by sound pressure moving forward in time and space from left to right. For visualization purposes data below $-65 \mathrm{~dB}$ are filtered out (black background).

Figure 4. Panel A shows the path of a single bubble through 23 pings with an inset showing bubble location in EK80 field of view. The crosses demarcate the center of the sampled data. Panel B plots the time elapsed since the first ping against the calculated bubble depth and the linear regression through the path of the bubble. Average rise velocity is the slope of the regression. Panel C plots the bubble location in the EK80 field of view as determined from the mechanical along and across track phase angle. Panel D shows TS curve data for the same single bubble plotted as a function of frequency. The black dashed line represents the average of all TS curves for this bubble, calculated from the mean of bubble TS curves across all pings at each frequency......

Figure 5. The top panel shows the measured bubble radii and uncertainty values from Herald Canyon dataset and count of samples in radii bins centered at each $\mathrm{mm}$. Bubble radii data are plotted against altitude (bubble height above the seafloor) in order to compare data from seeps with a wide range of seafloor depths Bubble altitude is calculated by subtracting bubble depth from the depth of the seafloor. The lower panel shows the measured bubble radii plotted against rise velocities and uncertainty values from Herald Canyon dataset. Binned averages are calculated from intervals of equal number of samples $(\mathrm{N}=25)$. Clean and dirty modeled rise velocities are based of Clift et al., 1978.

Figure 6. Yearly volumetric gas flux estimates for all sampled seep in the Herald Canyon dataset. Black diamonds denote instantaneous observed gas flux estimates and red diamonds indicate gas flux estimates calculated from inferred seep parameters. Seeps are group by geomorphological clustering.

Figure 7. Spatial distribution of seep clusters in Herald Canyon, water column bubble size distributions plotted against altitude of the seep clusters, distributions of binned bubble size data, and gas flux as a function of bubble size. Cluster 1 bin centered at $25.2 \mathrm{~m}$ has an $\mathrm{N}=180$ and bubble water column density of 5.1 bubbles $/ \mathrm{m}$, Cluster 2 bin centered at $16.6 \mathrm{~m}$ has an $\mathrm{N}=32$ 
and bubble water column density of 1.1 bubbles/m; and Cluster 3 bin centered at $19 \mathrm{~m}$ has an $\mathrm{N}$ $=109$ and bubble water column density of 2.1 bubbles $/ \mathrm{m}$. ........................................... 24 Figure 8. Inferred seafloor bubble size distributions (blue squares), yearly seafloor methane mass flux (black diamonds), and yearly atmospheric methane mass flux (black circles) for seep clusters. 28

Figure 9. Acoustically tracking the ascent and separation of two bubble tracers. The top panel shows the zoomed view of the series of pings where the two bubbles separate. Target time series were sampled in a series of successive pings (point of maximum acoustic intensity is marked by cross). The first two samples time series (ping 113 and 114) include the additive acoustic response of multiple bubbles. The bottom panel shows the frequency modulated target strength

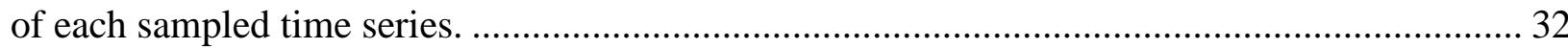
Figure 10. Locations and interactions between two bubble targets. First bubble (plotted in green) placed at 6.8 meters in range from transducer, second bubble placed at $5 \mathrm{~m}$ (yellow), $3.75 \mathrm{~m}$ (magenta), $1.1 \mathrm{~m}$ (red), $20 \mathrm{~cm}$ (blue), and $3 \mathrm{~cm}$ (cyan)...................................................... 33 Figure 11. Illustration of EK80 calibration procedure set up on the icebreaker Oden. .............. 34 Figure 12. The final calibration sphere location data is plotted in the left panel. The right panel shows the final calibration offset look-up table produced from field calibration activities. Offset value, given in decibels, were added to acoustic sound pressure data to account of beam pattern

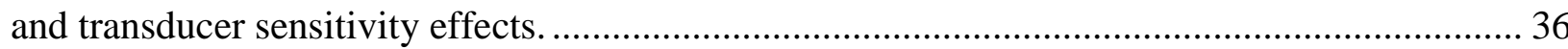
Figure 13. EK80 FM acoustic response of a single bubble (blue and black line) and acoustic background noise (red line). ............................................................................................. 37 Figure 14. Sampled seep files starting at top left: T000559, T010336, T014257, T042631_1 _... 38 Figure 15. Sampled seeps: Sampled seep files starting at top left: T043037_1, T063136_1, T063136_2, T063136_3 ...................................................................................... 39 Figure 16. Sampled seep files starting at top left: T063822, T065828_1, T065828_2, T071055 40 Figure 17. Sampled seep files starting at top left: T091020_1, T091020_3, T091439_1, T091439_3 41

Figure 18. Sampled seep files starting at top left: T091439_7, T091439_9, T091439_13,

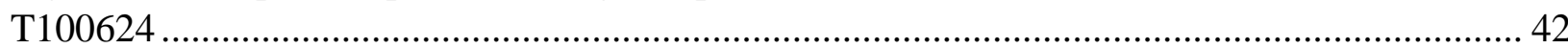
Figure 19: Sampled seep files starting at top left: T171859, T172318_1, T172318_3, T172318_4

Figure 20. Sampled seep files starting at top left: T173156_1, T174032_1, T174032_2, T175325

Figure 21. Sampled seep files starting at top left: T222721_1, T222271_2, T223151_1,

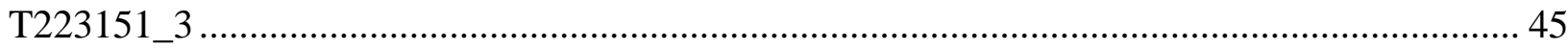

Figure 22. Sampled seep files starting at top left: T223151_5, T223620, T224048, T225859 _... 46

Figure 23. Sampled seep files, starting at top left: T234343_2, T234343_3 .......................... 47

Figure 24. Seep files not sampled: T023550, T042631_2, T043037_2, T043037_3 ................. 48

Figure 25. Seep files not sampled: T043037_3, T04307_4, T043441, T063136_2 _................ 49

Figure 26. Seep files not sampled: T071455, T071903, T091020_2, T091439_2, T091439_4... 50

Figure 27. Seep files not sampled: T091439_4, T091439_5, T091439_6, T091439_8 ............. 51

Figure 28. Seep files not sampled: T091439_10, T091439_11, T091439_12, T095942 ........... 52

Figure 29. Seep files not sampled: T101306, T123404_1, T123404_2, T150133_1 ................ 53 
Figure 30. Seep files not sampled: T150133_2, T150133_3, T150133_4, T150133_5 _............ 54

Figure 31. Seep files not sampled: T171445, T172318_2, T172318_5, T173156_2 _............... 55

Figure 32. Seep file not sampled: T174907_1, T174907_2, T174907_3, T223151_2.............. 56

Figure 33. Seep files not sampled, starting at top left: T223151_4, T224955_1, T224955_2,

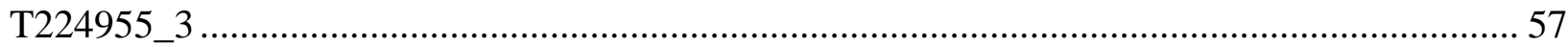

Figure 34. Seep files not sampled, starting at top left: T234343_1, T234343_4 ....................... 58

Figure 35. Individual bubble samples sorted by radius and plotted with calculated uncertainty (red) and running average uncertainty (black).

Figure 36. Individual bubble samples sorted by rise velocity and plotted with calculated uncertainty (red) and running average uncertainty (black).

Figure 37. Transducer geometry showing final mechanical angle (top panel) and plane-view transducer geometry for electrical phase angle calculation (bottom panel).

Figure 38. Left image depicts a transducer with split aperture array, with aperture centers separated by distance $\mathrm{d}$, a target located in the beam of transducer $\theta$ degrees off center axis, and recorded signals $S_{1}$ and $S_{\mathrm{r}}$ separated in space/time by $\delta$, defined below. The right image depicts the complex plane of with amplitude of $A$ and phase angle of $\varphi$.

Figure 39. Acoustic response of an individual bubble in an EK80 WBT echogram. An acoustic time series was sampled in each ping over range indicated by the black lines and the electrical phase angle was sampled from the point of maximum amplitude (red marker)....................... 70 Figure 40. Electrical phase angles of the bubble record calculated from the split aperture processing for an individual bubble record. 72

Figure 41. Left panel shows estimated electrical phase angles for the individual bubble (in red), plotted with the electrical phase angles of the rest of the sampled acoustic time series (in black) for each ping. Right panel shows the bubble location (as determined from the maximum amplitude sample) in plane view through the series of pings.

Figure 42. An example of the rise velocity derivation from the paired time and depth values for a bubble record. Average rise velocity is estimated from the slope of the regression and measurement uncertainty is calculated from the deviation of the measurement values from the regression.

Figure 43. Frequency dependence of bubble electrical phase angle for each ping record. Along track angle is plotted by a dotted line, across track angle is plotted by a dashed ling, analysis angle is plotted by a solid line, and the measurement of electrical phase angle from the single amplitude measurement is plotted by a horizontal red line (no frequency dependence). The location where the amplitude measurement of phase angle crosses the frequency dependent phase

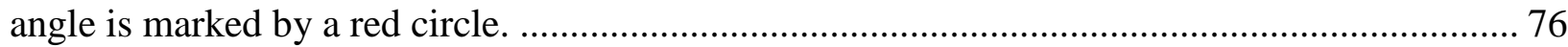
Figure 44. Examples of acoustic records where the measured frequency dependence of electrical phase angle matches to theoretical model for sensitivity well (ping number in lower right corner). 78

Figure 45. Examples of acoustic records where the measured frequency dependence of electrical phase angle does not match the theoretical model for sensitivity (ping number in lower right corner). 79

Figure 46. Spatial relationship between $18 \mathrm{kHz}$ bubble phase angles and theoretical model trends. Left figure indicates the level of agreement only considering the final analysis angle 
(combination of across and along track angles), while the right figure considers the agreement of along and across track angle agreement with the model. Full agreement (left panel) indicates the measured frequency dependency matched the model across the whole frequency range ( 16-26 $\mathrm{kHz}$ ), partial agreement (both left and right panel) indicates at there was agreement between measurements and model for a portion of the frequency range, and no agreement indicates there was little to no agreement between measurements and model in any part of the frequency range.

Figure 47. Top left panel shows the frequency where the original electrical phase angle (measured from the max amplitude value) crosses the frequency dependent electrical phase angle measured from the full bubble record. The average frequency crossing point is $18.8 \mathrm{kHz}$. The bottom left panel shows three different electrical phase angles calculated via different methodologies: red markers indicate the original electrical phase angle, black are the electrical phase angles at $18 \mathrm{kHz}$, and green are the electrical phase angles at $18.8 \mathrm{kHz}$ (average cross point from first panel). The right panel show the plane view of the electrical phase angles calculated from the three different methods.

Figure 48. Time and depth data pairs for each ping calculated from the three electrical phase angle options (same as figure 11). Rise velocity is estimated from the slope of the regression through the time and depth pairs.

Figure 49. Modeled target strength for $100 \%$ methane bubble with parameters: $\mathrm{z}=95 \mathrm{~m}, \mathrm{~T}=6$ $\mathrm{C}, \mathrm{S}=30$ PSU.

Figure 50. Comparison of modeled target strength of $1-5 \mathrm{~mm}$ bubbles composed of $100 \%$ methane and two different gas combinations. 86

Figure 51. Zoomed view of a $3 \mathrm{~mm}$ bubble target strength value at resonance peak (left) and

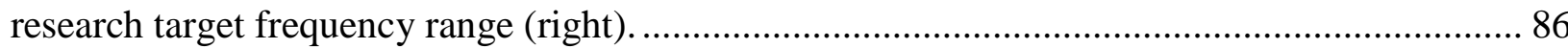

Figure 52. Cluster 1 bubble data binned at $5 \mathrm{~m}$ intervals. ................................................. 89

Figure 53. Cluster 2 bubble data binned at $5 \mathrm{~m}$ intervals. .................................................. 89

Figure 54. Cluster 3 bubble data binned in $5 \mathrm{~m}$ intervals................................................. 90

Figure 55.Histograms and fitted Rayleigh PDF of the binned bubble data for cluster 1 (cyan), cluster 2 (red), and cluster 3 (green).

Figure 56. BSD of each cluster in the watercolumn (solid line) and projected to the seafloor (dashed lines). Cluster 1 (left), cluster 2 (center), and cluster 3 (right).................................. 91

Figure 57.CTD cast locations in Herald Canyon during SWERUS-C3 operations..................... 97 Figure 58. Methane distribution in Herald Canyon - transects A, B (box 1). From SWERUS-C3 cruise report 97

Figure 59. Oceanography parameter profiles measured at CTD station \#74 during SWERUS survey operations. .................................................................................................. 98 Figure 60. TAMOC model output of bubble radius as a function of altitude for the seep cluster starting depths: cluster $1 @ 52$ m, cluster $2 @ 67$ m, and cluster $3 @ 89$ m.............................. 99 Figure 61. TAMOC model output of methane mass (moles) for each bubble size as a function of altitude: cluster1@52 m, cluster $2 @ 67$ m, and cluster $3 @ 89$ m. 100 


\section{LIST OF TABLES}

Table 1. Estimated yearly volumetric gas flux rates and methane mass flux rates to atmosphere as derived from both flux methodologies.

Table 2. Estimated mean uncertainty in the bubble radius and rise velocity measurements for the binned dataset. 61

Table 3. Constant parameters calculated in gas mixture function ........................................... 87

Table 4. Bubble parameters calculated in gas mixture function........................................... 87

Table 5. Bubble size distribution parameters for the clustered data set.................................. 91

Table 6. Direct flux estimations of Cluster 1 seeps ............................................................ 92

Table 7. Direct flux estimations of Cluster 2 seeps ............................................................ 92

Table 8. Direct flux estimations of Cluster 3 seeps .............................................................. 92

Table 9. Direct flux estimations of all seeps from study region ......................................... 93

Table 10. Flux estimations of Cluster 1 seeps based on the inferred parameter method............. 93

Table 11. Flux estimations of Cluster 2 seeps based on the inferred parameter method............. 94

Table 12. Flux estimations of Cluster 3 seeps based on the inferred parameter method............. 94

Table 13. Flux estimations of all seeps based on the inferred parameter method ...................... 94

Table 14. Methane mass flux estimations of Cluster 1 seeps ................................................ 95

Table 15. Methane mass flux estimations of Cluster 2 seeps ............................................... 95

Table 16. Methane mass flux estimations of Cluster 3 seeps .............................................. 95

Table 17. Methane mass flux estimations of all seeps ......................................................... 96 


\begin{abstract}
A WIDEBAND ACOUSTIC METHOD FOR DIRECT ASSESSMENT OF BUBBLEMEDIATED METHANE FLUX
\end{abstract}

By

\title{
Elizabeth Weidner
}

University of New Hampshire, May, 2018

The bubble-mediated transport and eventual fate of methane escaping from the seafloor is of great interest to researchers in many fields. Acoustic systems are frequently used to study gas seep sites, as they provide broad synoptic observations of processes in the water column.

However, the visualization and characterization of individual gas bubbles needed for quantitative studies has routinely required the use of optical sensors which offer a limited field of view and require extended amounts of time for deployment and data collection. In this paper, we present an innovative method for studying individual bubbles and estimating gas flux using a calibrated wideband split-beam echosounder. The extended bandwidth $(16-26 \mathrm{kHz})$ affords vertical ranges resolution of approximately $7.5 \mathrm{~cm}$, allowing for the differentiation of individual bubbles in acoustic data. Split-aperture processing provides phase-angle data used to compensate for transducer beam-pattern effects and to precisely locate bubbles in the transducer field of view. The target strength of individual bubbles is measured and compared to an analytical scattering model to estimate bubble radius, and bubbles are tracked through the water column to estimate rise velocity. The resulting range of bubble radii $(0.68-8.40 \mathrm{~mm}$ in radius) agrees with those found in other investigations with optical measurements, and the rise velocities trends are consistent with published models. Together, the observations of bubble radius and rise velocity 
offer a measure of gas flux, requiring nothing more than vessel transit over a seep site, bypassing the need to deploy time-consuming and expensive optical systems. 


\section{INTRODUCTION}

On the continental shelves and slopes of the world's oceans gas bubbles escape the seabed from subsurface methane reservoirs (Judd, 2004). In some regions the bubbles reach the sea surface injecting methane, a greenhouse gas, into the atmosphere where it directly influences climate (Ruppel and Kessler, 2016). Bubble-mediated methane transport is of particular concern in the climatically sensitive Arctic Ocean, where regional highs in atmospheric methane levels (AMAP, 2015) combined with reductions in ice cover (Maslanik et al., 2007), warm water influx from other ocean basins (Walczowski and Piechura, 2006; Woodgate et al., 2006), and high river runoff (Lammers et al., 2001) are accelerating the effects of climate change. Although the study of marine seeps goes back decades (e.g., Merewether et al., 1985), the methane flux from these systems remains unmeasured at the global level and poorly constrained on a basin or local scale (AMAP, 2015).

The major challenge in calculating flux arises from the need to make time-consuming groundtruth measurements of the number and size distribution of gas bubbles at individual seeps, combined with the ephemeral nature of seep activity and highly heterogeneous spatial distribution of seep systems on both basin and ocean scales (Greinert, 2008; Greinert et al., 2006;

Römer et al., 2012a; Kannberg et al., 2013; Jerram et al., 2015; Römer et al., 2016). Furthermore, the fraction of the original methane released that reaches the atmosphere is a function of transport and consumption processes in the water column, which depend on local environmental conditions that are not fully constrained (Leifer and Patro, 2002; MacDonald et al., 2002; McGinnis et al., 2006; Reeburgh, 2007; Rehder et al., 2009; Ruppel and Kessler, 2016). Even when methane flux is successfully measured at seep sites, extrapolation of flux estimates to a larger area is difficult given the small data sets and variable environmental conditions (Weber et 
al., 2014; Veloso et al., 2015); the result being flux estimates that vary widely between studies (Kirschke et al., 2013). In this work, we present an approach that uses ship-mounted acoustic remote sensing to determine bubble-size distribution and thus flux, and allows for more rapid coverage of large areas without the need for ground-truth measurement.

Acoustic systems have long been utilized to precisely identify and locate marine seeps by exploiting the high acoustic impedance and strong scattering properties of gas bubbles (Merewether et al., 1985; MacDonald et al., 2002; Heeschen et al., 2003; Greinert et al., 2006; Schneider von Deimling et al., 2011; Römer et al., 2012b; Kannberg et al., 2013; Jerram et al., 2015). These systems offer the potential for synoptic measurements of the water column, allowing for broad survey areas to be covered. However, the limited bandwidth (and thus resolution) of systems typically used for gas seep surveys cannot resolve individual bubbles, without knowledge of gas bubble size, bubble volume and consequently seep flux cannot be determined. In response, many gas flux estimation approaches have coupled acoustic mapping operations with optical point-source measurements, such as vehicle-mounted cameras, bubble traps (Nikolovska et al. 2008; Greinert et al. 2010; Römer et al. 2012a; Weber et al., 2014; Wang et al., 2016). However, point-source measurements require highly specialized gear and operators as well as long deployment durations, hours at a single seep site; coupled that with a small field of view, no more than a few tens of meters, and the logistics of combining acoustic and optical measurements and broad-spatial flux estimation becomes cost-prohibitive.

The flux estimation method presented here circumvents the need for optical measurements, instead relying on newly available wideband technology to directly estimate bubble parameters. Acoustic systems have previously employed broadband pulses to classify targets by exploiting their unique frequency response (Stanton et al., 2010; Lavery et al., 2010a; Lavery et al., 2010b), 
increase the detection range of targets (Stanton and Chu, 2008), and increase the range resolution of sonar pulses via match filtering (Turin, 1960). In this work, we employ the latter to break the ambiguity between the number and size of the bubbles. While this technique is not expected to work for very dense bubble seeps, it does work well for many seeps including for $70 \%$ of the seeps we examine in the work presented here.

In this study, a Simrad EK80 wideband transceiver (WBT), operating from 16-26 kHz, with a nominal vertical range resolution of $7.5 \mathrm{~cm}$, was utilized for the characterization of bubbles in marine seeps in the East Siberian Arctic Sea (ESAS) as part of the Swedish-Russian-US Arctic Ocean Investigation of Climate-Cryosphere-Carbon Interactions (SWERUS-C3) expedition (Jakobsson et al., 2015). The combination of frequency range and shallow water depths ( $<90 \mathrm{~m}$ ) resulted in acoustic scattering by bubbles above resonance. The ESAS is an area of significant importance for climate change studies due to the unique combination of climatically sensitive Arctic Ocean, massive methane reservoir, and shallow water column (Romanovskii et al., 2005; Semiletov et al., 2012). Gaseous methane released from the shallow ESAS can facilitate the transport of methane directly to the atmosphere, resulting in direct climate forcing. Research dating back over nearly two decades has shown extensive biogenic methane gas release from inundated permafrost in the ESAS (Semiletov, 1999; Shakhova et al., 2005; Shakhova et al., 2010; Shakhova et al., 2014; Sapart et al., 2017).

\section{WIDEBAND, SPLIT-BEAM ACOUSTIC OBSERVATIONS OF INDIVIDUAL BUBBLES}

The EK80 WBT produces a linear frequency modulated (LFM) acoustic signal; in the case of this research between 16 to $26 \mathrm{kHz}$. The broad bandwidth of the signal provides high vertical range resolution, improved signal to noise ratio (SNR) over similar length narrow-band pulses, and the 
ability to examine the acoustic frequency modulated response of targets, all of which are used to facilitate measurement of individual bubble radius and rise velocity.

The identification of individual bubbles in the acoustic data is made possible by the high vertical resolution achieved through a match filter signal processing procedure (Turin, 1960). The acoustic time-series $\left(v_{r}(t)\right)$ collected at the receiver and recorded by the WBT is convolved with the complex conjugate of the time-reversed idealized replica $\left(v_{t}(t)\right)$ of the original transmitted signal:

$$
c p_{r}(t)=v_{t}(t)^{*} \otimes v_{r}(t)
$$

The resulting match filtered signal $\left(c p_{r}\right)$ has a vertical range resolution that is proportional to the inverse of the bandwidth, improved from the vertical range resolution of half the pulse length for narrow band signals. The increased vertical range resolution provides an increased ability to discriminate between individual targets in the water column, allowing for the identification of closely-spaced single bubbles which might not have been resolved by similar length narrow band pulses, and facilitating the extraction of bubble parameters through the direct study of acoustic scattering.

The path of individual bubbles moving through the water column in the transducer field of view can be traced by employing the split-aperture correlation target-tracking techniques described in Burdic [1991]. These techniques are possible in the present work because the acoustic transducer (used for both transmit and receive) is split into four quadrants. Precisely locating individual bubbles in the transducer field of view enables direct measurements of in-situ bubble rise velocity. Additionally, split-aperture correlation enables the use of standard split-beam echo sounder (SBES) calibration techniques (Demer et al., 2015; Foote et al., 1987) which provide:

1) estimation of frequency-dependent transducer beam pattern effects, and 
2) the ability to measure target strength (TS) through removal of 1), as well as the frequency dependent effects of both the WBT and transducer on the recorded receive signal

In the case of the beam pattern effects, acoustic scatterers located off the main response axis (MRA) of the transducer will have an apparently weaker response than those at the MRA. By estimating the position of a target relative to the MRA, and documenting the sonar's beam pattern through calibration, the associated transducer beam pattern effects for that position can be removed and the TS can be calculated.

The TS for a single target is defined as the logarithmic measure of the acoustic backscattering cross-section, $\sigma_{b s}$, i.e., the effectiveness with which a target re-radiates sound back in the direction of signal arrival (Clay and Medwin, 1977):

$$
T S=10 \log _{10} \sigma_{b s}
$$

The backscattering cross-section of a single bubble of free gas at frequency $(f)$ is defined as:

$$
\sigma_{b s}=\frac{a^{2}}{\left[\left(\frac{f_{R}}{f}\right)^{2}-1\right]^{2}+\delta^{2}}
$$

where $a$ is the radius of the bubble, $f_{R}$ is the bubble's resonance frequency, and $\delta$ is a damping constant which accounts for damping from thermal conductivity, re-radiation, and shear viscosity (Clay and Medwin, 1977). This definition of TS requires several assumptions about the nature of the individual bubble:

1) the ensonifying wavelength is large compared to the bubble size $(\mathrm{ka}<<1)$;

2) the only mode of pulsation considered is radial;

3) the bubble is free from any coating (i.e. it is "clean"); and 
4) the bubble is spherical in shape.

TS measurements of individual bubbles can be compared to a well-known analytical model defined in Ainslie and Leighton (2011) to estimate bubble radius, examples of which are shown in Figure 1 for pure methane bubbles at depths of 50 meters. The frequency response for bubble sizes of interest show distinct resonance peaks at low frequencies and relatively constant TS values at frequencies above resonance. The frequency range of the EK80 WBT used for this work (16-26 $\mathrm{kHz}$ ) combined with the depths in the survey area, would place the observed acoustic response of typically-sized marine seep bubbles above resonance, in the fairly constant (with frequency) TS response regime (Figure 1).

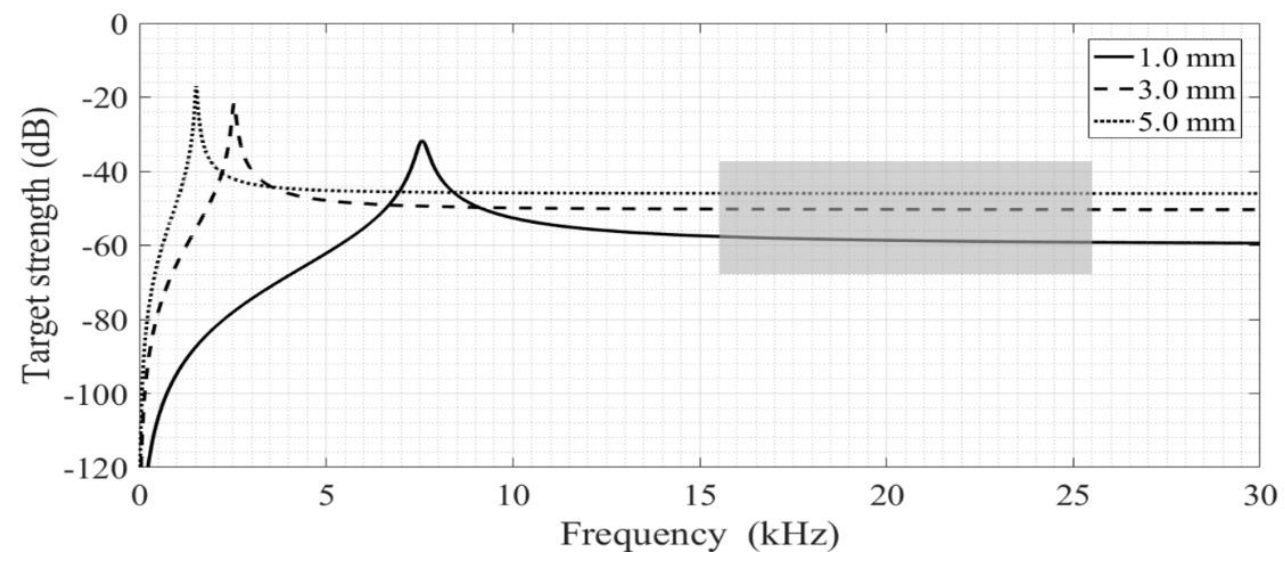

Figure 1. Modeled frequency modulated TS curves for typical seep sized bubbles in typical Arctic Ocean conditions (temperature of $6^{\circ}$ and salinity of $30 \mathrm{PSU}$ ) at $50 \mathrm{~m}$ depth, assuming bubble composition of $100 \%$ methane gas. Shaded box indicates the study frequency band $(16-26 \mathrm{kHz})$.

In addition to facilitating individual bubble TS measurements, the frequency content of broadband data provides the means to help identify cases where acoustic scattering is originating from unresolved targets. In acoustic time series data, it is often difficult to differentiate between the scattering from a single bubble and the scattering of multiple bubbles rising in close horizontal proximity or vertical proximity closer than the range resolution of the EK80 WBT. However, while the frequency-modulated (FM) modulated acoustic response of a single bubble 
is characterized by fairly constant TS, the FM acoustic response of multiple bubble scatterers is defined by a nodal structure with a series of peaks and nulls indicative of deconstructive interference. Thus, by examining the FM acoustic response, it is possible to resolve the ambiguity between single and multiple bubble scatterers. See section 8.1 for additional discussion of this issue.

\section{DATA COLLECTION AND IDENTIFICATION OF GAS SEEPS}

Water column backscatter data were collected with a Simrad EK80 WBT transmitting through a Simrad ES18-11 scientific split-beam echosounder on the Icebreaker Oden during Leg 2 of the SWERUS-C3 2014 expedition (Jakobsson et al., 2015). The EK80 WBT system was run continuously over the 45-day cruise, which covered more than $10000 \mathrm{~km}$ across the ESAS

(Figure 2). Seep features were detected solely in the shallow Herald Canyon region, which is found north of Wrangel Island on the western edge of the ESAS in the Russian Exclusive Economic Zone (EEZ).
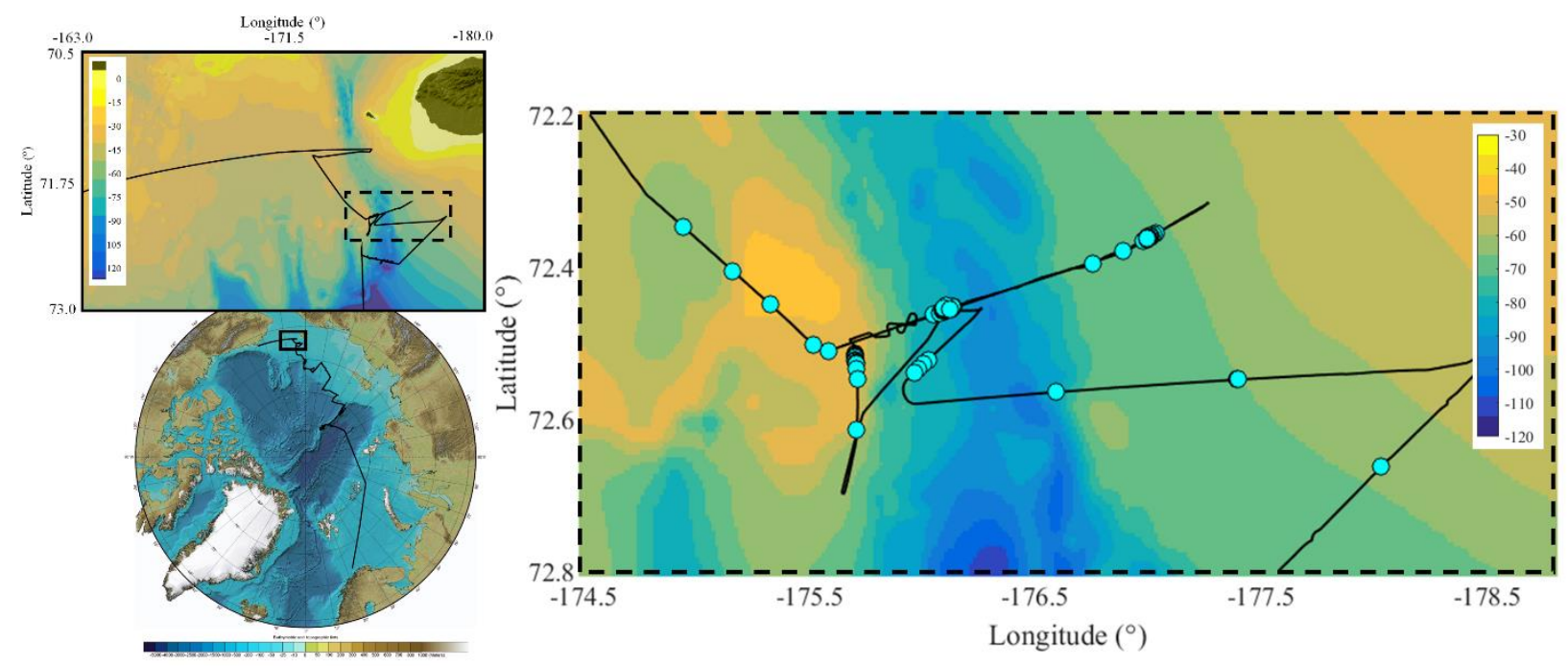

Figure 2. An overview of Icebreaker Oden's vessel track (black line) through the Arctic Ocean during SWERUS-C3 Leg 2. Cut-out box shows the vessel track from August 24-26, 2014 during operations in the Herald Canyon region of the ESAS. All identified 89 seep features are marked (blue markers), with areas of high seep density identified by additional boxes and total seep counts listed. IBCAO grid from: https://www.ngdc.noaa.gov/mgg/bathymetry/arctic/images/IBCAO_ver1map_letter.jpg. 
The ES18-11 transducer is mounted on the hull of the Oden behind the "ice knife" at approximately $9 \mathrm{~m}$ depth where it is protected by an ice window. Throughout survey operations the EK80 WBT was operated in fast-ramping LFM pulse. The transmission power was set to the maximum of 2000 W for all survey operations. The LFM transmission pulse lengths were switched between 4.096 ms and 8.192 ms using the Simrad user interface in response to changing depth conditions. Vessel attitude and position data were collected with a GNSS-enabled Seapath 330 vessel motion reference system, providing real-time corrections for the acoustic data.

During survey operations, the EK80 WBT was synchronized with the Oden's EM122 multibeam echosounder (operating at $12 \mathrm{kHz}$ ) and sub bottom profiler (operating between 2.5-7 kHz). System synchronization procedures triggered the EK80 WBT transmit-receive cycle immediately following the EM122 transmit-receive cycle, preventing acoustic interference from the other systems. Ship survey speed was kept below 8 knots to reduce noise from ship operations and bubble flow over the transducer face. Oden operated in open water during survey operations in Herald Canyon. On September 12, 2014 prior to survey operations, the EK80 WBT was calibrated for transducer sensitivity and beam pattern effects following the standardized method defined in Demer et al. (2015) and Foote et al. (1987).

The EK80 dataset was parsed using a set of MATLAB software scripts provided by Simrad [Lars Anderson, personal communication]. Each EK80 file consists of a series of successive pings, made up of an acoustic amplitude time series for each of the transducer quadrants. Data were matchfiltered using an ideal replica signal, and a bandpass Butterworth filter with cut off frequencies of 16 and $26 \mathrm{kHz}$ was applied to remove transducer transit and receive effects and additional shiprelated noise. The filtered data has a useable bandwidth of $10 \mathrm{kHz}$ with an approximate vertical resolution of $7.5 \mathrm{~cm}$. Sample range from the transducer was calculated using sound speed data 
from the nearest-in-time CTD cast. Range from the transducer was converted to absolute depth by adding the transducer vertical offset relative to the waterline on Oden. The acoustic intensity of each sample is determined from the summation of time series from the four transducer quadrants. Electrical phase angle information for individual targets was calculated by split-aperture processing (Burdic, 1991).

Each EK80 file was visually scrutinized for seep features, characterized by vertically oriented regions of elevated acoustic scattering strength, to be marked for further processing. A total of 89 seep features were identified in the Herald Canyon region of the ESAS (Figure 2). Seeps were observed in the canyon channel, on the relatively flat shelf to the east of the canyon, and on a local high immediately to the west of the canyon channel. Seafloor depths associated with seeps in Herald Canyon ranged from 50 to $95 \mathrm{~m}$. The SWERUS-C3 survey track was defined by other data collection goals and the acoustic data coverage over the Herald Canyon region is sparse. As a result, the dataset provides a snapshot view (approximately 30 seconds per seep) of seep activity instead of a long-term record. Figure 3 depicts variation in the visual appearance of seep features due to a variety of survey-related factors (e.g. vessel speed and pulse length settings) and environmental factors (e.g. currents, seafloor morphology, and volumetric gas flow rate). 

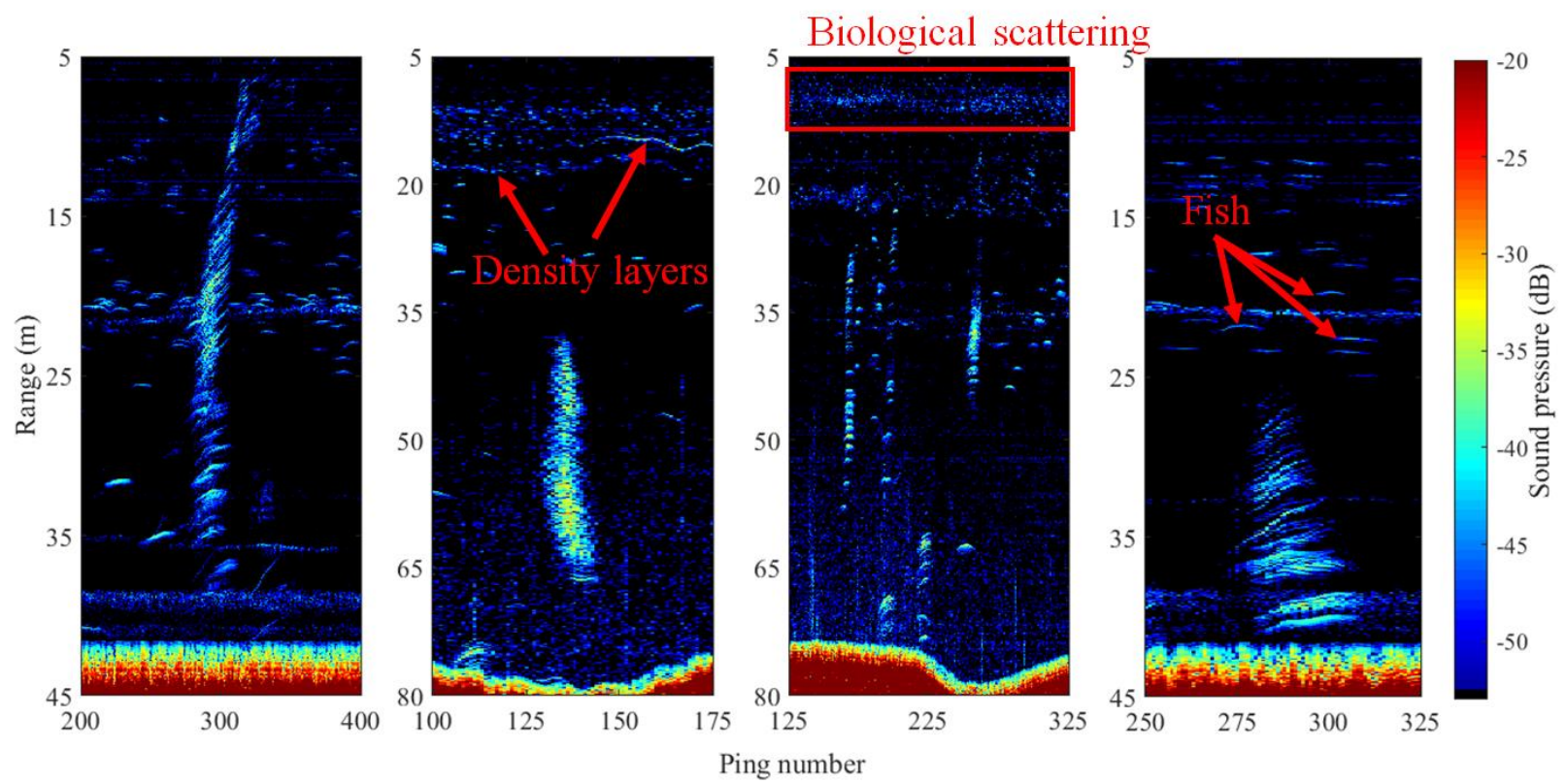

Figure 3. EK80 echograms showing acoustic anomalies associated with gas seep and other scatterers (e.g. fish and biological scattering). Each echogram is displayed as a series of vertical time series, colored by sound pressure moving forward in time and space from left to right. For visualization purposes data below -65 dB are filtered out (black background).

\section{INDIVIDUAL BUBBLE SAMPLING AND PARAMETER ESTIMATION}

Marked seep files went through additional visual scrutiny to identify all potential individual bubble scatterers. Individual bubbles were identified in the match filtered acoustic water column data by a peak in amplitude with a width of approximately $0.1 \mathrm{~ms}$ (the inverse of the bandwidth) within each ping time series, and by a rise in position at a nearly constant rate with a positive slope across pings (i.e. decreasing range as the bubble rises), as illustrated in Figure 4. Individual bubbles in EK80 datagrams were processed for analysis provided the potential target passed the following requirements:

1) Acoustic intensity at least $10 \mathrm{~dB}$ above background noise level. The acoustic response of scatterers with an SNR $<10 \mathrm{~dB}$ was ignored due to the increased possibility of interference in the acoustic scattering from background noise (see section 8.3 for calculation of acoustic background noise). 
2) At least $10 \mathrm{~cm}$ of separation from other scatterers. Acoustic returns from scatterers closer than this cut-off could potentially cause signal interference, confounding the analysis of individual bubbles (see section 8.1).

3) Identifiable acoustic response in at least three successive pings, which provides adequate data for in-situ bubble rise velocity calculation.

4) Individual scatterers had to be part of a larger, vertically-oriented plume feature (Figure 3), to reduce the unintended sampling of fish or other targets.

Of the original 80 seep features identified in the dataset, 49 seeps features contained resolvable individual scatterers fitting requirements 1-3. A total of 321 individual bubbles were identified to be part of a larger, vertically-oriented plume feature. Individual bubbles were sampled by identifying the point of maximum amplitude response in the acoustic time series in a succession of pings. From the point of maximum response, the data extracted for each bubble consisted of a position referenced to the transducer face, a range to bubble in meters, an acoustic time series of 30 samples centered on the point of maximum amplitude response, and an electrical phase angle sampled at the point of maximum amplitude response (Figure 4). 

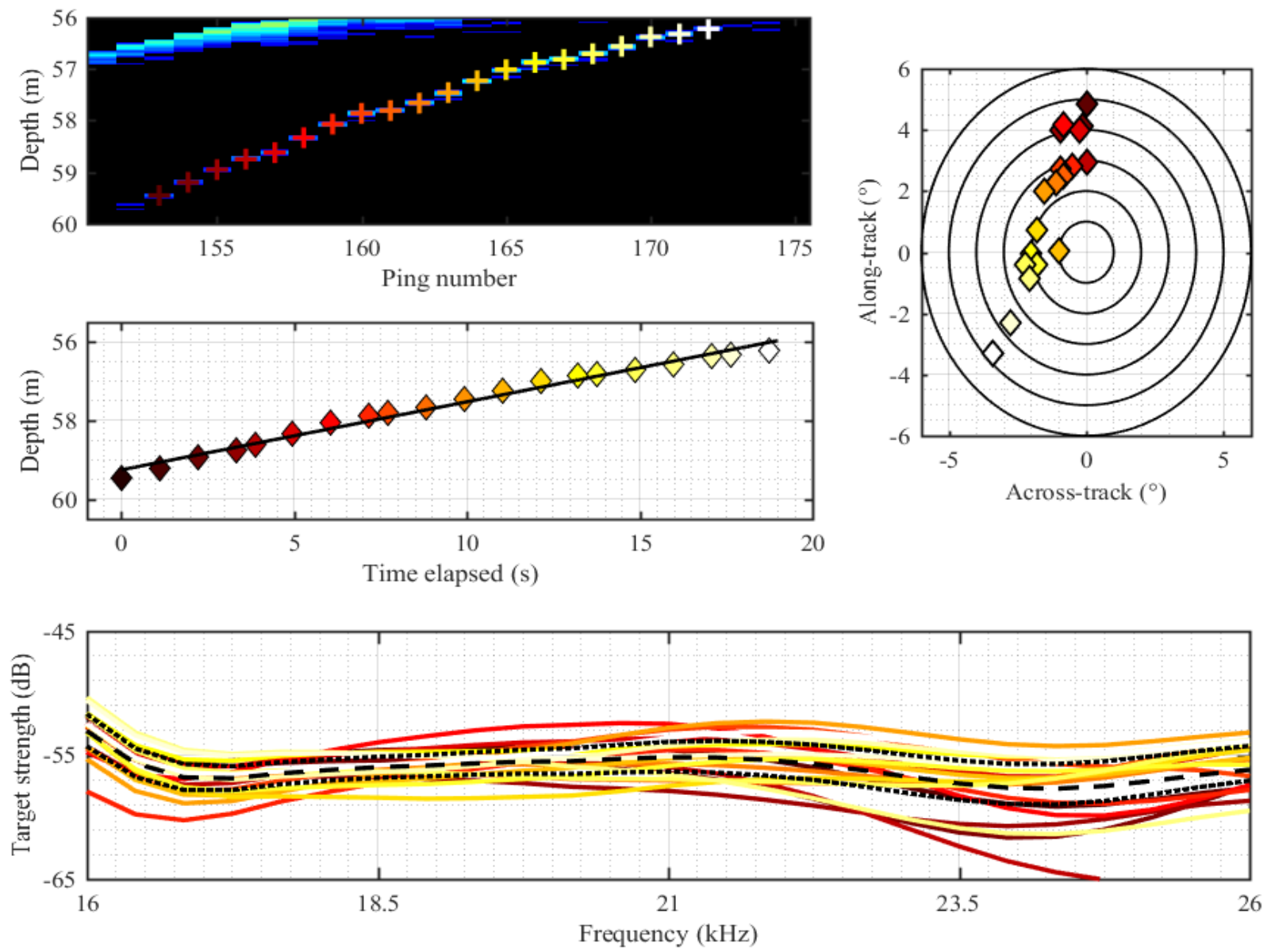

Figure 4. Panel A shows the path of a single bubble through 23 pings with an inset showing bubble location in EK80 field of view. The crosses demarcate the center of the sampled data. Panel B plots the time elapsed since the first ping against the calculated bubble depth and the linear regression through the path of the bubble. Average rise velocity is the slope of the regression. Panel C plots the bubble location in the EK80 field of view as determined from the mechanical along and across track phase angle. Panel D shows TS curve data for the same single bubble plotted as a function of frequency. The black dashed line represents the average of all TS curves for this bubble, calculated from the mean of bubble TS curves across all pings at each frequency.

The Fourier Transform of each bubble times series was taken to obtain the uncorrected frequency modulated acoustic response. The frequency modulated TS is then calculated by correcting for both beam pattern and transducer sensitivity by applying the appropriate correction factor, as determined by the electrical phase angle value of the bubble within each ping. The result is a set of $N$ TS curves over the experimental frequency range, where $N$ is equal to the number of observations of an individual bubble (Figure 4). Individual frequency-modulated TS curves were removed in instances where the electrical phase angle fell outside the limit of the correction factor 
look-up table and when TS curves, upon visual scrutiny, indicated scattering did not originate from a single target (indications of scattering from multiple targets). For each record, an average TS curve was computed from all individual TS curves.

To estimate the bubble radius, the average TS curve was compared against single bubble scattering model defined in section 2 and in Ainslie and Leighton [2009]. Acoustic scattering from a single spherical bubble is a function of bubble radius, temperature, salinity, pressure, ensonifying frequency, and gas composition. Temperature and salinity values were taken from the CTD casts closest in time (see section 8.11), and pressure was determined from the observed depths in the acoustic data. Previous research in the ESAS region suggests that gas reservoirs are composed of biogenically-produced methane (Sapart et al., 2017); however, measurements made by Sapart et al. (2017) were from the Laptev Sea and maybe not be representative of study site in this research. There is a possibility that the gas source studied here contains additional higher-order hydrocarbon gases from a thermogenic gas source; however, given that bubble composition is difficult determine without addition data and thermogenic gas is primarily composed of methane (>99\%), the composition of all bubbles was assumed to be $100 \%$ methane. The scattering model was run across the experimental frequency band $(16-26 \mathrm{kHz})$ for bubble radii from $0.5 \mathrm{~mm}$ to $9 \mathrm{~mm}$ at 0.1 $\mathrm{mm}$ increments. Using the method of least squares, the average TS curve was fitted to the model across the frequency band and the final bubble size was estimated from the mean of calculated bubble radii values across the frequency band $(16-26 \mathrm{kHz})$.

There is inherent bias in the bubble size calculation, stemming from the assumption that all bubbles are spherical. Marine seep bubbles have been observed to be increasingly non-spherical in shape with respect to increasing size (Ostrovsky et al. 2008; Leifer and Cullings, 2010; Wang and Socolofsky, 2015). However, the effects of bubble shape have not been quantified and so this bias 
is left unaccounted for in the final bubble size estimation. The sources of quantified uncertainty in the bubble radius estimation include: error in the electrical phase angle calculation and the resulting uncertainty in applied beam pattern correction, acoustic scattering model sensitivity to real-time environmental conditions, poor spatial resolution of the CTD data, and surfactant coating. However, the magnitude of all these sources of error are dominated by the measurement error, stemming from the variability in the TS curves from ping to ping, which on average was measured at $\pm 1.5 \mathrm{~dB}$ (Figure 4). This FM-TS variability would produce an expected uncertainty of approximately $0.33 \mathrm{~mm}$ radial uncertainty for a $1.5 \mathrm{~mm}$ bubble given the acoustic scattering definition in equation 2. A full derivation of the expected uncertainty, calculations of other uncertainty sources, and discussion of bubble radius uncertainty can be found in section 8.6.1.

For this method, rise velocity is defined by the vertical component of the bubble motion through the water column. The path of every individual bubble observation was traced upwards through the water column in order to estimate the average bubble rise velocity over the short window of observation ( $<30$ seconds at maximum). The bubble location in the water column was calculated by computing the bubble's range from the transducer face, considering the bubble position in the transducer field of view and the vertical displacement of the vessel from resting conditions due to ship heave. Other sources of vessel motion during survey operations were minimal (typically $<0.5^{\circ}$ of pitch and roll); therefore, the effect of vessel attitude was disregarded in the bubble depth calculations. Bubble position in the transducer field of view, defined by mechanical angle off MRA $(\theta)$, is calculated from the electrical phase angle $(\varphi)$ by account for transducer sensitivity:

$$
\theta=\frac{c}{2 \pi f d} \varphi
$$


where $c$ is the speed of sound, $f$ is frequency, and $d$ is the distance between the center of mass of the quadrants. The ES18-11 transducer sensitivity is defined by the manufacturer at the center frequency of $18 \mathrm{kHz}$. However, transducer sensitivity is a function of frequency, meaning the true sensitivity of the EK80 system is a weighted average of sensitivity values across the experimental frequency band $(16-26 \mathrm{kHz})$ and without more information about the transducer design it is difficult to determine the correct weighting values for the frequency band. A sensitivity test was performed and the results indicate that the published transducer sensitivity can be used without adding a significant uncertainty to the final rise velocity calculations. See section 8.7 for full sensitivity test.

The average bubble rise velocity across the observed time interval was computed from linear regression of the time and depth values extracted from pings for each bubble. For a given set of time and depth points the slope of the linear regression provides an estimate of rise velocity. Bubble rise velocity on a ping-to-ping basis shows variation from the regression due to physical processes associated with bubble rise (e.g. bubble wobble (Ostrovsky et al., 2008), shape (Padilla et al., 2017), and turbulence (Wang et al., 2016)). Other potential sources of error in the rise velocity estimate arise from survey equipment (e.g. split-aperture calculation, motion reference system, and computer time-stamp). As with the bubble radius calculation, the magnitude of uncertainty from the measurement variation far exceeds any other source of uncertainty. A discussion of all the sources of uncertainty in rise velocity estimate can be found in section 8.6.2.

\section{BUBBLE PARAMETER MEASUREMENTS}

The final dataset consists of 321 individual bubbles (Figure 5). Bubbles were sampled throughout the water column in a variety of depths across the survey area; to facilitate comparison between data found at different depths all bubble data are plotted as altitude (height off bottom) rather than 
depth. Bubble radii range from $0.68 \mathrm{~mm}$ to $8.14 \mathrm{~mm}$ with an average bubble radius of $2.58 \mathrm{~mm}$ and average uncertainty for each bubble-size measurement of $0.15 \mathrm{~mm}$. The majority (>90\%) of the sampled bubbles are between 1 to $5 \mathrm{~mm}$ in radius. The observed sizes are consistent with previously published bubble radii ranges from studies utilizing camera-based size estimation methods (Römer et al., 2012b; Leifer and MacDonald, 2013; Weber et al., 2014; Wang et al., 2016).

Uncertainty in estimates of bubble size increase with increasing bubble radius. When data are sorted into $1 \mathrm{~mm}$ wide bins the mean radial uncertainty nearly triples, from 0.12 to $0.34 \mathrm{~mm}$, between the smallest and largest measured bubble radii, respectively. Variability of the frequencydependent TS does not appear to be a function of bubble radius (see Figure 4), mean variability across all bubble radii was estimated to be approximately $1.5 \mathrm{~dB}$. The greater uncertainty associated with larger bubble radii resulted from the application of the acoustic scattering model. The backscattering cross-section of a single bubble is proportional to radius squared (Eq. 3); as radii increases, acoustic scattering values begin to converge (Figure 1) and there is a corresponding increase in uncertainty in the radius measurement for a fixed variability in TS.

Measured bubble rise velocities range from $4.05 \mathrm{~cm} / \mathrm{s}$ to $36.4 \mathrm{~cm} / \mathrm{s}$, with an overall average estimated uncertainty, for the rise velocity of any individual bubble, of $1.42 \mathrm{~cm} / \mathrm{s}$. To visualize the underlying distribution of rise velocity in the final dataset, the data were binned and averaged. Data were separated into 15 intervals with equal number of samples $(\mathrm{N}=25)$, resulting in irregularly spaced bins, based on data density. Error values are estimated from the combined uncertainty of data falling in each interval. Figure 5 illustrates two trends in binned rise velocity:

1) smallest bubble radii $(<1.5 \mathrm{~mm})$ : rise velocity increases rapidly with increasing size, at approximately $20 \mathrm{~cm} / \mathrm{s}^{*}(\mathrm{~mm})^{-1}$, 
2) bubble radii $>1.5 \mathrm{~mm}$ : the rate of increase in rise velocity with size is small, approximately $1 \mathrm{~cm} / \mathrm{s}^{*}(\mathrm{~mm})^{-1}$

Additionally, Figure 5 shows the modeled predictions from Clift et al. (1978) of rise velocities of clean bubbles (with surfaces are free from surfactants) and dirty bubbles (with surfactants, surface impurities, which impede mass transfer rates) given the oceanographic parameters measured in the Herald Canyon region (see section 8.11). There is variability about the binned-average trend and deviation from the modeled rise velocity values, possibly due to differences in bubble shape or currents. Empirical rise velocities have similar trends to those measured in previous studies (Leifer and MacDonald, 2003; Sauter et al., 2006; Sahling et al., 2009; Romer et al., 2012; Wang et al., 2016). The majority of measurements (> 75\%) fall between modeled rise velocities of clean and dirty bubbles, suggesting that surfactants could be influencing bubble rise and fate in the water column. 

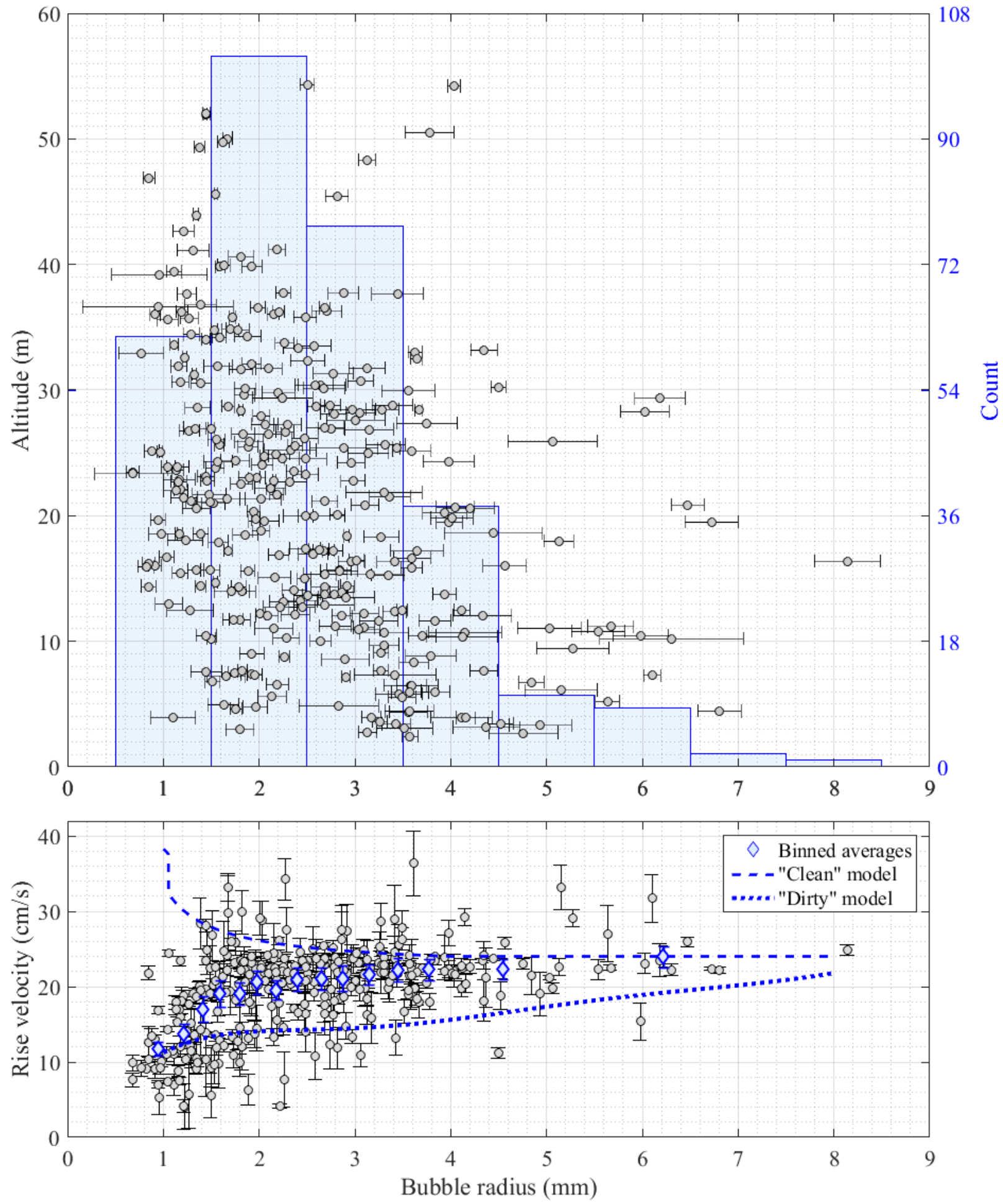

Figure 5. The top panel shows the measured bubble radii and uncertainty values from Herald Canyon dataset and count of samples in radii bins centered at each $\mathrm{mm}$. Bubble radii data are plotted against altitude (bubble height above the seafloor) in order to compare data from seeps with a wide range of seafloor depths Bubble altitude is calculated by subtracting bubble depth from the depth of the seafloor. The lower panel shows the measured bubble radii plotted against rise velocities and uncertainty values from Herald Canyon dataset. Binned averages are calculated from intervals of equal number of samples $(N=25)$. Clean and dirty modeled rise velocities are based of Clift et al., 1978. 


\section{GAS FLUX ESTIMATION}

Given the high range resolution of the EK80 acoustic data individual bubbles were observed throughout the water column, providing a unique means to examine bubble fate and gas transport. Previously published studies (Weber et al., 2014; Wang et al. 2016) of seep gas flux have collected bubble data (bubble size distribution, rise velocity, bubble release rate/bubble density) via optical systems, sitting over a single seep for extended periods of time to accurately describe bubble parameters. This acoustic dataset provides snapshots, no longer than 45 seconds, of seep activity in a variety of geomorphological settings and depths across the study site (Figure 2). Here, we describe two methods to characterize gas flux from seeps in the survey area given the short duration of the acoustic records.

\subsection{Instantaneous gas flux estimation}

At any depth, we can calculate the instantaneous volumetric gas flux $\left(Q_{\text {inst }}\right)$ by multiplying the number of bubbles per unit depth by the average volume and the average rise velocity. $Q_{\text {inst }}$ provides an integrated measurement of the gas transport in the water column during the short time of observation and, with the assumption that seep activity is constant, could be extrapolated to a longer time frame. Because the observations of bubble size and rise velocity are matched, we calculate the average of the product of volume and rise rate, rather than the product of the averages, to account for the potential covariance in the two quantities. Due to the scarcity of the observations in this dataset, the average is computed over the entire vertical extent of the seep, resulting in

$$
Q_{\text {inst }}=\frac{N}{z}\left[\frac{1}{N} \sum_{i}^{N}\left(\frac{4}{3} \pi a_{i}^{3}\right) v_{i}\right]
$$

where the bracketed quantity represents the average product of bubble volume $\left(\frac{4}{3} \pi a_{i}{ }^{3}\right)$ and rise velocity $\left(v_{i}\right)$ and $\mathrm{N} / \mathrm{z}$ estimates of the number of bubbles per unit depth. 
The uncertainty in $Q_{\text {inst }}$ is estimated directly from individual bubble measurement uncertainties in bubble radius and bubble rise velocity, as described in section 5. There is an unaccounted-for bias in $Q_{\text {inst }}$ given that flux can only be measured from observed individual bubbles. In many cases the bubble populations of seep features are not fully sampled when individual bubbles cannot by distinguished; this is most often in cases where bubble release rates are high and bubbles rise closer to each other than the vertical resolution of the EK80. In such cases the instantaneous observed gas flux provides an estimate of a lower bound of gas flux, rather than an estimate of the total volumetric gas flux. Additionally, there is a depth dependence to both bubble size and rise rate. In the case of bubbles decreasing in radius during ascent, averaging flux over the vertical extent of the seep biases the flux estimate at the top and bottom of the seep, high and low respectively. The opposite effect would be seen for bubbles growing with rise through the water column.

The resulting volumetric flux measurements range from $3.3 \times 10^{-10} \frac{\mathrm{m}^{3}}{\mathrm{~s}}$ to $2.5 \times 10^{-7} \frac{\mathrm{m}^{3}}{\mathrm{~s}}$, with a mean volumetric flux of $2.8 \times 10^{-8} \frac{\mathrm{m}^{3}}{\mathrm{~s}}$ (Figure 6., Table 1). The majority of the seeps $(\sim 85 \%)$ have a volumetric flux lower than $5.0 \times 10^{-8} \frac{\mathrm{m}^{3}}{\mathrm{~s}}$, although in many cases low flux estimates are due to under sampling of bubble features in the water column. For example, seep features T063136_1 and_2 have reported volume flux estimates of $1.4 \times 10^{-9} \frac{m^{3}}{\mathrm{~s}}$ and $4.7 \times 10^{-9} \frac{\mathrm{m}^{3}}{\mathrm{~s}}$ respectively; however, investigation of the EK80 echogram clearly shows very high gas ebullition rates, where individual bubbles are not distinguishable. Of the 38 seep features with sampled individual bubbles approximately half seeps are under-sampled, resulting in low flux estimates (see section 8.4 for seep echograms). 

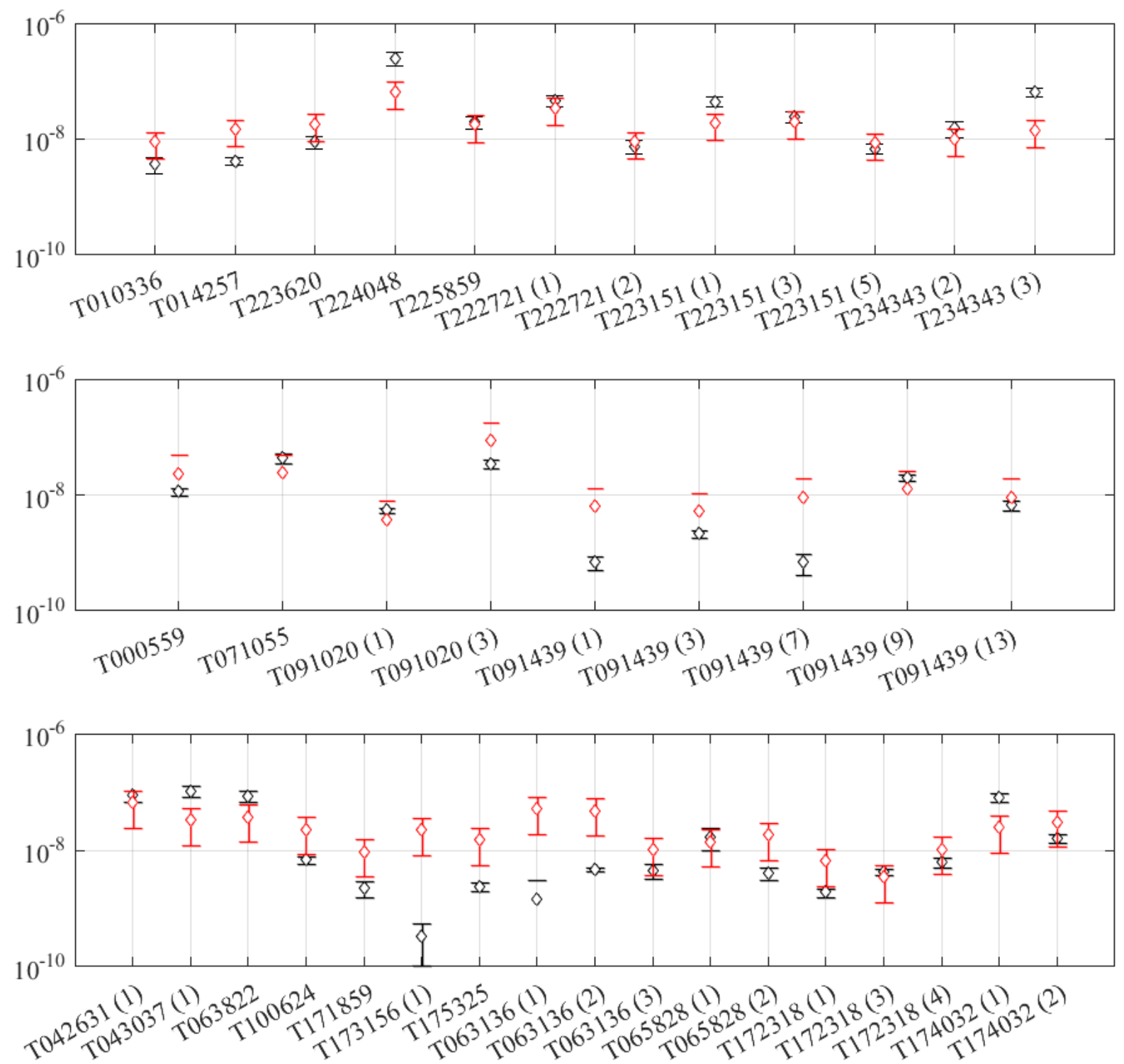

Figure 6. Yearly volumetric gas flux estimates for all sampled seep in the Herald Canyon dataset. Black diamonds denote instantaneous observed gas flux estimates and red diamonds indicate gas flux estimates calculated from inferred seep parameters. Seeps are group by geomorphological clustering.

Table 1. Estimated yearly volumetric gas flux rates and methane mass flux rates to atmosphere as derived from both flux methodologies.

\begin{tabular}{|l|c|c|c|c|}
\hline & Min Q $\left(\frac{m^{3}}{y r}\right)$ & Max Q $\left(\frac{m^{3}}{y r}\right)$ & Mean Q $\left(\frac{m^{3}}{y r}\right)$ & Total HC Q $\left(\frac{m^{3}}{y r}\right)$ \\
\hline Direct estimate & $0.010 \mp 0.0072$ & $7.7 \mp 2.0$ & $0.87 \mp 0.19$ & $33 \mp 7.1$ \\
\hline $\begin{array}{l}\text { Inferred parameter } \\
\text { estimate }\end{array}$ & $0.11 \mp 0.068$ & $2.8 \mp 2.0$ & $0.70 \mp 0.48$ & $27 \mp 18$ \\
\hline
\end{tabular}




\subsection{Inferred parameter gas flux estimation}

For a given seep feature, the instantaneous observed volume flux provides a measure of flux over the period of observation into but likely does not capture a complete picture of flux as the distribution of bubble sizes emanating during the short time period may not fully sample the seep's true distribution of bubble sizes. A well-defined seep bubble size distribution (BSD) provides a more complete estimate of gas flux over longer time frames. Volumetric gas flux can be estimated using parameterized values for both BSD and rise velocity as given by (Weber et al., 2014):

$$
Q_{i . p .}=\frac{N}{z} \int_{0}^{a_{\max }} \frac{4}{3} \pi a^{3} \rho(a) v(a) d a
$$

where the flux, referred to as the inferred parameter volume flux $\left(Q_{i . p .}\right)$, is calculated for a seep with total number of observed bubbles $(N)$, water column depth $(z)$, and a $\operatorname{BSD}(\rho(a))$ and rise velocity $(v(a))$ defined as functions of bubble size. $N$ and $z$ are calculated identically to the instantaneous observed gas flux equation and the binned rise velocity data (Figure 5) was used to estimate the bubble size dependent rise velocity $(v(a))$.

BSD reported in previous literature are derived from datasets containing between 200 to $>700$ measurements (Römer et al., 2012b; Weber et al., 2014; Wang et al., 2016). Given the snapshot nature of the present dataset it is not possible to determine a BSD for a single seep with the data density quoted in previous literature; however, if bubble data from multiple seeps are grouped together higher data density can be established and a BSD for a general area could be estimated. By determining a regional BSD and employing the inferred parameter volume flux equation, a regionally generalized volume flux estimate can be employed for all sampled seep features.

To increase bubble data density, seeps were grouped by morphological setting within the Herald Canyon survey site with the underlying assumption that these seeps should be occurring in a 
similar morphological regime with analogous bubble release mechanism, gas reservoir, and environmental conditions. Three morphological regimes were identified: the shallowest, cluster 1 seeps, are found in the shallow morphological high just west of the submarine canyon; cluster 2 on the flat-lying shelf east of Herald Canyon; and cluster 3 along the canyon edges. The grouping resulted in three seep clusters (Figure 7). 

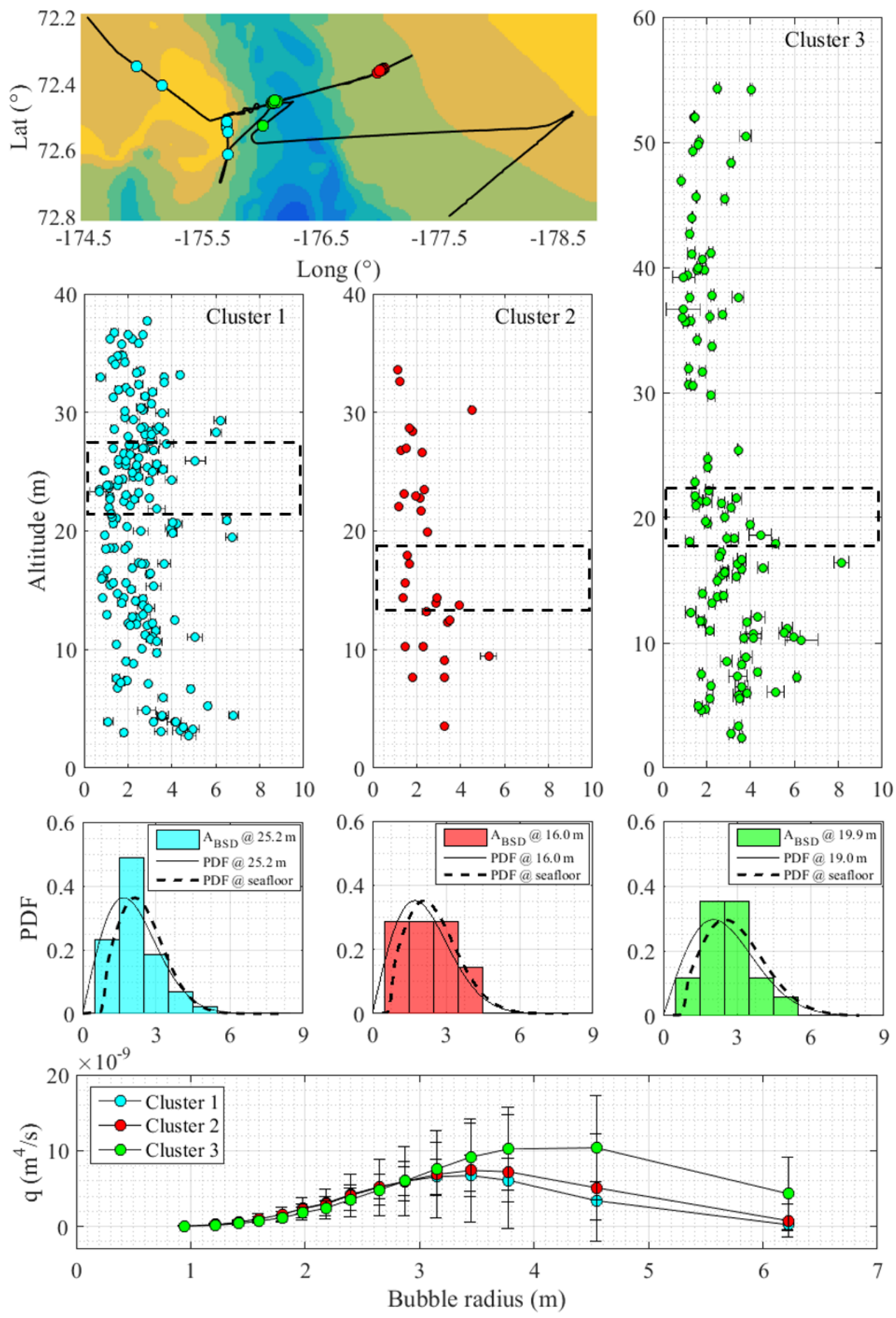

Figure 7. Spatial distribution of seep clusters in Herald Canyon, water column bubble size distributions plotted against altitude of the seep clusters, distributions of binned bubble size data, and gas flux as a function of bubble size. Cluster 1 bin centered at 25.2 $m$ has an $N=180$ and bubble water column density of 5.1 bubbles $/ m$, Cluster 2 bin centered at $16.6 m$ has an $N=32$ and bubble water column density of 1.1 bubbles $/ \mathrm{m}$; and Cluster 3 bin centered at $19 \mathrm{~m}$ has an $N=109$ and bubble water column density of 2.1 bubbles/m. 
To estimate a BSD for each cluster, the bubble size data was grouped into bins of 5-meter thickness, starting at the altitude of the shallowest bubble sample. BSD are traditionally determined from data collected at a single altitude, most commonly the seafloor, but the data density available here makes this prohibitive. The altitude bin with the largest sample size was selected and the resulting bubble data was fitted to a Rayleigh distribution (Figure 7). Previous seep studies (Römer et al., 2012b; Weber et al., 2014; Wang et al., 2016) have suggested various distribution fittings to describe bubble size data including normal, lognormal, and Rayleigh.

Figure 7 illustrates both the source data and the initial fitted Rayleigh distributions from the water column data for each cluster. The resulting Rayleigh distributions for cluster 1 and cluster 3 passed a KS test at a 95\% confidence interval; cluster 2 distribution did not pass the KS test for lognormal, normal or Rayleigh distributions due to low data density, but for the sake of method consistency the Rayleigh distribution of cluster 2 was kept.

The fitted distributions were projected down to the seafloor, where bubble composition is best defined, by employing the Texas A\&M Oilspill Calculator (TAMOC) bubble dissolution and transport model published in Gros et al., (2016) and Gros et al. (2017). The TAMOC model computes the transport and fate (e.g. size and composition changes) of individual bubbles rising through the water column, given a set of source conditions (e.g. water column temperature and salinity profiles, dissolved gas concentrations, initial depth). Bubble composition exiting the seafloor was assumed to be pure methane, given Sapart et al. (2017) reported that gas bubbles in the ESAS are mainly composed of biogenic methane (>99\%) from the breakdown of organic matter in the sediment; although, as noted in section 4 there is uncertainty in this assumption given the spatial separation between the Sapart et al. (2017) measurements and Herald Canyon methane reservior. Temperature, salinity, dissolved gas profiles from SWERUS cruise activities were input 
to the TAMOC model. The model was run for bubbles radii from $0.375-8.0 \mathrm{~mm}$ at $0.125 \mathrm{~mm}$ intervals with the measured oceanographic parameters from Herald Canyon. A complete description of the TAMOC model input and output parameters and runtime information can be found in section 8.12. Using the fitted Rayleigh distributions from data in the water column (Figure 7), a seafloor BSD was estimated for each cluster by accounting for the model-predicted change in bubble-size with depth (i.e., the model was used to back-project the BSD to its seafloor-source size distribution). The seafloor distributions are skewed to the right of the water column distribution (larger mean bubble size).

The $Q_{\text {i.p. }}$ at the seafloor was evaluated by numerically integrating (Eq. 6), using the cluster-specific seafloor BSD $(\rho(a))$ and the binned rise velocity $(v(a))$ shown in Figure 5. The integration points were chosen to match the resolution of the rise velocity dataset, as it was the most coarsely sampled. The integrands of (Eq. 2) are depicted in Figure 7, illustrating the importance of large ( $a$ $>3 \mathrm{~mm})$ bubbles in the final volumetric gas flux estimates; while small $(a<2.5 \mathrm{~mm})$ bubbles contribute minimally to the overall volumetric flux and could be disregarded. The resulting volume flux measurements range from $3.5 \times 10^{-9} \frac{\mathrm{m}^{3}}{\mathrm{~s}}$ to $8.8 \times 10^{-8} \frac{\mathrm{m}^{3}}{\mathrm{~s}}$, with a mean volume flux of $2.2 \times$ $10^{-9} \frac{m^{3}}{s}$ (Figure 6., Table 1).

The standard error in fitting the Rayleigh parameter to the bubble data was propagated to an uncertainty in the $\rho(a)$ term, which was combined with the estimated rifse velocity uncertainty from the binned data (Figure 5) to generate an uncertainty in the flux estimates (Table 1).

\subsection{Methane mass flux estimation}

Many seep studies aim to quantify methane gas transport from a seep system to the upper ocean and/or atmosphere. Methane gas flux can be computed for a single seep system from the estimated 
seafloor volumetric gas flux by determining the initial composition of gas in the bubble and incorporating a gas transport model (e.g. McGinnis et al., 2006; Socolofsky et al., 2015) to understand the fate of bubble-bound methane during transport. The volumetric flux as estimated by the inferred parameter method was incorporated into the methane gas flux estimate because it represents the gas flux from the seafloor; as opposed to the instantaneous observed gas flux estimate which measures gas flux throughout the water column where bubble composition is more difficult to estimate.

Assuming the bubbles exit the seafloor as pure methane, the molar mass flux of methane can be computed by modifying the inferred parameter volumetric gas flux equation to the following:

$$
Q_{C H 4}\left(\frac{g}{s}\right)=\frac{N}{z} \int_{0}^{a_{\max }} m(a) \rho(a) v(a) d a
$$

Where $m(a)$ denotes the number of grams of methane in a bubble of radius $a$, at a given depth as output from the TAMOC model. The mass flux of methane at the seafloor and at the sea surface, analogous to methane transport to the atmosphere, can be computed from the $Q_{\mathrm{CH} 4}$ estimation (Figure 8).

Methane mass flux transported by individual seeps to the atmosphere was measured at a minimum of $2.1 \times 10^{-6} \mathrm{~g} / \mathrm{s}(67 \mathrm{~g} / \mathrm{year})$ and maximum of $6.3 \times 10^{-5} \mathrm{~g} / \mathrm{s}\left(2.0 \times 10^{3} \mathrm{~g} / \mathrm{year}\right)$. The mean methane mass flux for all observed seep features in the Herald Canyon area was estimated at $1.6 \times$ $10^{-5} \mathrm{~g} / \mathrm{s}(500 \mathrm{~g} / \mathrm{year})$ and the combined methane flux to the atmosphere from all seeps is estimated to be $6.0 \times 10^{-4} \mathrm{~g} / \mathrm{s}(19 \mathrm{~kg} / \mathrm{year})$. This figure could be extrapolated to the larger survey area, by assuming the seep activity captured during survey operations is typical for the region. Given that the total area covered during the SWERUS-C3 survey of Herald Canyon was approximately 6 
$\mathrm{km}^{2}$, for the total $9000 \mathrm{~km}^{2}$ region depicted in Figure 2, the yearly methane flux would be approximately $2.9 \times 10^{4} \mathrm{~kg} /$ year.
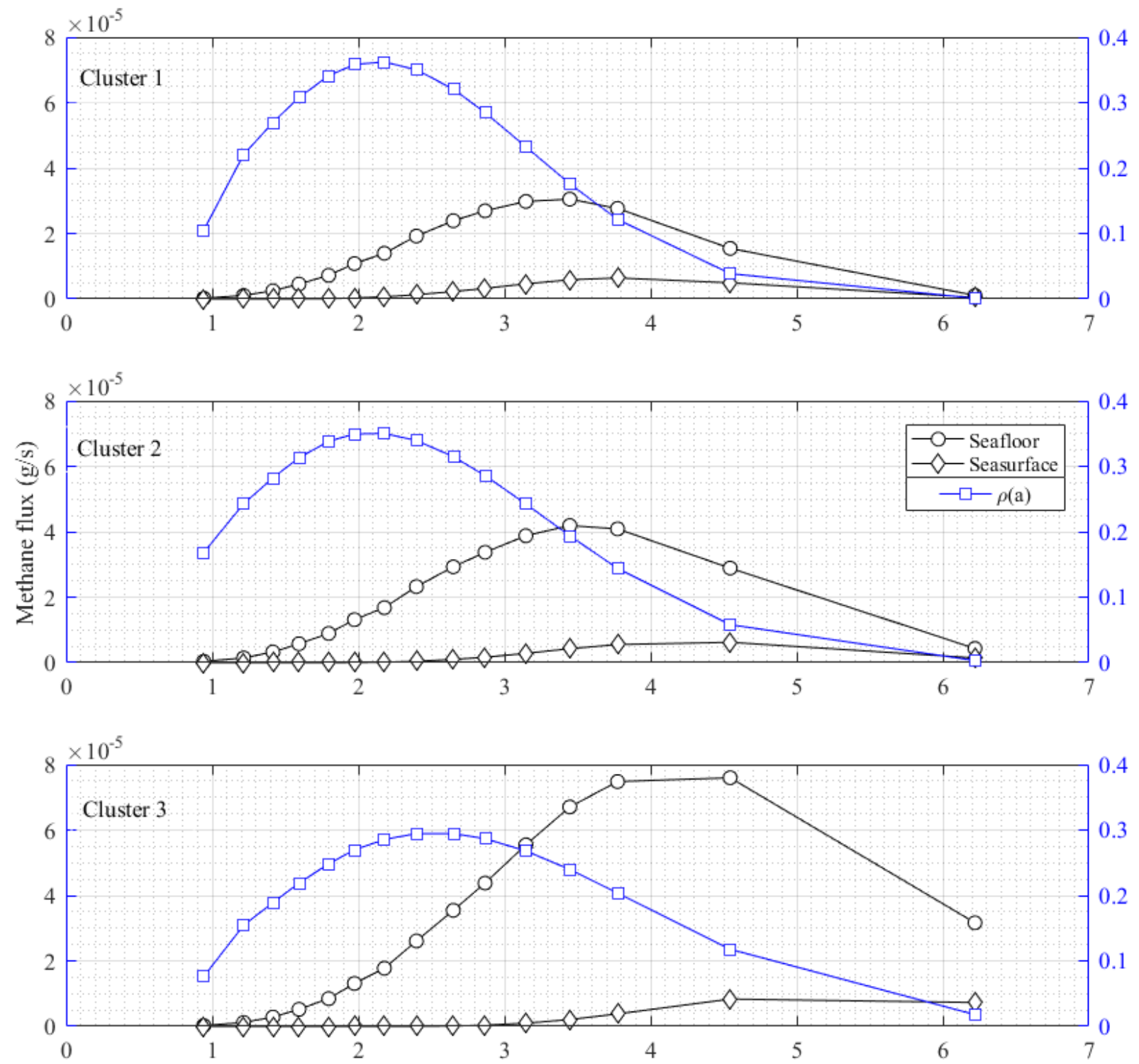

Figure 8. Inferred seafloor bubble size distributions (blue squares), yearly seafloor methane mass flux (black diamonds), and yearly atmospheric methane mass flux (black circles) for seep clusters.

\section{DISCUSSION}

The high vertical resolution and frequency response of the wideband $(16-26 \mathrm{kHz})$ acoustic measurements have allowed us to unambiguously identify individual gas bubbles rising through the water column data. Individual bubble radii and rise rates were estimated from the acoustic data 
with the aid of well documented split-beam echosounder calibration and split-aperture processing techniques (Burdic, 1991; Demer et al., 2015). The measurements of bubble radii and rise velocity agree well with previous studies of seep systems in different environments (Leifer and MacDonald, 2003; Sauter et al., 2006; Sahling et al., 2009; Romer et al., 2012; Weber et al., 2014; Wang et al., 2016). In addition to the direct estimation of bubble parameters, the method outlined here provides several pathways to measurements of volumetric gas flux and methane mass flux, all of which are achievable without ground-truthing by optical data collection.

The volumetric gas flux and methane mass flux estimated in this research are consistently lower than flux reported in previously published studies (Shakhova et al., 2010; Weber et al., 2014; Leifer et al., 2017). This is not surprising as both our estimates of volumetric gas flux and subsequent estimates of methane flux represent lower bounds of the true regional flux. This is because the fundamental measurement of bubble density ( $N / z$, Eq. 5-7) was calculated from the sampled individual bubbles; however, in many seep features there are additional bubbles in the water column that were not sampled. These regions represent areas of higher bubble density, where the vertical resolution of the EK80 was not high enough to differentiate between bubbles. Additionally, more than half of all seep features identified in the survey region contained no distinguishable individual bubbles and were not sampled. These seeps likely represent higher flux rates than sampled seeps, given that individual bubbles were not identifiable in the seep plume. Both methods of regional volumetric gas flux used here, as well as corresponding estimates of methane flux assume that the SWERUS-C3 observations were representative of seep activity throughout the year, without considering any temporal or regional variability in seep activity (Greinert, 2008; Kannberg et al., 2013; Jerram et al., 2015). Repeat surveys of the region may 
reveal continuation of seeping at some sites, cessation of seeping at other sites, and seeping at new sites.

The transport of methane from the seafloor to the atmosphere has a strong dependence on bubble size; only larger bubbles (>3.0 mm radius) transport significant amounts of methane to the atmosphere, due to high volume-surface area ratios and high initial volume of methane gas upon release (Figure 8). Although there is low data density in our data at bubble radii above $3.5 \mathrm{~mm}$, it is clear for clusters 1 and 2 (depths between 50-70 meters) that maximum methane transport arises from bubbles with radii between approximately 3.75 and $4.0 \mathrm{~mm}$; while for cluster 3 , methane transport increases with increasing radius to the largest radii sampled with no peak value. At all depth intervals bubbles smaller than $2.5 \mathrm{~mm}$ in radius transport no methane to the atmosphere, either due to complete dissolution in the water column or mass-transport and could be ignored from any methane flux estimation. However, the short-term data records used in this research are unlikely to fully describe the long-term ebullition nature of the seep systems. Given an unknown BSD, it is likely short acoustic records will only identify the most common bubble sizes, in the case of the seeps observed between $1.5-3.0 \mathrm{~mm}$ in radius. This leaves the tail ends of the distribution under-sampled, generally leading to an underestimation of volumetric gas flux, as the largest bubble radii have not been accounted for. In cases where large radii bubbles are identified in short records, they make up a larger proportion of the BSD then would be expected from previously published research (Weber et al., 2014; Wang et al., 2016). Increasing the observational period of specific seep feature, will better describe the BSD, as well as define the variability (if any) in flux.

Within the larger framework of both the global estimation of bubble-mediated methane transport, this method will be an effective addition to research operations, as the majority of ocean research 
vessel are equipped with acoustic equipment capable of producing wideband signals with only minor modifications or upgrades. Flux estimates can be made over large areas, requiring nothing more than vessel transit over a seep site, bypassing the need to deploy time-consuming and expensive optical systems. Wideband data would be most successful in regions where individual bubbles can be identified, characterized by environments where gas ebullition originates from individual point sources at a slow rate. In regions of rapid bubble ebullition, where the vertical distance between bubbles is minimal, or areas with multiple ebullition sites in close spatial

proximity (e.g. seep fields), the vertical range resolution of the system we used may not be high enough to break the acoustic ambiguity between multiple scatterers; in these environments, broader band systems will be required. The acoustic identification of bubbles (e.g. successful identification of fish or other acoustic scatters) will always contain some measure of ambiguity without optical verification and the best practice to insure viable bubble parameter data is ergodic measurements.

\section{APPENDICES}

\subsection{Acoustic scattering from single vs multiple bubble scatterers}

The fine vertical range resolution afforded by the approximately $10 \mathrm{kHz}$ of bandwidth from the EK80 WBT allow for discrimination of single bubble targets in the echogram. The method presented here defined the bubble separation at a minimum of $18 \mathrm{~cm}$ to prevent signal interference from other scatterers. However, empirical data shows individual bubbles are identifiable at even closer vertical proximity. Figure 9 illustrates the acoustic response of two bubble scatterer in close vertical proximity, whose paths diverge due to different rise velocities.

The initial acoustic response, when the bubbles positions are closer than to range resolution of the EK80 WBT, is indicative of deconstructive interference with a nodal structure of peaks and nulls. 
As the bubbles rise, the vertical separation grows and the acoustic responses of the individual bubbles become clearly distinct. In this example, the bubbles were distinguishable at less than 9 cm apart in ping 115 .
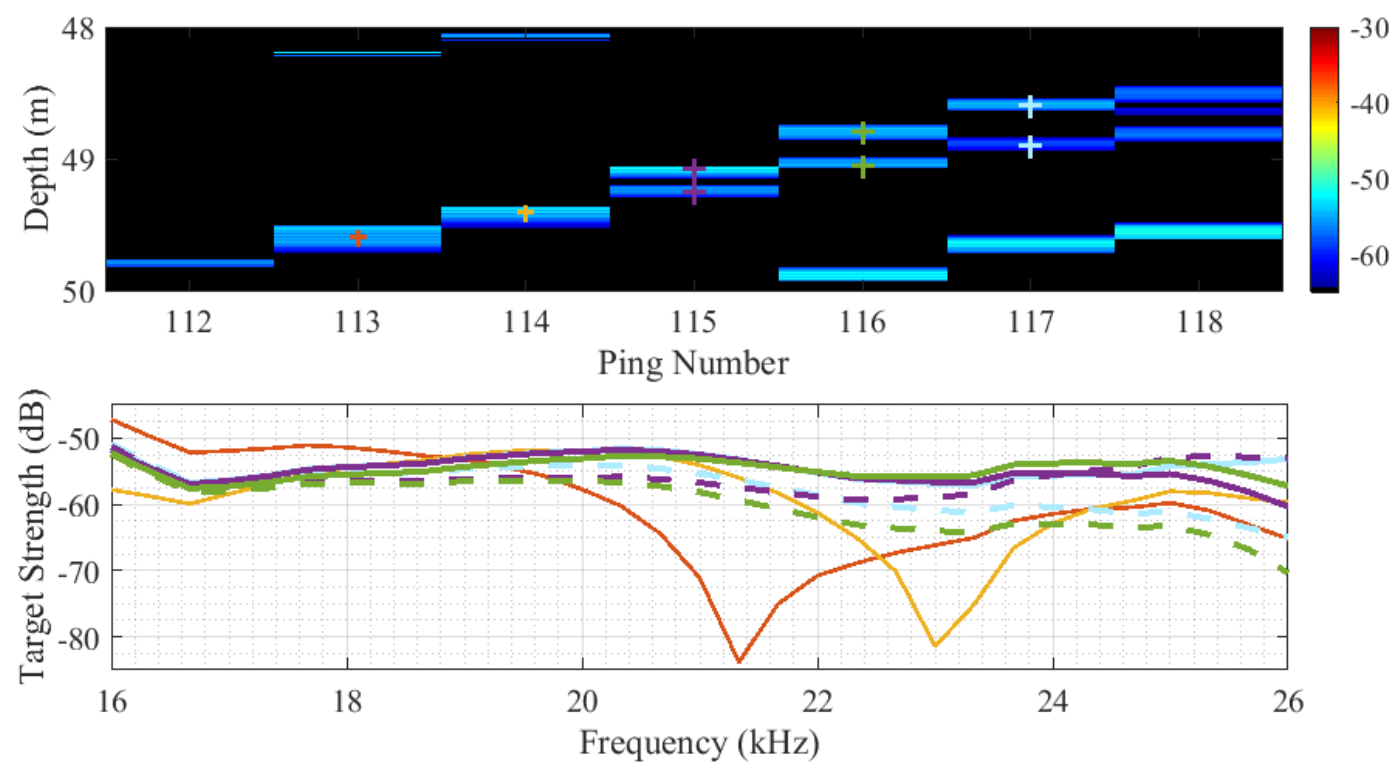

Figure 9. Acoustically tracking the ascent and separation of two bubble tracers. The top panel shows the zoomed view of the series of pings where the two bubbles separate. Target time series were sampled in a series of successive pings (point of maximum acoustic intensity is marked by cross). The first two samples time series (ping 113 and 114) include the additive acoustic response of multiple bubbles. The bottom panel shows the frequency modulated target strength of each sampled time series.

To verify the differences in acoustic scattering response of individual gas bubbles vs multiple bubbles in close proximity, analytical modeling of a gas filled sphere was employed (Anderson, 1950; Jech et al., 2015). A linear-frequency modulated signal was produced using the same signal configuration as EK80 field data. The signal was convolved with combined impulse response of ocean environment and target to predict the acoustic response. The ocean environment was defined by the CTD profile data taken during SWERUS C-3: $2^{\circ} \mathrm{C}, 30 \mathrm{PSU}$, and $50 \mathrm{~m}$ depth. The bubbles were defined as $100 \%$ methane in composition and the mean bubble size of the EK80 dataset, 2.5 $\mathrm{mm}$, was utilized. Gaussian noise was added to the modeled system.

Bubble scatterers were separated by varying distances and the FM acoustic response of the closer of the two bubbles was measured (Figure 10). 


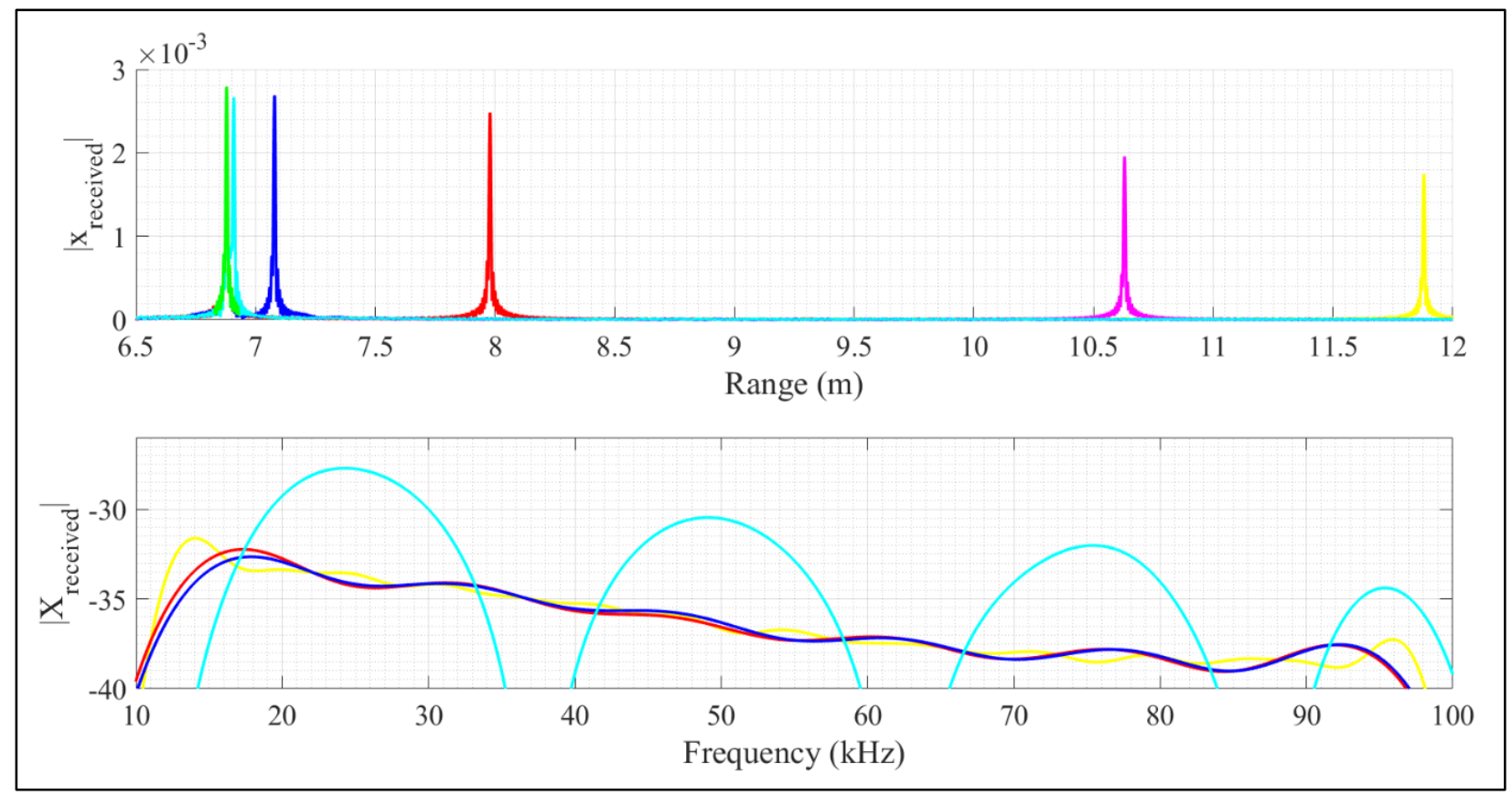

Figure 10. Locations and interactions between two bubble targets. First bubble (plotted in green) placed at 6.8 meters in range from transducer, second bubble placed at $5 \mathrm{~m}$ (yellow), $3.75 \mathrm{~m}$ (magenta), $1.1 \mathrm{~m}$ (red), $20 \mathrm{~cm}$ (blue), and $3 \mathrm{~cm}$ (cyan).

There is are two clear FM acoustic scattering patterns in Figure 9. The first, is a relatively constant scattering intensity across the frequency band, with an overall negative slope due to frequency dependent acoustic absorption; the second, is a nodal structure defined by peaks and nulls. The secondary structure occurs when the acoustic responses of the two bubbles interacting with constructive and deconstructive interference.

\subsection{Wideband split-beam echosounder calibration}

On September 12, 2014 prior to survey operations, the EK80 WBT was calibrated for transducer sensitivity and beam pattern effects following the standardized methodology defined in [Demer et al., 2015; Foote et al., 1987].

A standard $64 \mathrm{~mm}$ copper calibration sphere was suspended in the transducer field of view (FOV) on a monofilament line (Figure 11). Calibration procedures were conducted while Oden drifted, with all propulsion systems secured, to minimize unnecessary ship noise in the data. A 
conductivity-temperature-depth (CTD) profile was taken immediately before calibration procedures commenced to characterize the oceanographic and sphere conditions. Sphere location was controlled by manual operation of a series of reels on Oden's lower deck while operators monitored the sphere location in the echosounder FOV through the Simrad EK80 acquisition software. Calibration data consisting of a time series of acoustic scattering by the calibration sphere were collected with the EK80 using the expected operational survey pulse length and power settings.

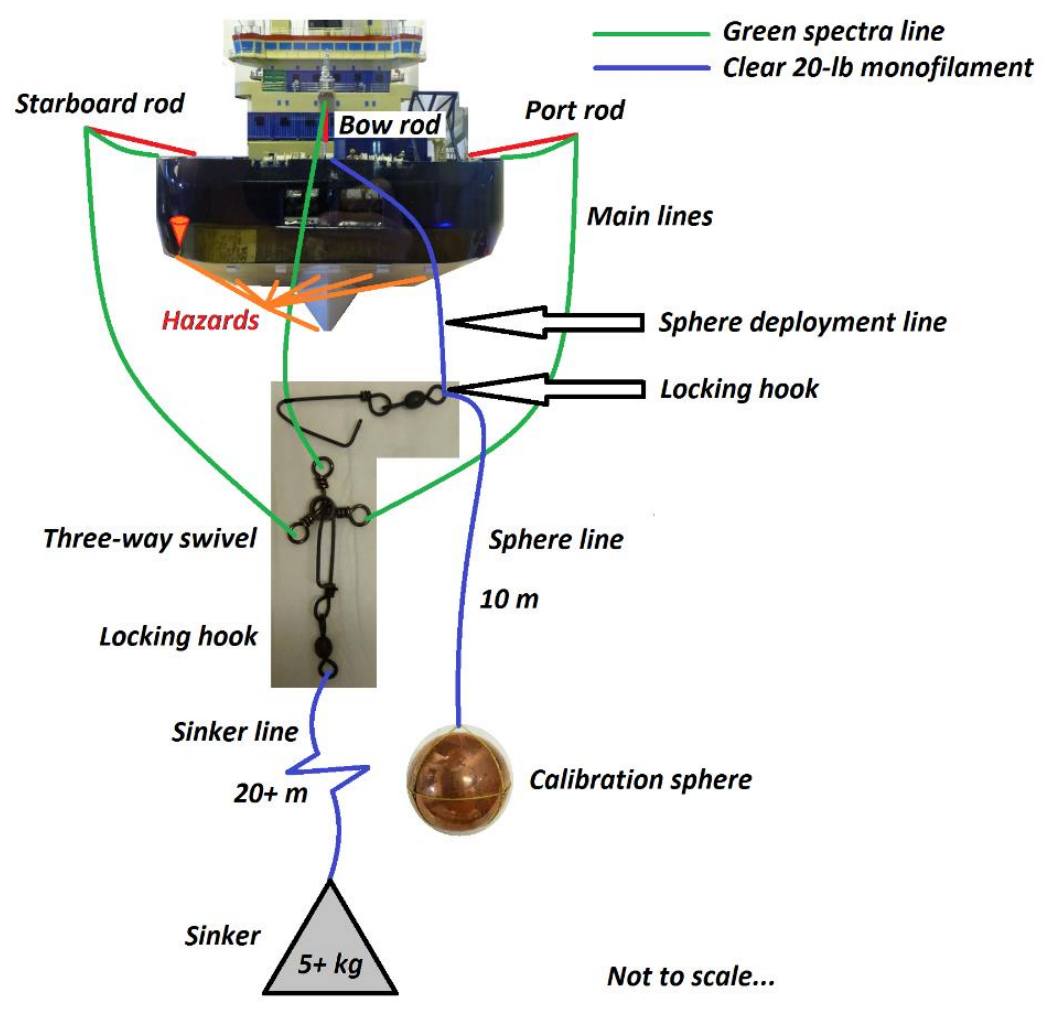

Figure 11. Illustration of EK80 calibration procedure set up on the icebreaker Oden.

A TS model for the calibration sphere was calculated with a MATLAB script provided by [D. Chu, personal communication] using water temperature of $6 \mathrm{C}$ and salinity of 30 PSU from the CTD cast at the sphere depth of $26 \mathrm{~m}$. Acoustic absorption was accounted for utilizing oceanographic data from the CTD cast and an absorption model from [Francois and Garrison, 1982]. 
Optimally data would have been collected at the echosounder MRA and throughout the FOV to completely characterize echosounder beam pattern. Unfortunately sphere positioning was complicated by local currents and sphere deployment procedures on a large vessel. These conditions reduced the coverage of calibration data to one quadrant of the echosounder FOV (Figure 12). The beam pattern of the ES18-11 transducer was assumed to be radially symmetric with electrical phase angles from $0-90^{\circ}$.

The electrical phase angle data derived from split-aperture processing defined in [Burdic, 1991]. The measured acoustic response of the calibration sphere was observed as a function of electrical phase angle and frequency to characterize the echosounder beam pattern. For each frequency between $16-26 \mathrm{kHz}$ the echosounder sensitivity was described with third-degree polynomial fit.

Assuming radial symmetry, a TS correction factor look-up table was produced from the difference between the modeled TS of the sphere and field observations across the ranges of frequency and electrical phase angle (Figure 12). The limit of the correction factor look-up table is the two-way $3 \mathrm{~dB}$ beam width corresponding to an electrical phase angle of $90^{\circ}$ and a mechanical angle of $5.5^{\circ}$ from the MRA. The derived offsets represent the difference between the sound pressure level (SP) observed at a location off the MRA in the SBES FOV and the TS of the sphere. The offset at each angle and frequency provides the necessary corrections for both beam pattern effects and transducer sensitivity in subsequent measurements of TS for targets throughout in the FOV. 

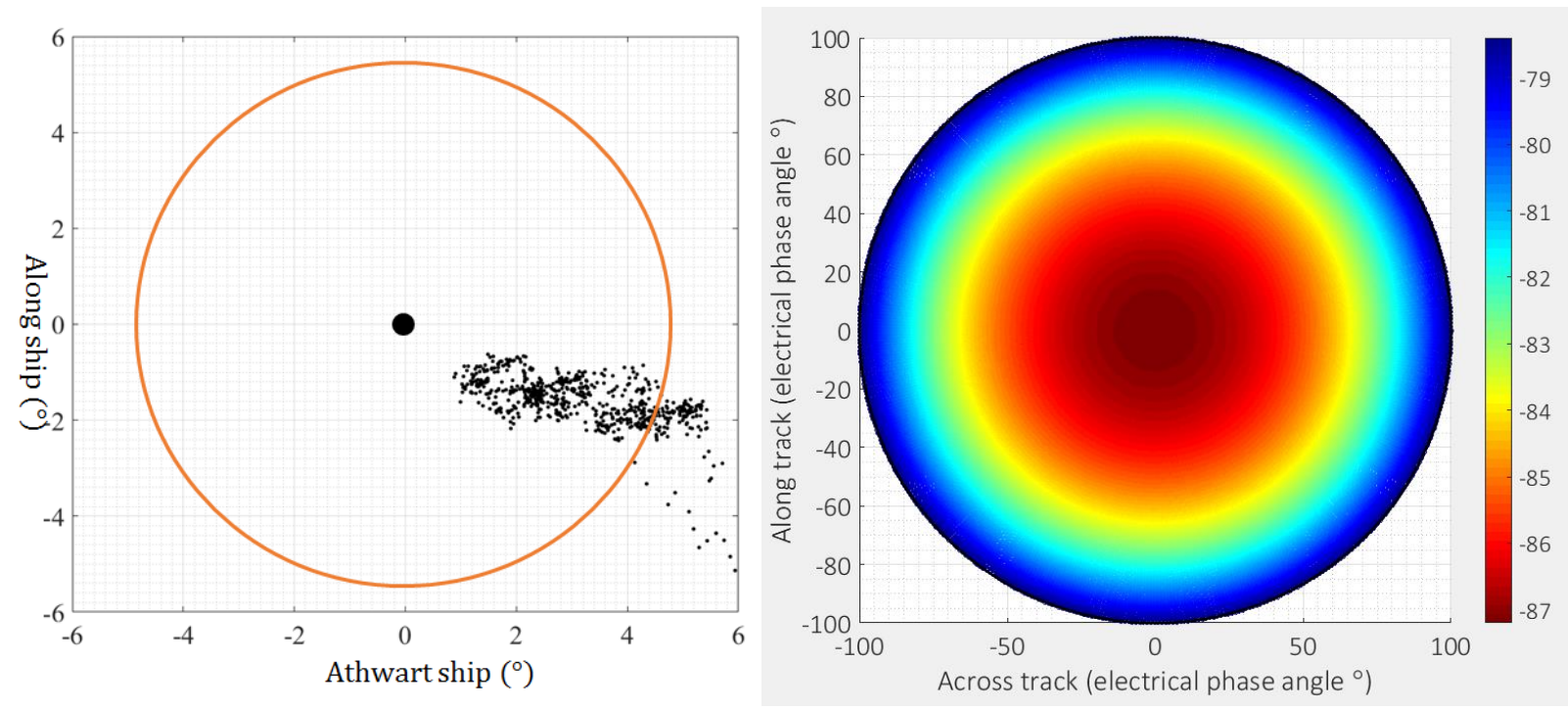

Figure 12. The final calibration sphere location data is plotted in the left panel. The right panel shows the final calibration offset look-up table produced from field calibration activities. Offset value, given in decibels, were added to acoustic sound pressure data to account of beam pattern and transducer sensitivity effects.

\subsection{Acoustic background noise intensity}

The frequency-modulated acoustic background noise intensity was calculated for each EK80 file to determine SNR on a file-by-file basis. The noise was calculated from a Fourier transform of the average acoustic time series of 80 samples in three successive ping records. The frequency modulated noise for each file was saved for comparison against individual bubbles data (Figure 13).

The mean of the FM acoustic background noise TS and bubble TS was calculated over the experimental frequency band $(16-26 \mathrm{kHz})$. The mean bubble TS must be at least $10 \mathrm{~dB}$ higher then mean background noise. 


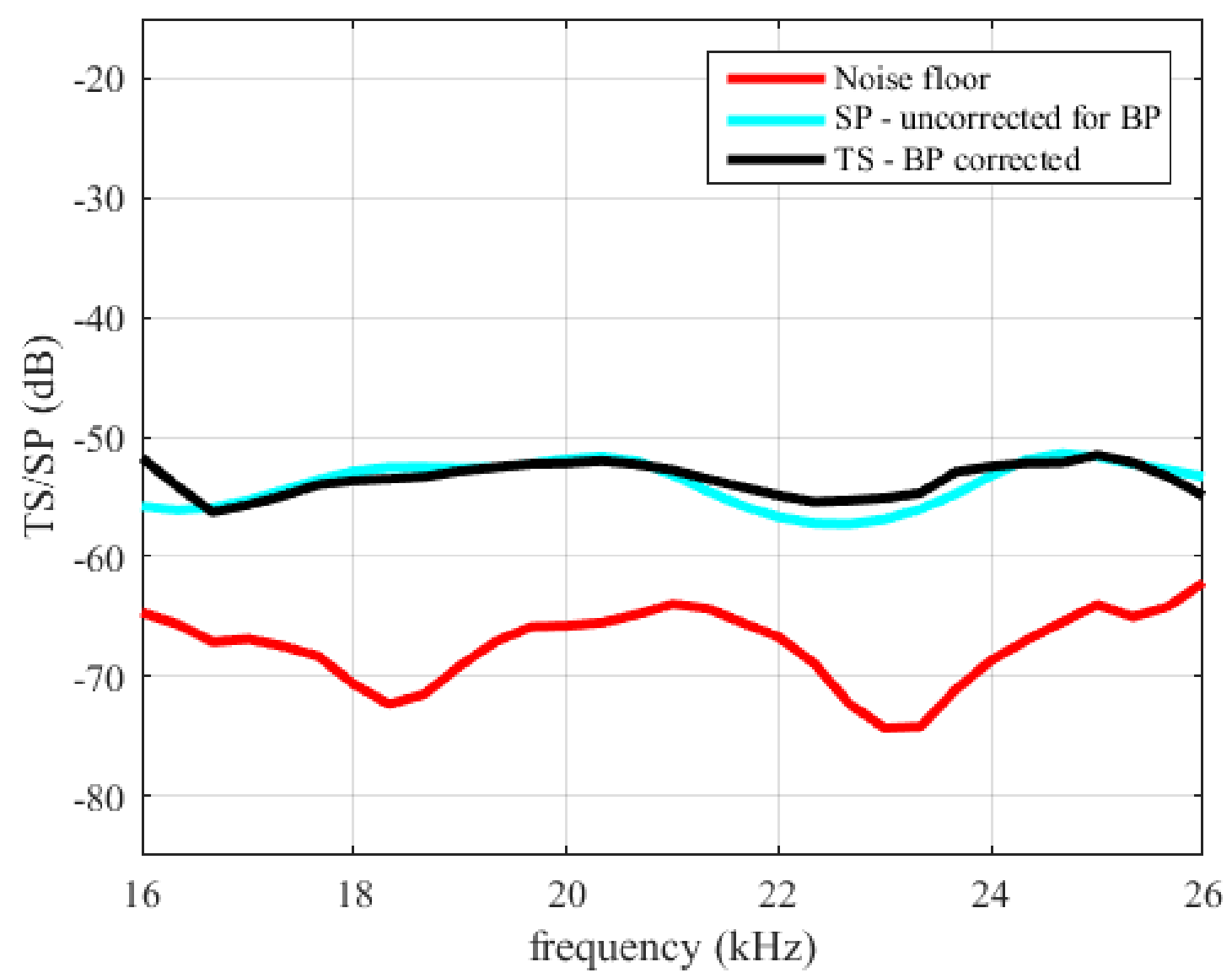

Figure 13. EK80 FM acoustic response of a single bubble (blue and black line) and acoustic background noise (red line). 


\subsection{Seep files: sampled}
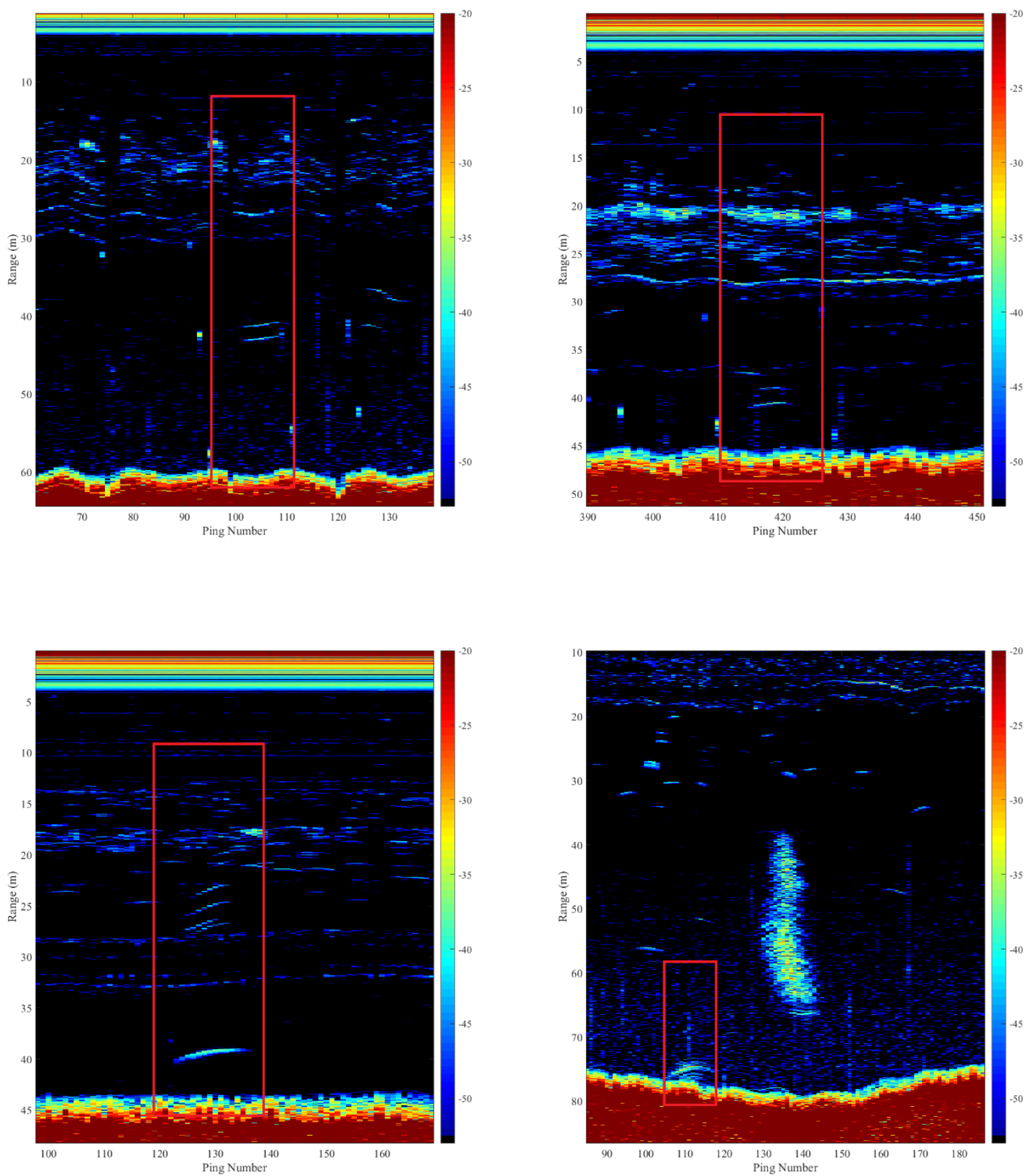

Figure 14. Sampled seep files starting at top left: T000559, T010336, T014257, T042631_1 

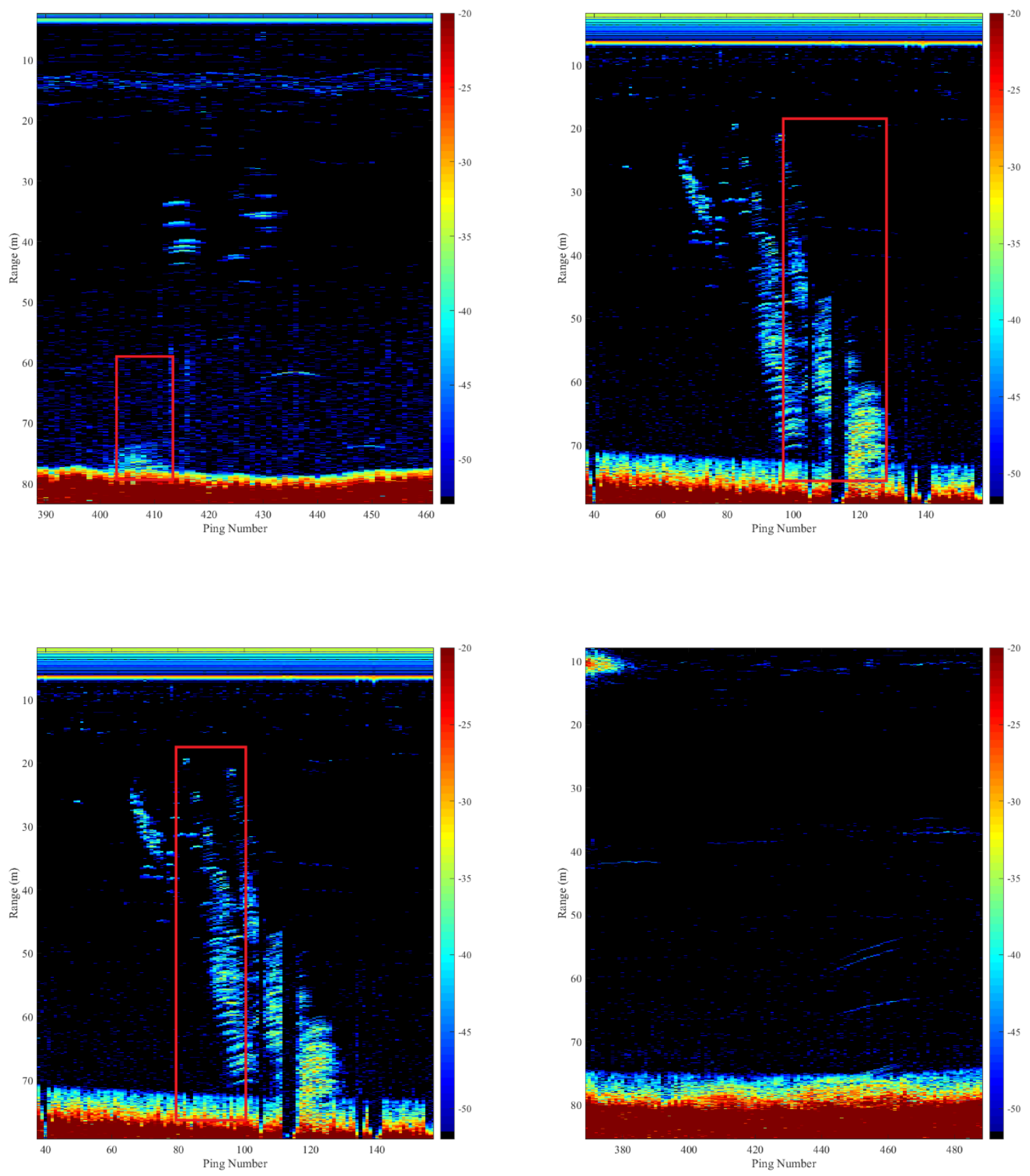

Figure 15. Sampled seeps: Sampled seep files starting at top left: T043037_1, T063136_1, T063136_2, T063136_3 

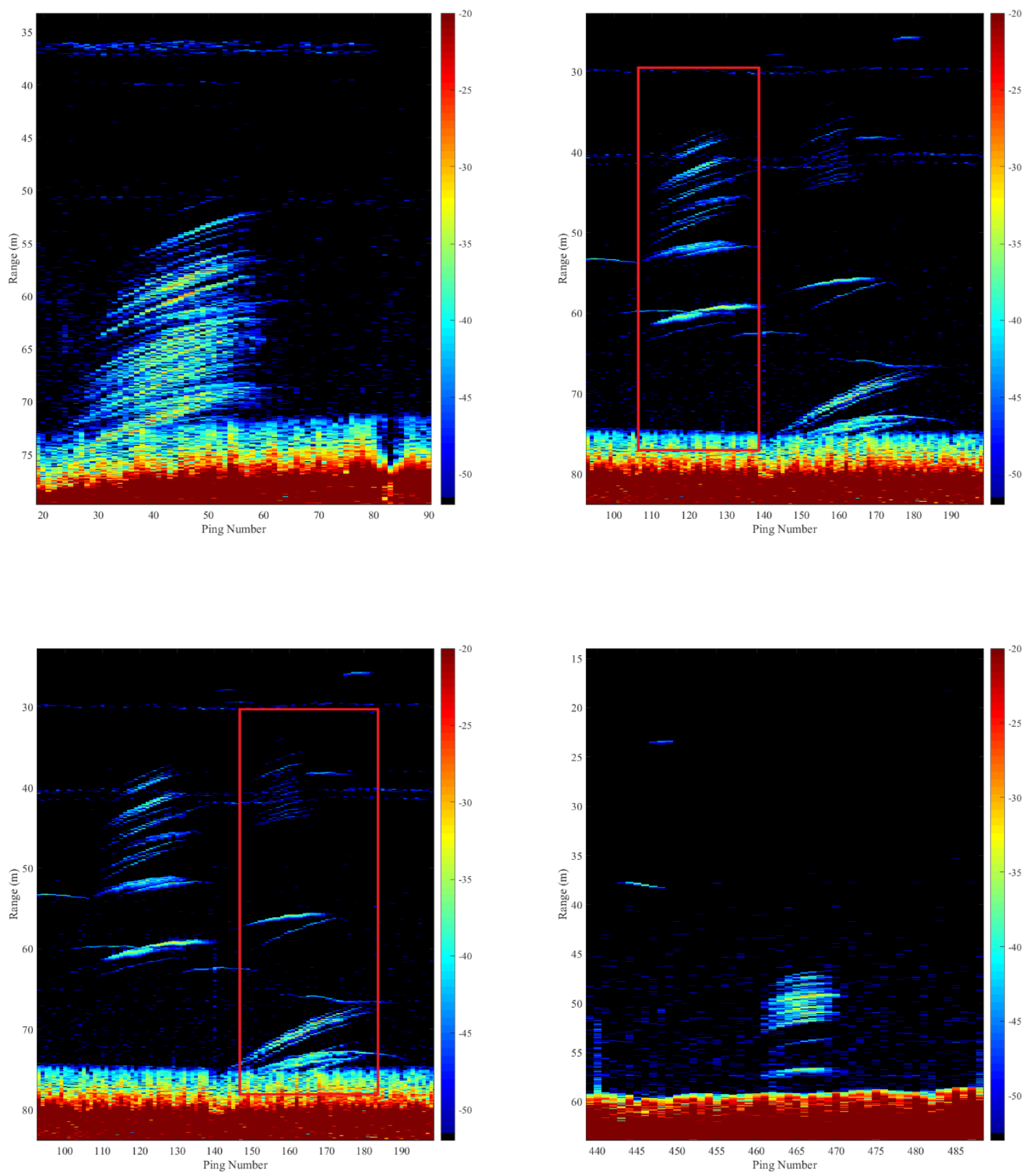

Figure 16. Sampled seep files starting at top left: T063822, T065828_1, T065828_2, T071055 

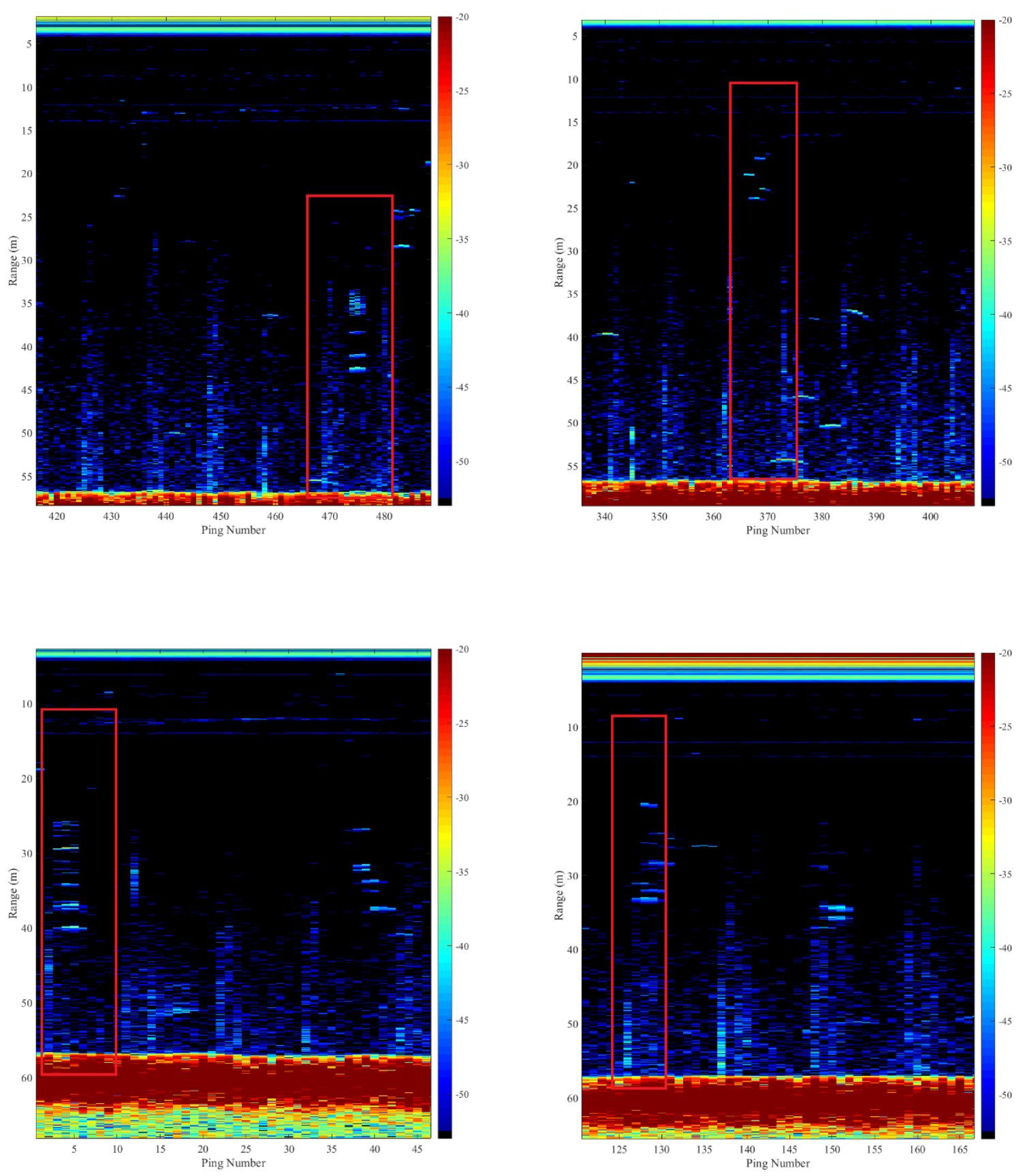

Figure 17. Sampled seep files starting at top left: T091020_1, T091020_3, T091439_1, T091439_3 

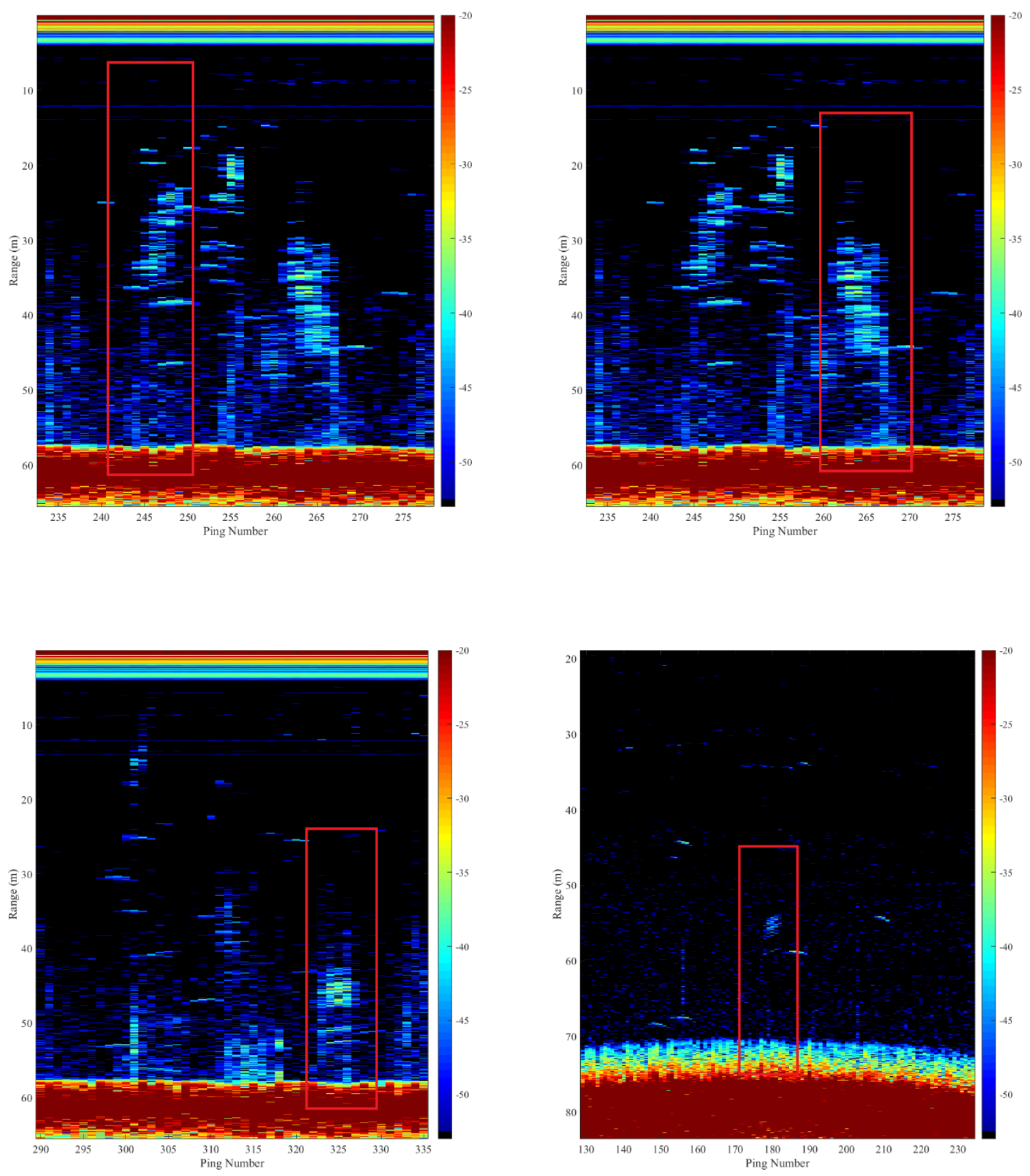

Figure 18. Sampled seep files starting at top left: T091439_7, T091439_9, T091439_13, T100624 

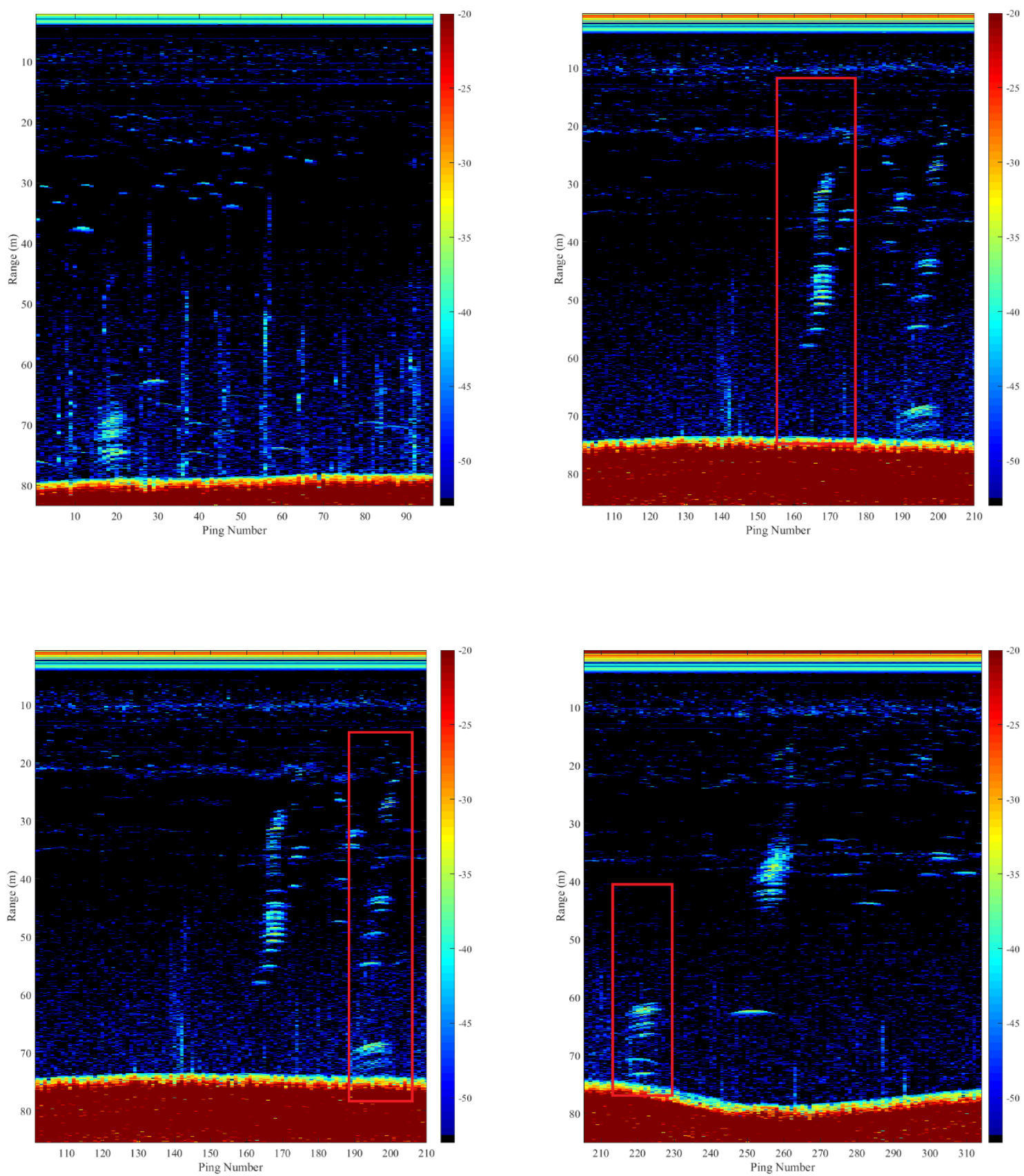

Figure 19: Sampled seep files starting at top left: T171859, T172318_1,T172318_3,T172318_4 

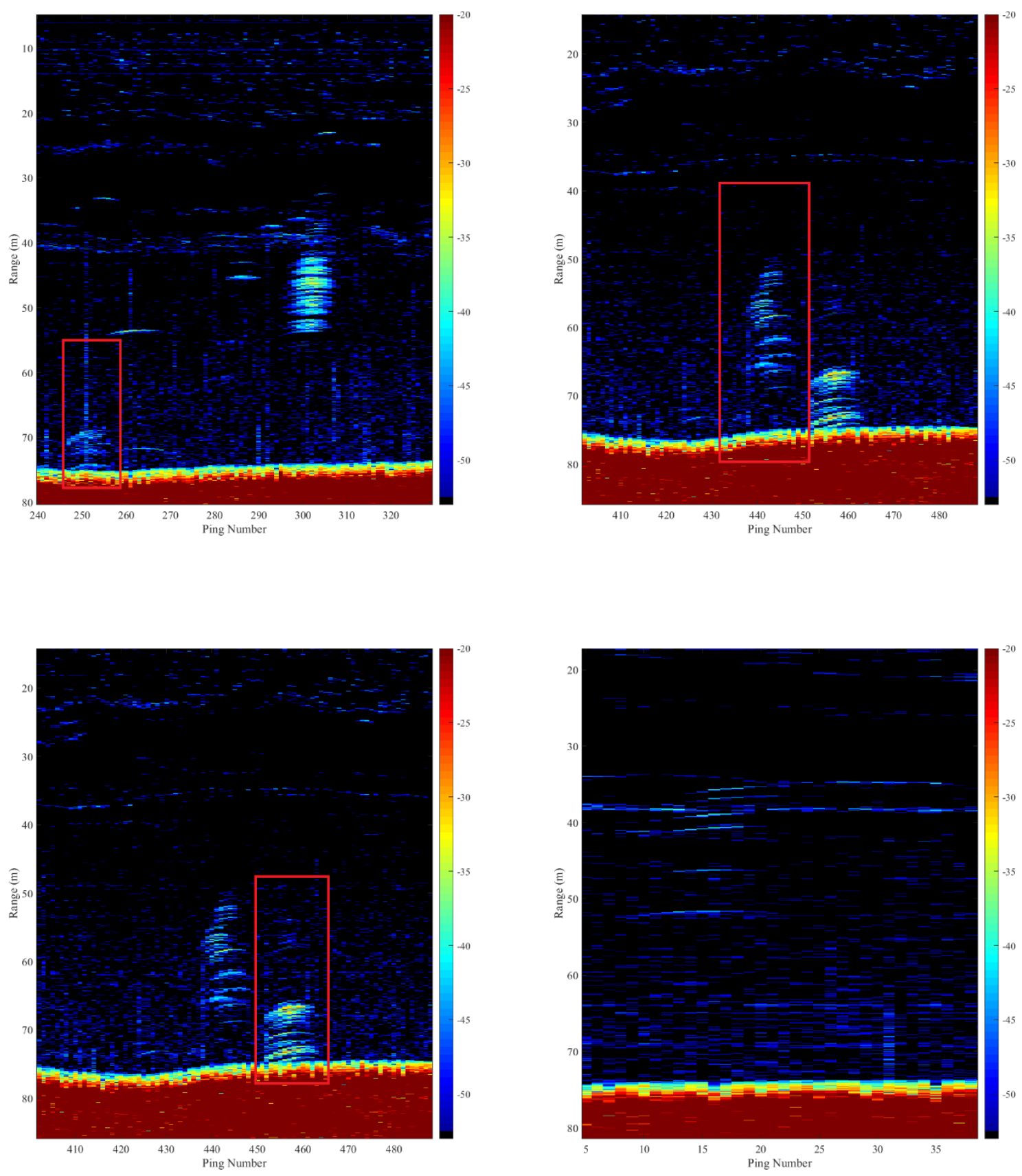

Figure 20. Sampled seep files starting at top left: T173156_1,T174032_1, T174032_2, T175325 

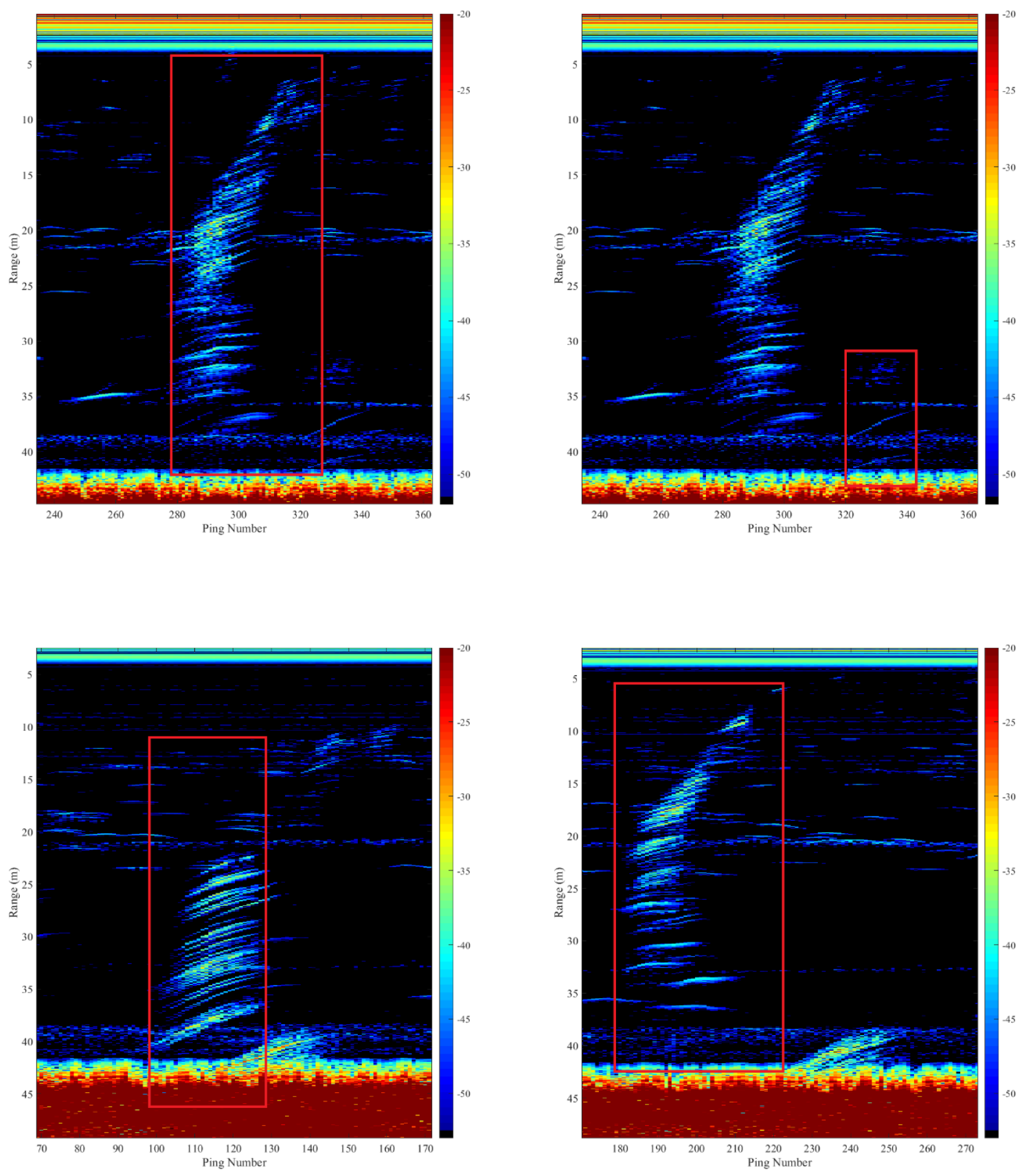

Figure 21. Sampled seep files starting at top left: T222721_1, T222271_2, T223151_1,T223151_3 

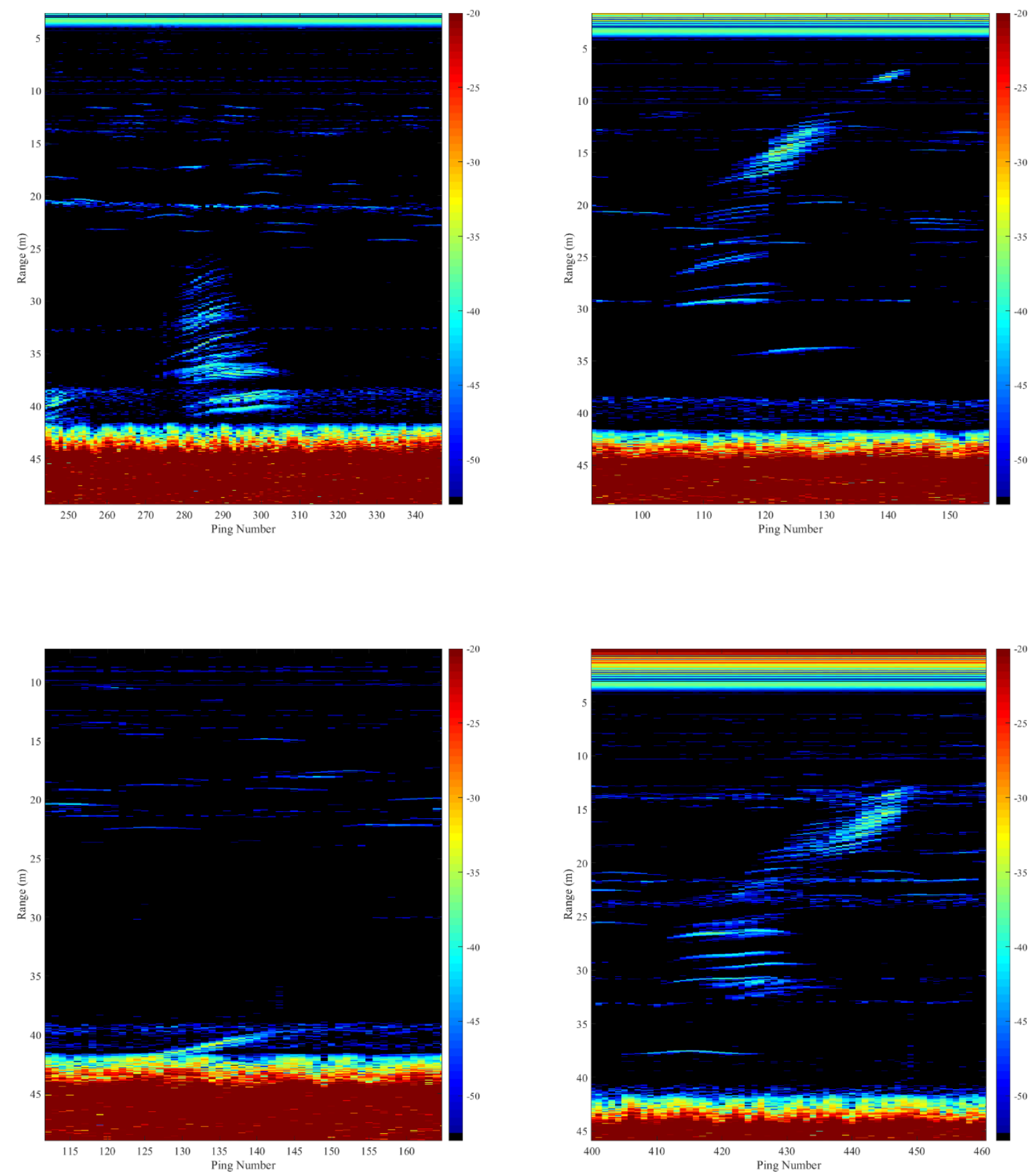

Figure 22. Sampled seep files starting at top left: T223151_5, T223620, T224048, T225859 

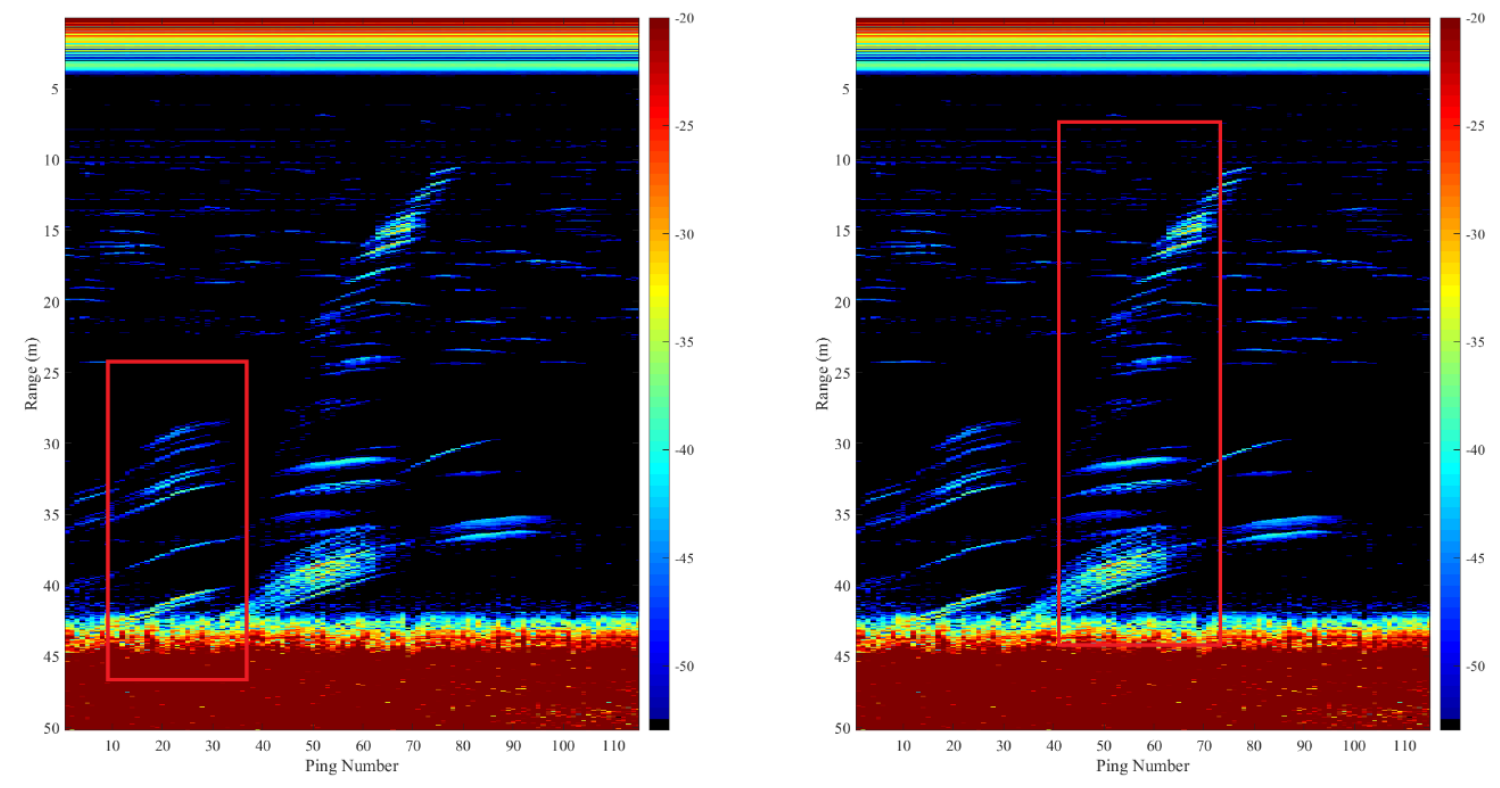

Figure 23. Sampled seep files, starting at top left: T234343_2, T234343_3 


\subsection{Seep files: not sampled}
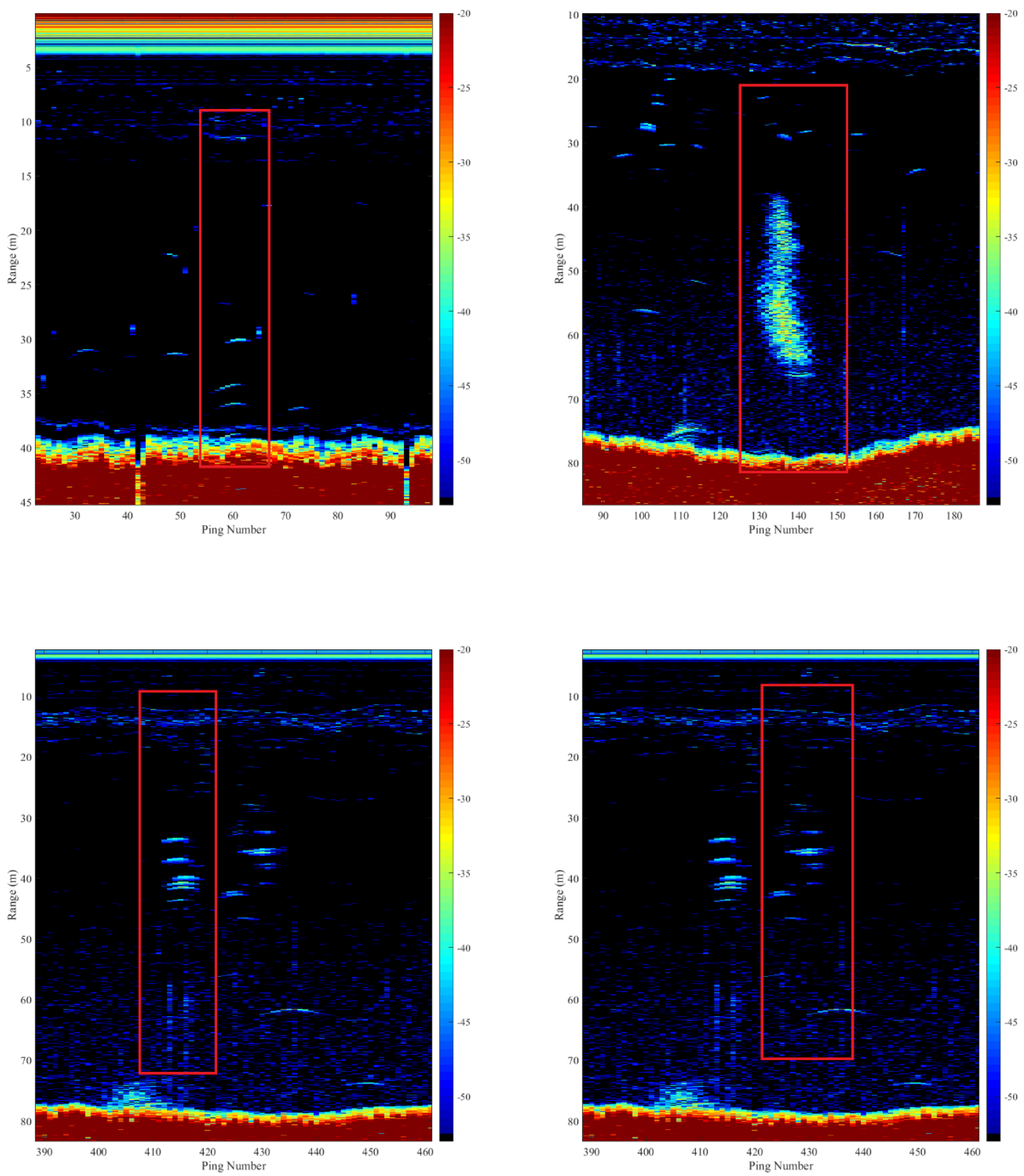

Figure 24. Seep files not sampled: T023550, T042631_2, T043037_2, T043037_3 

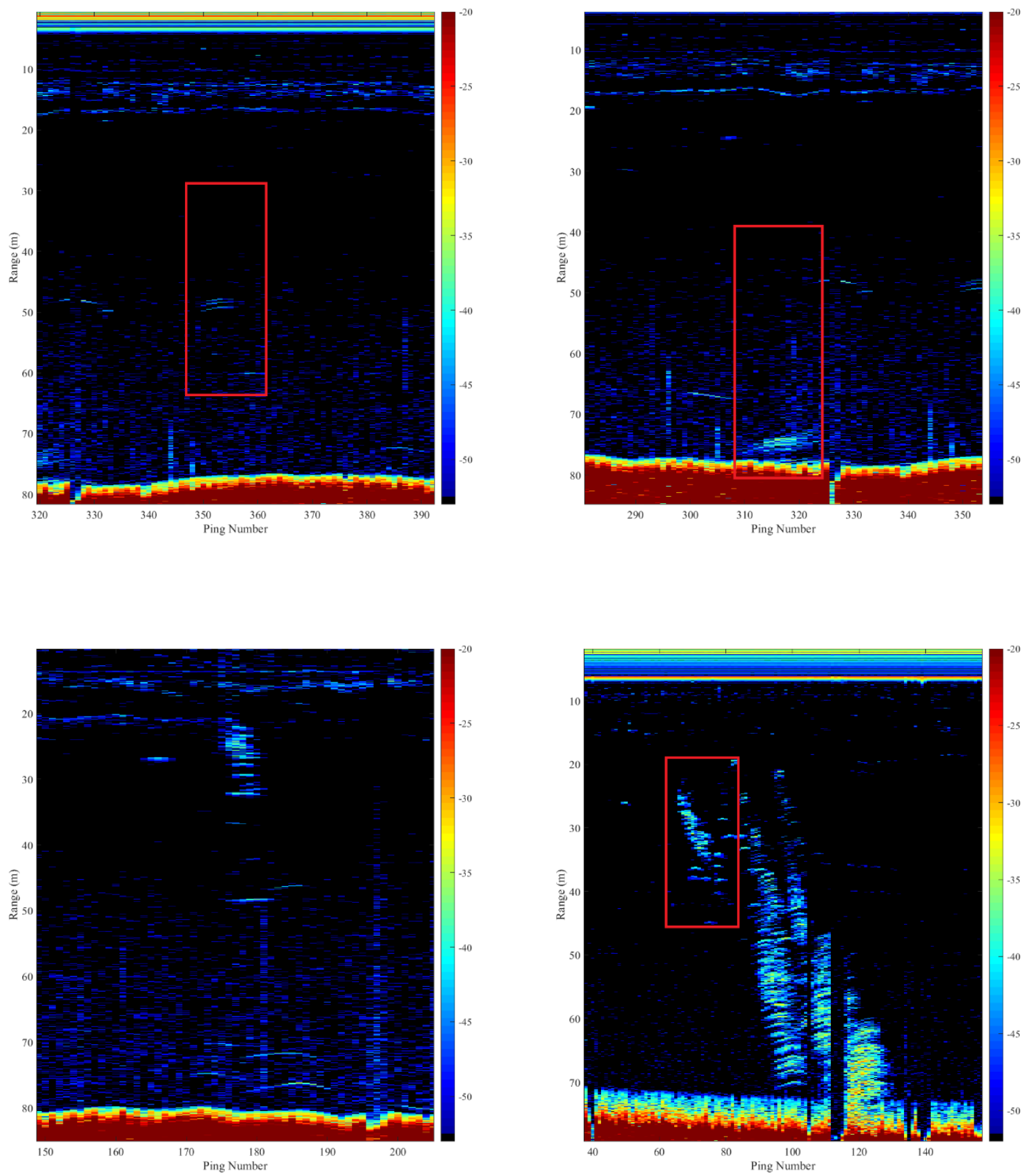

Figure 25. Seep files not sampled: T043037_3, T04307_4, T043441, T063136_2 

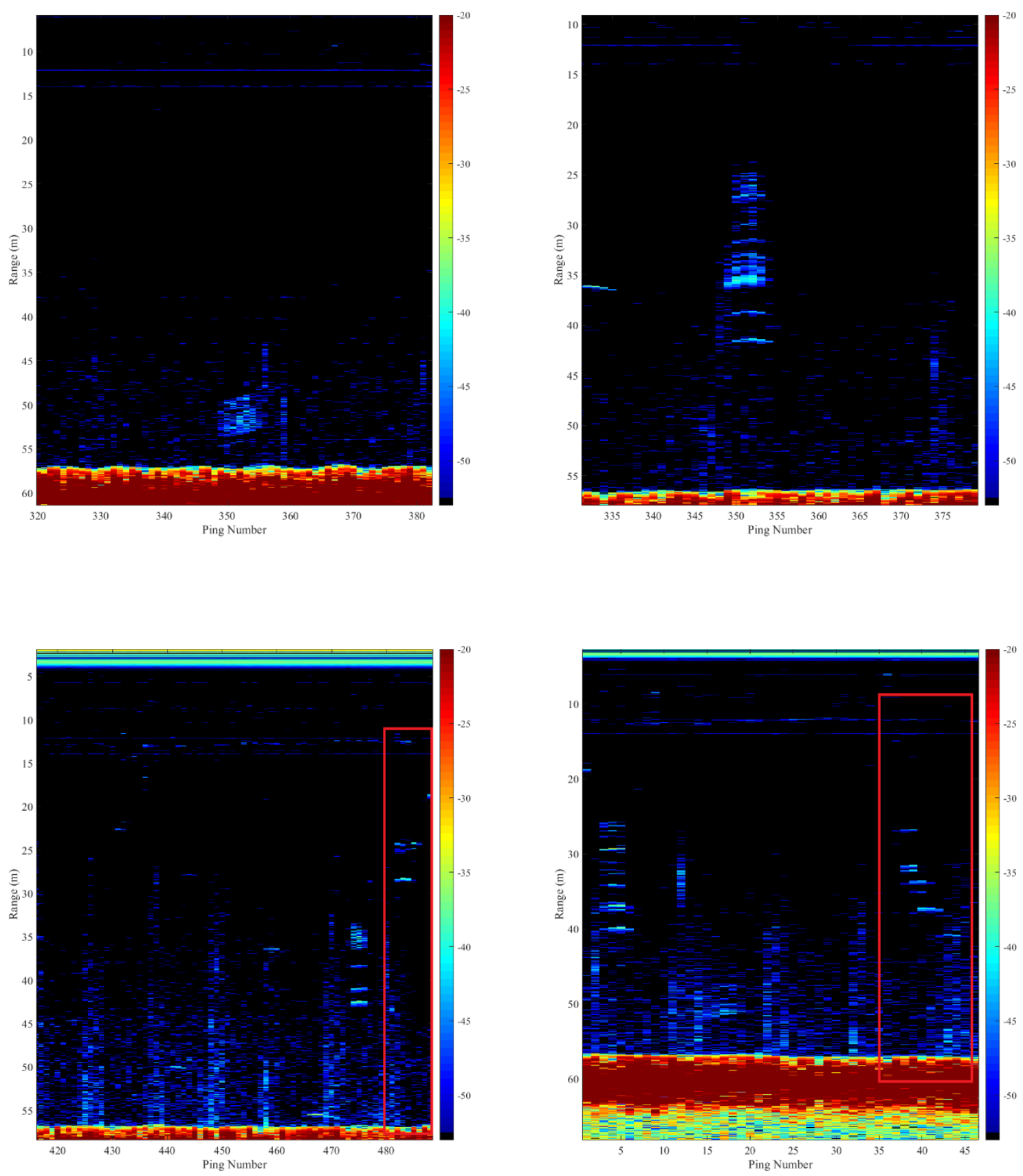

Figure 26. Seep files not sampled: T071455, T071903, T091020_2, T091439_2, T091439_4 

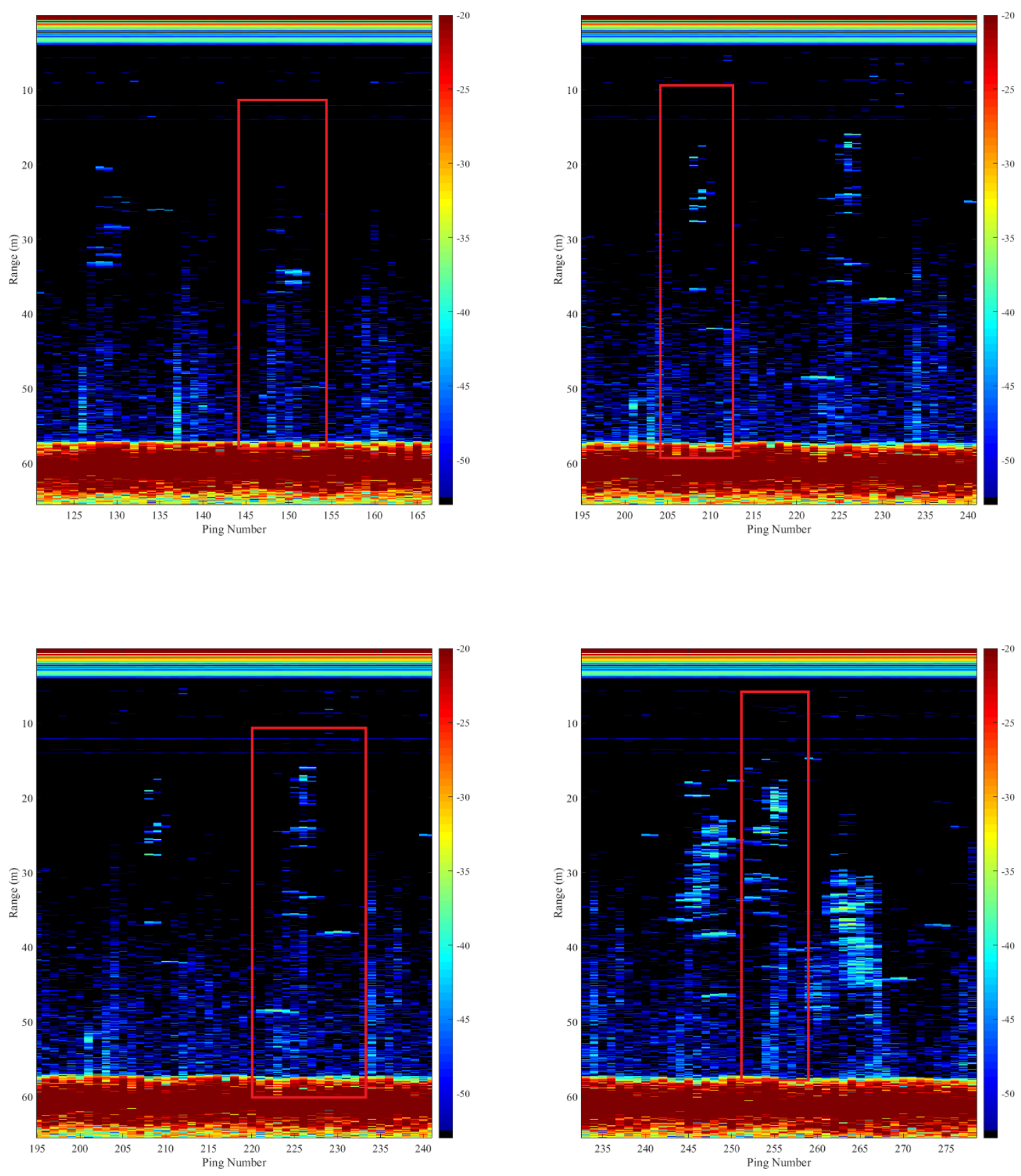

Figure 27. Seep files not sampled: T091439_4, T091439_5, T091439_6, T091439_8 

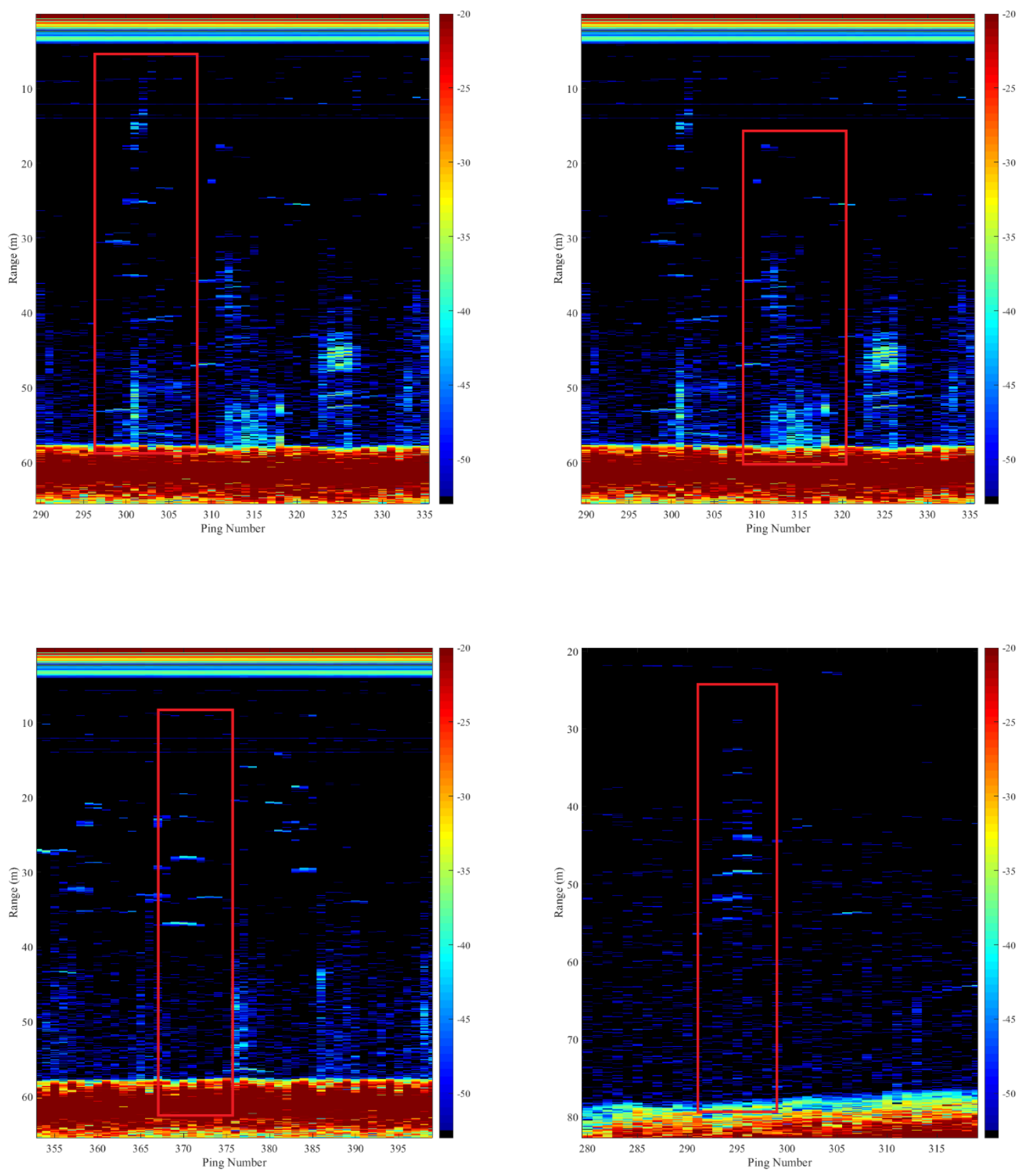

Figure 28. Seep files not sampled: T091439_10, T091439_11, T091439_12, T095942 

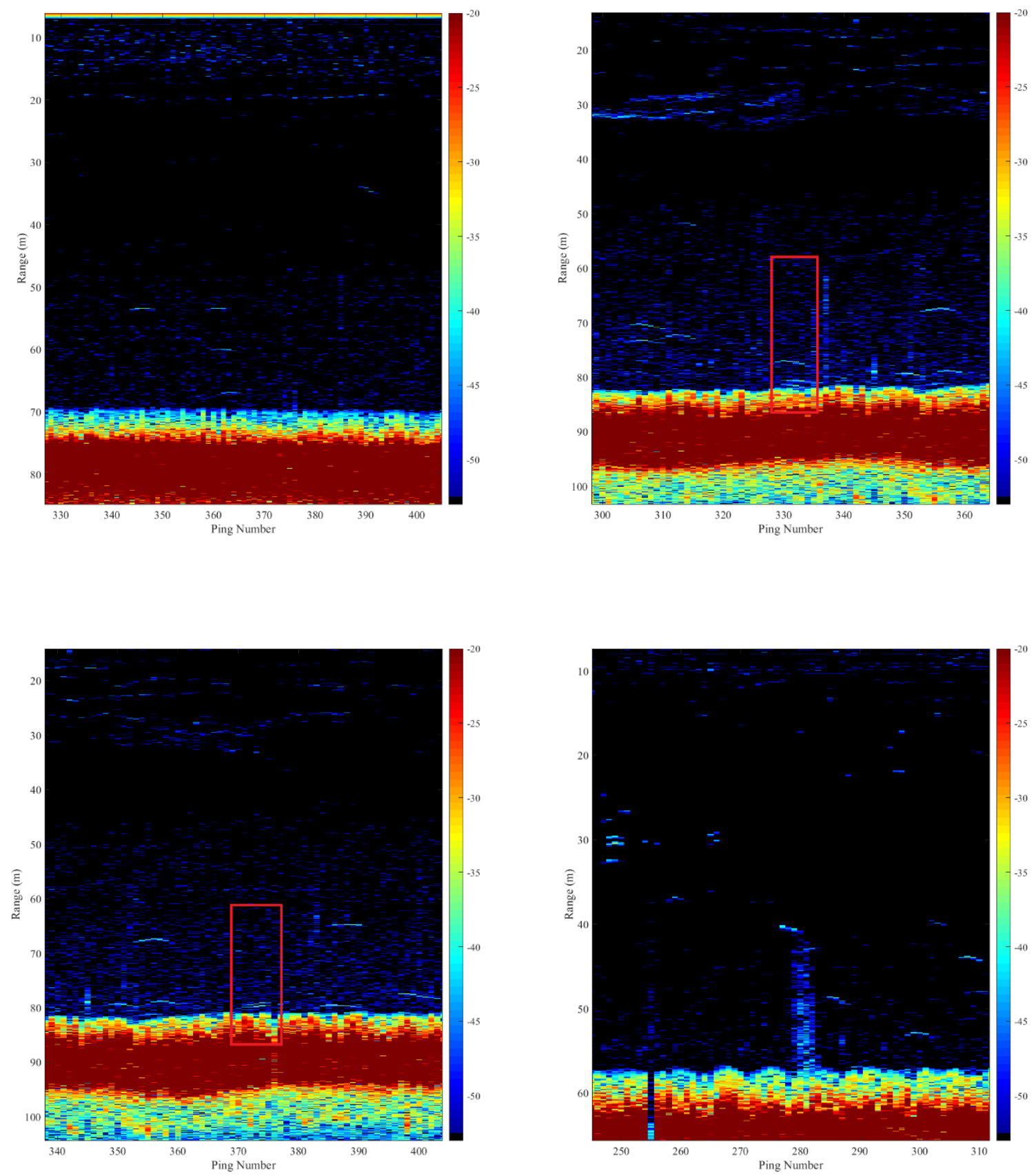

Figure 29. Seep files not sampled: T101306, T123404_1, T123404_2, T150133_1 

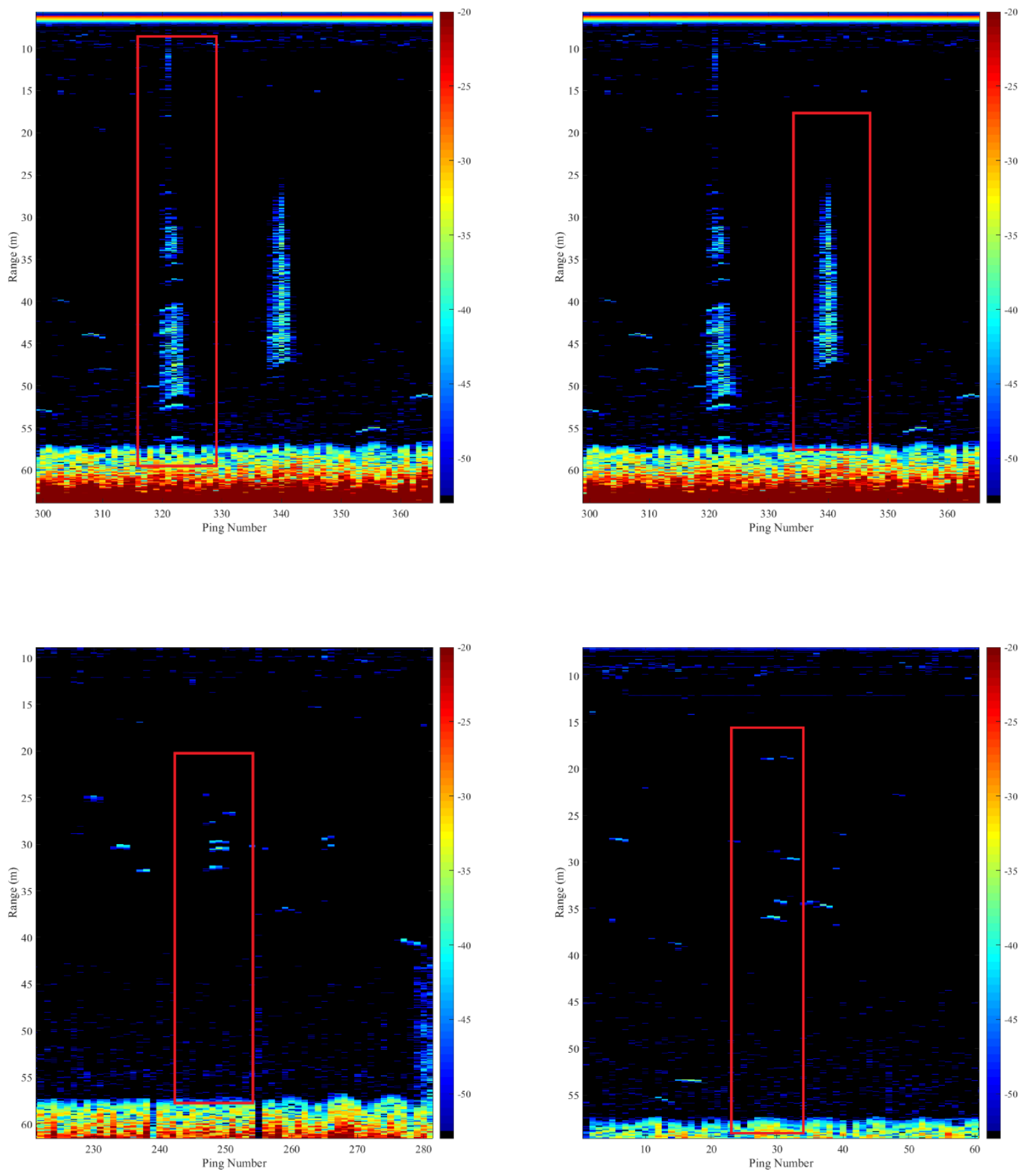

Figure 30. Seep files not sampled: T150133_2, T150133_3, T150133_4, T150133_5 

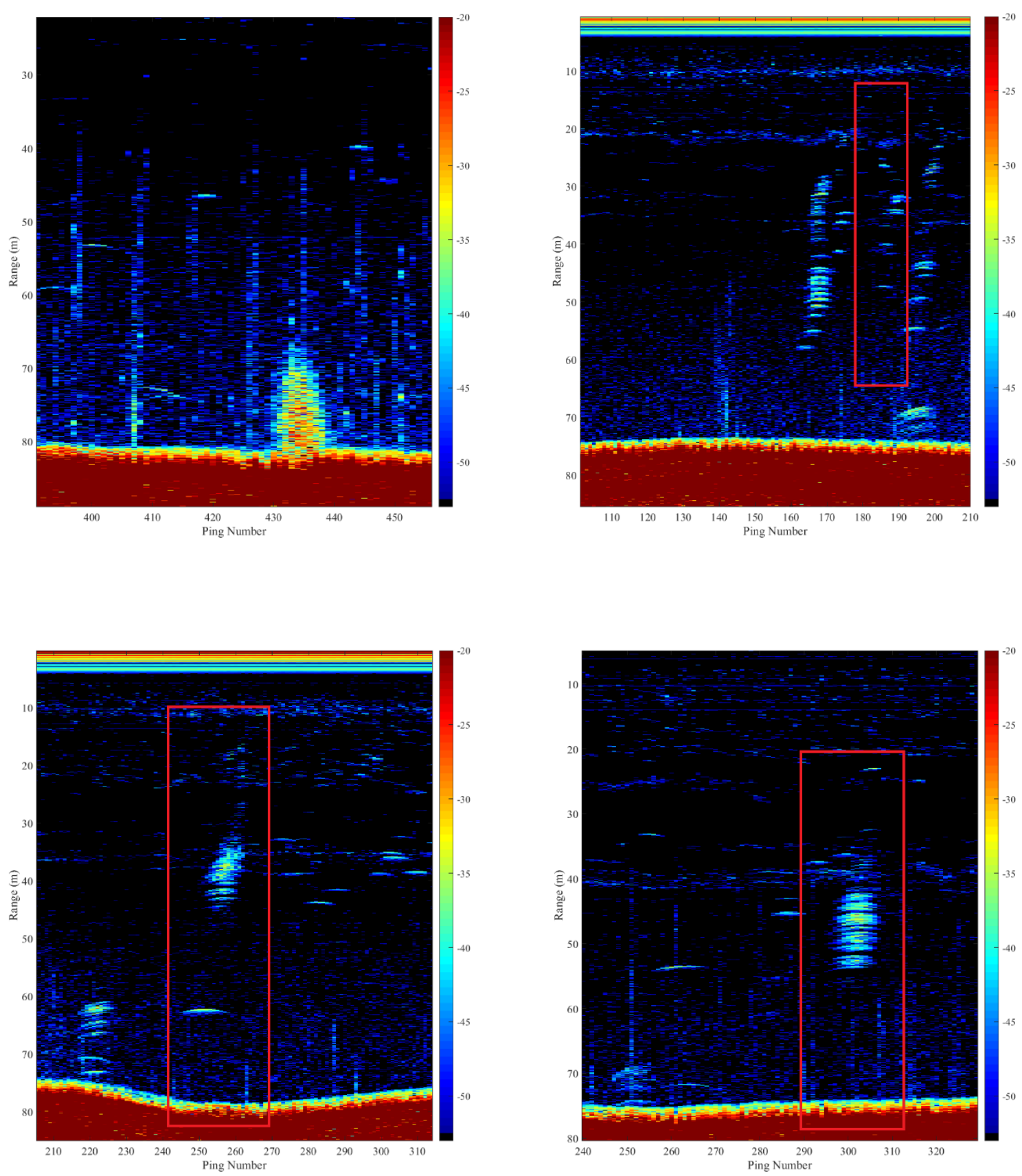

Figure 31. Seep files not sampled: T171445, T172318_2, T172318_5,T173156_2 

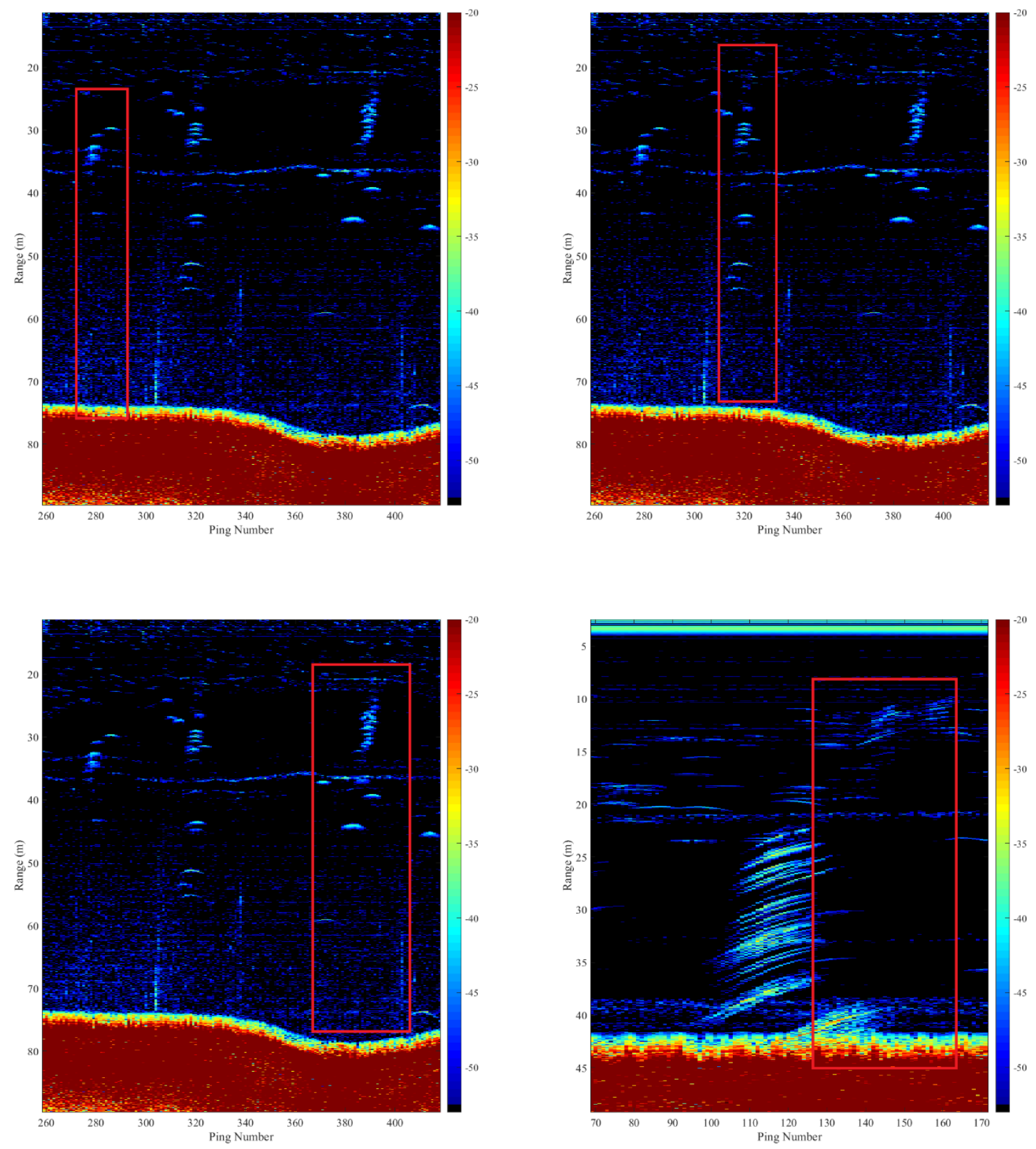

Figure 32. Seep file not sampled: T174907_1, T174907_2, T174907_3, T223151_2 

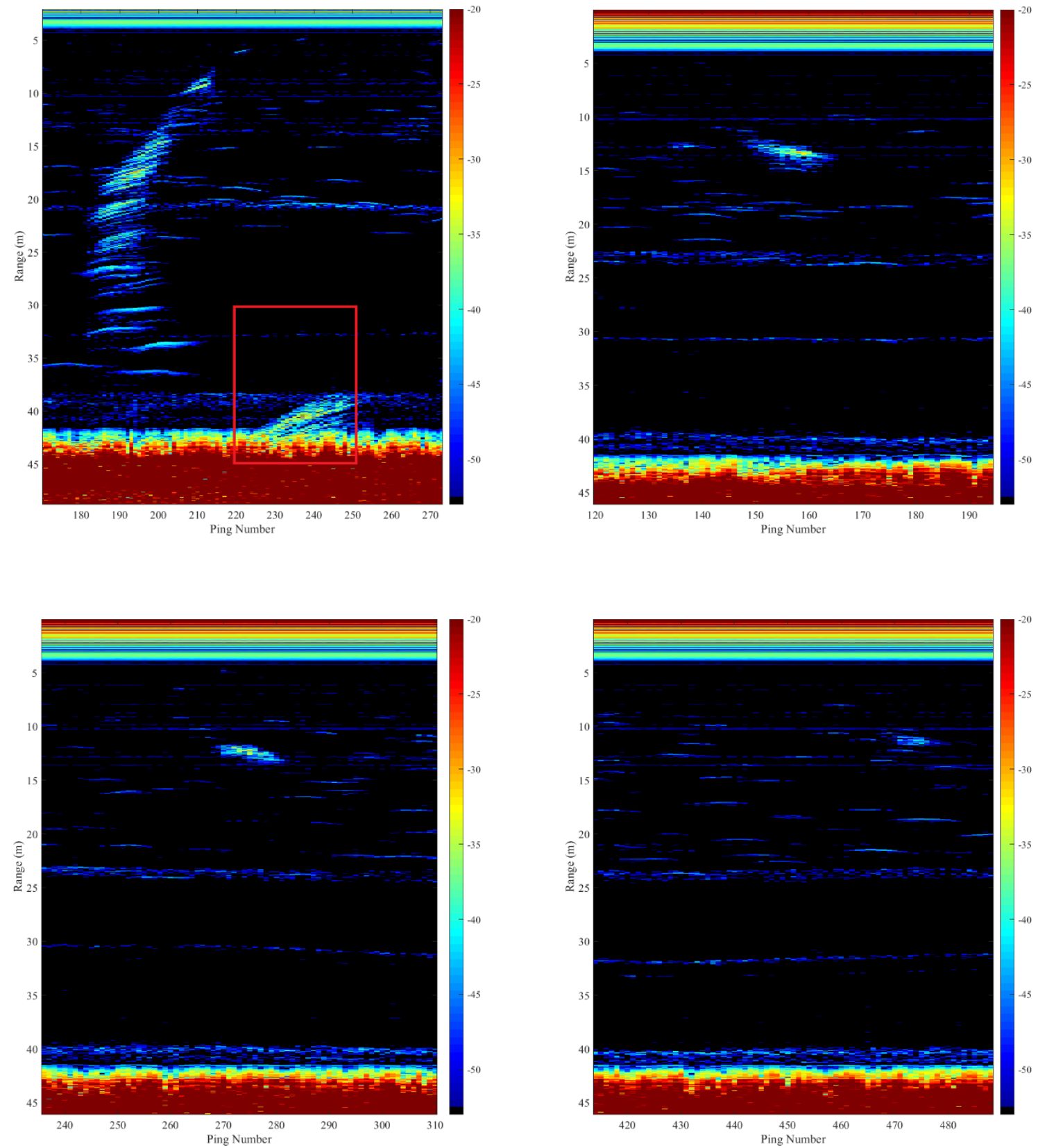

Figure 33. Seep files not sampled, starting at top left: T223151_4, T224955_1, T224955_2, T224955_3 

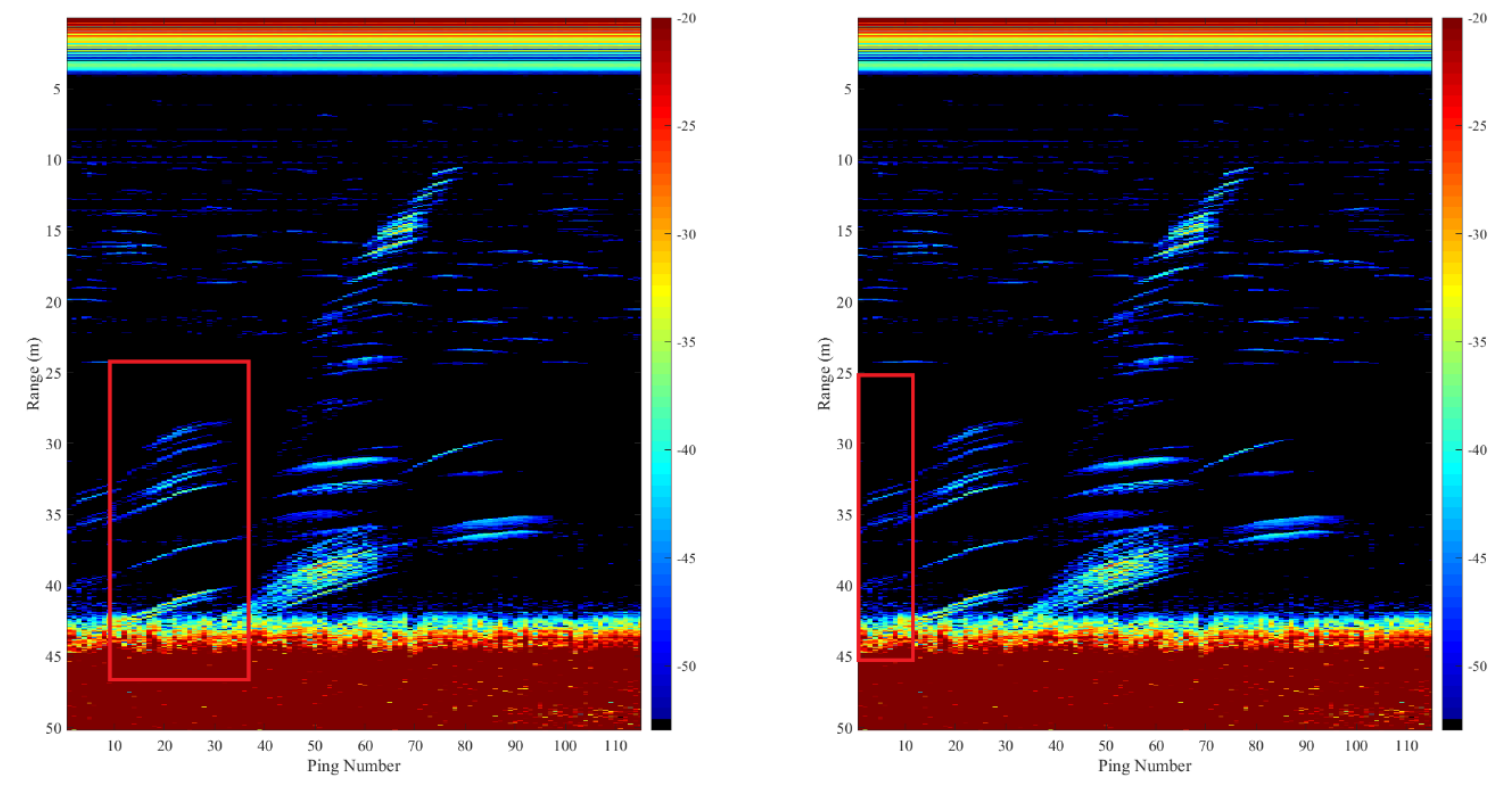

Figure 34. Seep files not sampled, starting at top left: T234343_1, T234343_4 


\subsection{Uncertainty}

\subsubsection{Bubble radius}

Expected uncertainty estimation derivation:

$$
\begin{aligned}
& \sigma_{a}=\frac{d a}{d \sigma_{b s}} \sigma_{\sigma_{B S}} \\
& T S=10 \log \sigma_{B S} \\
& \sigma_{B S}=\frac{a^{2}}{\left[\left(\frac{f_{r}}{f}\right)^{2}-1\right]+\delta^{2}}
\end{aligned}
$$

Outside resonance $f_{r} \ll f$ :

$$
\begin{gathered}
\therefore\left(\frac{f_{r}}{f}\right)^{2}=\text { small } \\
\therefore\left[\left(\frac{f_{r}}{f}\right)^{2}-1\right]+\delta^{2}>>>1+\delta^{2} \\
\therefore \sigma_{B S}=\frac{a^{2}}{1+\delta^{2}} \\
\frac{d \sigma_{b S}}{d a}=\frac{2 a}{1+\delta^{2}}
\end{gathered}
$$

If $\delta^{2}$ is small:

$$
\begin{gathered}
\frac{d a}{d \sigma_{b s}}=\frac{1}{2 a} \\
\sigma_{a}=\frac{d a}{d \sigma_{b s}} \sigma_{\sigma_{B S}}=\frac{\sigma_{\sigma_{B S}}}{2 a}
\end{gathered}
$$

Nominal uncertainty estimate for $1.5 \mathrm{~mm}$ bubble with $1.5 \mathrm{~dB}$ variability about the average TS curve: 


$$
\begin{gathered}
T S_{\text {ave }}=-55 \mp 1.5 \mathrm{~dB}, \quad \sigma_{\sigma_{B S}}=1 \times 10^{-6} \\
\sigma_{a}=\frac{1 \times 10^{-6}}{2 \times 0.0015}=0.33 \mathrm{~mm}
\end{gathered}
$$

The average estimated uncertainty in the bubble radius measurement, as determined from the pingto-ping variability in TS curve, is approximately $0.14 \mathrm{~mm}$. The average estimated uncertainty generally increases with increasing bubble radius (Figure 37). The ping-to-ping variability in TS curves does not show any clear size dependence, but as bubble size increases there is increasingly smaller separation between TS curve magnitude. The result in an increased uncertainty at larger bubble sizes for a given amount of variability ping-to-ping in measured TS curves.

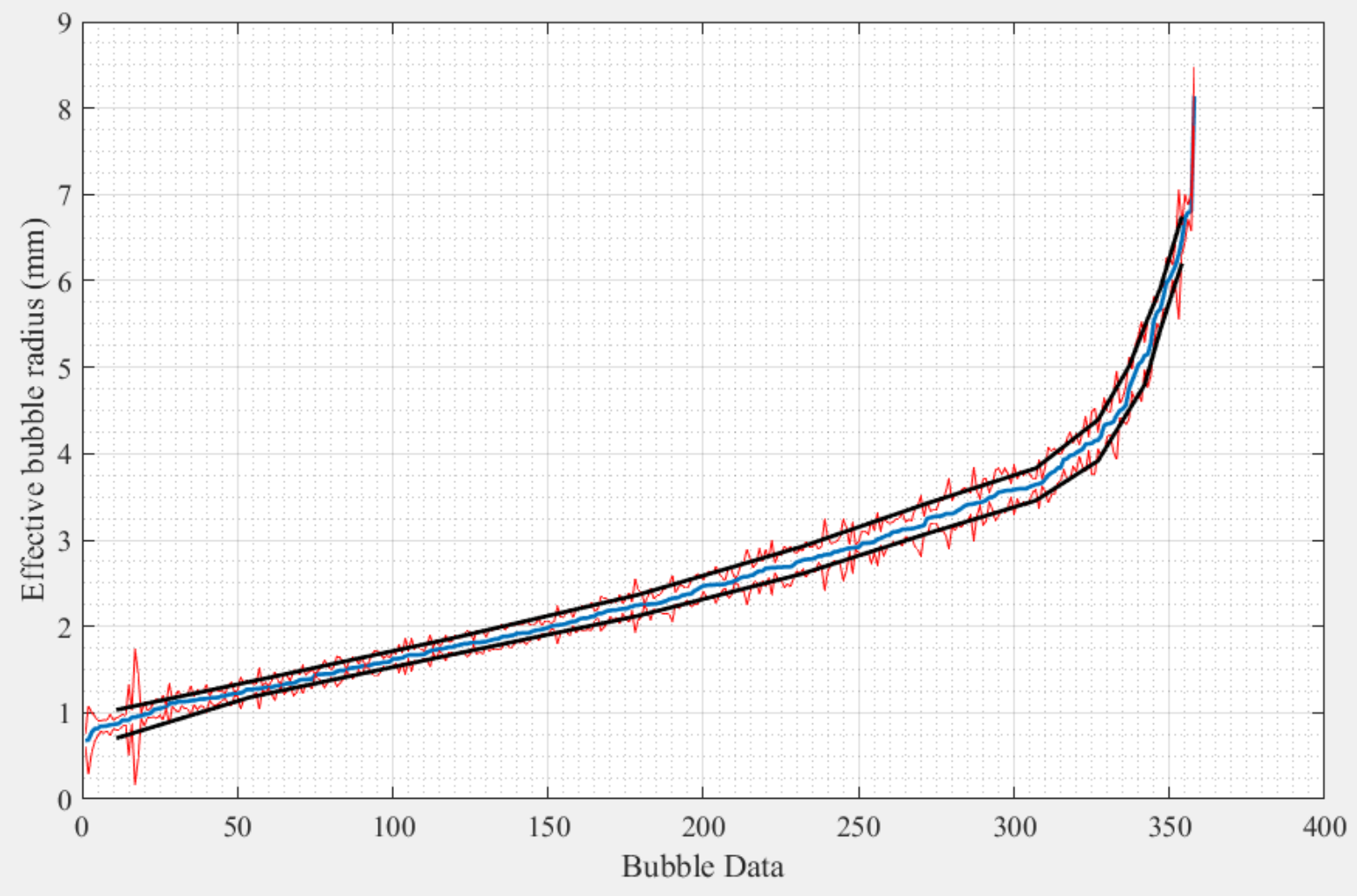

Figure 35. Individual bubble samples sorted by radius and plotted with calculated uncertainty (red) and running average uncertainty (black). 
Table 2. Estimated mean uncertainty in the bubble radius and rise velocity measurements for the binned dataset

\begin{tabular}{|c|c|c|c|c|c|c|c|c|}
\hline Bubble radius $(\mathrm{mm})$ & $<1.0$ & $1.0-2.0$ & $2.0-3.0$ & $3.0-4.0$ & $4.0-5.0$ & $5.0-6.0$ & $6.0-7.0$ & $>7.0$ \\
\hline $\mathrm{N}$ & 15 & 109 & 97 & 63 & 20 & 9 & 7 & 1 \\
\hline Radius: $\sigma_{a}$ & 0.12 & 0.11 & 0.17 & 0.21 & 0.27 & 0.27 & 0.25 & 0.34 \\
\hline Rise velocity: $\sigma_{v}$ & 0.96 & 1.45 & 1.46 & 1.45 & 1.40 & 1.57 & 1.25 & 0.65 \\
\hline
\end{tabular}

As stated in section 5, the magnitude of the estimated uncertainty due to ping-to-ping variation far outweighs any other source of uncertainty in the bubble size calculation. However, there is unresolved bias in the estimation of bubble radius stemming from assumptions made in modeling the acoustic backscattering of a single bubble as mentioned in the introduction:

1) the ensonifying wavelength is large compared to the bubble size $(\mathrm{ka}<<1)$;

2) the only mode of bubble pulsation considered is radial;

3) the bubble is spherical in shape; and

4) the bubble is free from any coating ("clean").

Assumptions 1 and 2 do not introduce any major error in the estimation of bubble size. The shortest wavelength of the experimental frequency band $(16-26 \mathrm{kHz})$ is approximately $60 \mathrm{~mm}$, large compared to the largest bubble identified $(7.8 \mathrm{~mm})$ and the higher modes of bubble pulsation have an negligible effect on the re-radiation of sound when $k a<<1$ (Strasberg, 1956). However, there is bias introduced by assuming all bubbles are spherical in shape. Marine seep bubbles have been observed to be increasingly non-spherical in shape with respect to increasing size (Ostrovsky et al. 2008; Leifer and Cullings, 2010; Wang and Socolofsky, 2015). The magnitude of acoustic backscattering is likely dependent on the on angular position of bubble in reference to transducer face. As bubble orientation changes during rise acoustic scattering measurements will exhibit 
natural variability. The effects of bubble shape have not been quantified and so this bias is left unaccounted for in the final bubble size estimation.

In addition to unresolved bias introduced by assuming spherical bubble shape, the acoustic scattering model assumes all bubbles are "clean" (i.e. free from surface coating). Although the Herald Canyon region is too shallow for hydrate coating and there is no indication of oil in the region, biological surfactants could be present on some of the sampled bubbles. It is possible that the presence of surfactants on a bubble could influence the acoustic scattering intensity but without optical observations it is difficult even to verify the presence of surfactants and this bias is unaccounted for in bubble size estimations.

The model for acoustic scattering from a bubble is some function oceanographic parameters (temperature and salinity) and bubble parameters (gas composition). Oceanographic parameters are defined by the nearest-in-time CTD profile. Although CTD profiles were taken at minimum every 12 hours, the variability in the watercolumn thermohaline structure cannot be completely defined and it is likely that for a given bubble location thermohaline structure is somewhat different than the closest-in-time CTD profile. Previous research in the ESAS has suggested that bubbles originate from a biogenic source of methane and when released from the seafloor should be nearly $100 \%$ methane gas (Sapart et al, 2017). However, as bubbles rise through the watercolumn gas transfer across the bubble-water interface alters their composition based on the local concentrations of dissolved gases in the ocean. Bubble composition diverges from $100 \%$ methane with increasing altitude off the seafloor.

Sensitivity tests of the acoustic model indicated that changes in gas composition has no discernable effect on expected TS values in the experimental frequency band at given study depths. Additional sensitivity testing for temperature and salinity changes up to $25 \%\left(+/-1.5^{\circ} \mathrm{C}\right.$ and $+/-7.5$ PSU) 
showed no appreciable changes in TS values in the experimental frequency band at given study depths.

In the application of the EK80 WBT calibration, to account for beam pattern effects, the location of the bubble in the beam is determined via split-aperture phase differentiation. Any error in positioning the bubble would lead to an incorrect calibration offset value, resulting in some uncertainty in the TS measurement and subsequent uncertainty in the bubble size measurement. The estimated uncertainty of the split-aperture calculation of mechanical angle of a target from the MRA is given in [Burdic, 1991]:

$$
\sigma_{\theta}^{2}=\frac{\sigma_{\varphi}^{2}}{k d}
$$

where $k d$ is the transducer sensitivity, defined by Simrad as 17.37 and $\sigma_{\varphi}{ }^{2}$ is the uncertainty in the electrical phase angle calculation, given as:

$$
\sigma_{\varphi}^{2}=\frac{E\left[N^{2}\right]}{A^{2}}
$$

where $E\left[N^{2}\right]$ is an estimation of the background noise and $A^{2}$ is the amplitude of the measured signal. The lower the SNR, the larger the error in the split-aperture calculation; low SNR can be a result of a weakly backscattering target and/or increased background noise. The minimum SNR for sampled bubbles was 10, as defined in section 4.1. This SNR gives an approximate estimated uncertainty of $0.8^{\circ}$, which corresponds to a change in calibration offset of less than $1 \mathrm{~dB}$ at maximum. 


\subsubsection{Rise velocity}

The average estimated uncertainty in the bubble rise velocity measurements is approximately 1.6 $\mathrm{cm} / \mathrm{s}$. This value is determined from the variation of the ping-to-ping measurements of bubble vertical position and time from a linear regression.

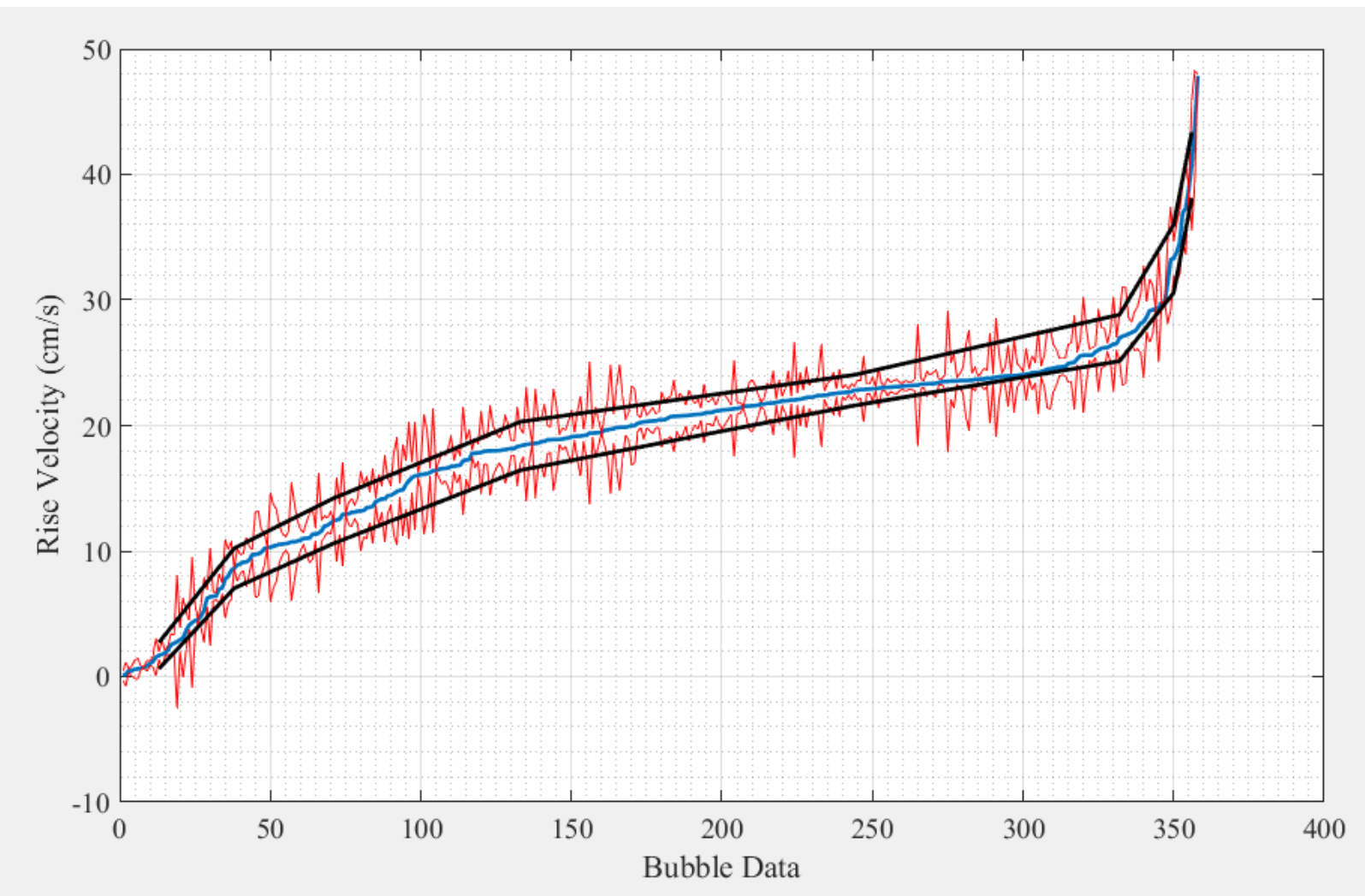

Figure 36. Individual bubble samples sorted by rise velocity and plotted with calculated uncertainty (red) and running average uncertainty (black).

The estimated uncertainty in the split-aperture calculation, discussed in the section above, is approximately $0.8^{\circ}$. The position of the bubble in the transducer FOV, in degrees from the MRA, was used in the calculation of bubble depth. A small amount of uncertainty is introduced into the bubble depth value from uncertainty in the bubble position. However, after propagating this uncertainty through to the final bubble depth, it was found to be minor in comparison to other courses of uncertainty and was disregarded. 
In addition to the uncertainty from the split-aperture calculation, there is ambiguity in range of the bubble from the transducer face. Bubble range is determined from the location of the maximum amplitude sample in the bubble record; however, the length of the acoustic response is a function of the EK80 WBT pulse length and bandwidth (match filtering process). The average bubble record is approximately $18 \mathrm{~cm}$, which introduces a vertical ambiguity of $+/-9 \mathrm{~cm}$ into the bubble range measurement. All bubble scatterers are sampled in the same manner, providing a relative position ping-to-ping to reduce bias from this ambiguity.

Vessel heave motion accuracy is defined by the manufacturer as $2 \mathrm{~cm}$ and time accuracy as 0.001 s. Neither produced a meaningful source of uncertainty in final calculations.

Rise velocity is dependent on the presence of surfactants on the bubble surface; a bubble without any surfactants will rise much faster than an equivalently sized dirty bubble (Leifer and Wilson, 2004). Without visual observations it is difficult to verify the presence or absence of surfactants; however, the binned average rise velocity trends suggest bubbles are not entirely clean, as they fall between the clean and dirty modeled curves.

\subsubsection{Acoustic ambiguity}

In addition to the sources of uncertainty in the calculation of bubble size and bubble rise velocity, there will always be ambiguity in the acoustic identification of single bubble scatterers. In the watercolumn, there are many targets that scatter sound and certain targets can appear very similar to single bubbles. Some fish have swim bladders which are filled with gas and can be particularly challenging to differentiate acoustically from gas bubbles.

Barring the effects of an underlying current gas bubbles will have an upward trajectory through the watercolumn. Fish were identified in the Herald Canyon dataset by their downward or 
unmoving position with increasing ping number; this method does not account for fish moving upwards through the watercolumn at similar rates of gas bubbles. Over the short time-scales observed in this dataset gas bubbles are not changing dramatically in size or rise velocity. Variations in rise velocity can also be indicative of a fish target

\subsubsection{Bubble size distribution}

The bubble size distribution (BSD) was estimated from a Rayleigh distribution fitting of the binned data. Rayleigh distribution $(\rho(a))$ is defined by:

$$
\rho(a)=\frac{a}{\beta^{2}} e^{-a^{2} /\left(2 \beta^{2}\right)}
$$

where $a$ is the effective bubble radius and $\beta$ is the Rayleigh parameter. For the calculation of flux $(Q)$ the uncertainty in $\rho(a)$ defined by the uncertainty in fitting of the distribution. Rayleigh distributions are defined by a single parameter, $\beta$ for which a standard error $\left(\sigma_{\beta}\right)$ is defined. Given the standard error in $\beta$, the uncertainty in $\rho(a)$ is defined as:

$$
\sigma_{\rho(a)}=\left|\frac{d \rho(a)}{d \beta}\right| \sigma_{\beta}=\left(-\frac{2 a \beta^{2}-a^{3}}{\beta^{5}} e^{-a^{2} / 2 \beta^{2}}\right) \sigma_{\beta}
$$




\subsection{Transducer sensitivity}

Bubble rise velocity calculation requires a mechanical angle to calculation bubble location in beam ping-to-ping (Figure 37). The mechanical angle of the bubble in the beam $(\varnothing)$ is calculated from the electrical phase angle $(\varphi)$ and the transducer sensitivity with the equation:

$$
\begin{aligned}
& \varphi=\sqrt{\varphi_{\text {along }^{2}+\varphi_{\text {across }^{2}}}} \\
& \theta=\frac{\varphi}{\left(\varphi_{s^{*}} \frac{f_{c}}{f_{\text {nom }}}\right)}
\end{aligned}
$$

The electrical phase is calculated (Eq. 21) from the combination of the along and across track electrical phase angle as calculated from the split-aperture processing. The mechanical angle of the bubbles is calculated (Eq. 22) from the calculated electrical phase angle by taking into account the angle sensitivity $\left(\varphi_{s}\right)$ as published by Simrad, the center frequency of the pulse $\left(f_{c}\right)$ and the starting frequency of the pulse $\left(f_{\text {nom }}\right)$.

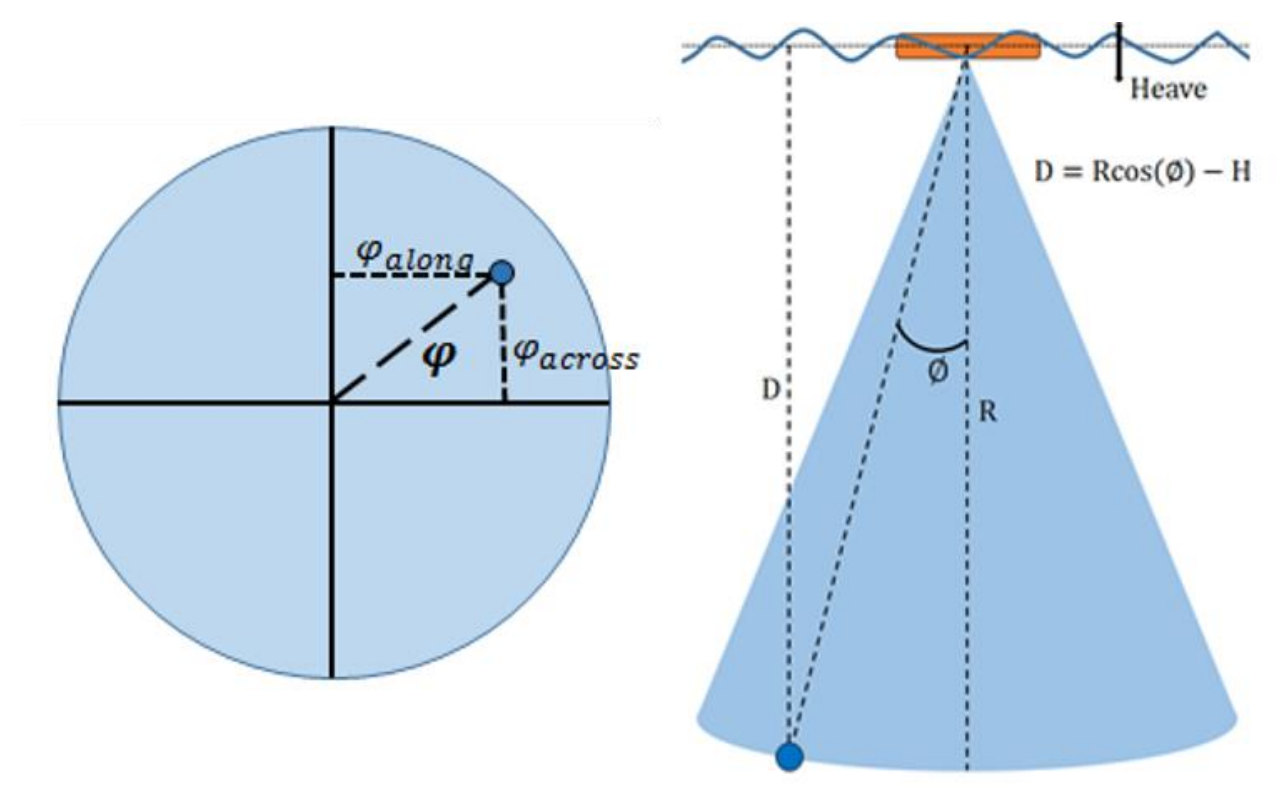

Figure 37. Transducer geometry showing final mechanical angle (top panel) and plane-view transducer geometry for electrical phase angle calculation (bottom panel). 
Given the published value for angle sensitivity and the survey pulse parameters the equation for mechanical angle can be simplified to:

$$
\theta=\frac{\varphi}{17.3750}
$$

The published angle sensitivity value was calculated for the center frequency of the ES18-11 transducer, $18 \mathrm{kHz}$. The survey pulse parameters define a frequency range of 15 to $30 \mathrm{kHz}$ and the final frequency range in all bubble size calculations was reduced to $16-26 \mathrm{kHz}$. Regardless, changes in frequency over the pulse duration results in changes to the effective transducer beam angle (for an array of fixed length, increasing frequency decreases the beam angle) and the transducer sensitivity value becomes increasing unrealistic as the pulse frequency deviates from the published center frequency of $18 \mathrm{kHz}$. The magnitude of the error in the sensitivity value is unknown and the resulting error in the mechanical angle of the bubble has not been quantified or accounted for in final calculations.

This sensitivity analysis aims to investigate the effects of pulse frequency content on calculated electrical phase angle in an effort to determine if the error introduced into the mechanical angle calculation can be ignored or if it is necessary to account for such error in final calculations.

\section{Split-aperture processing overview}




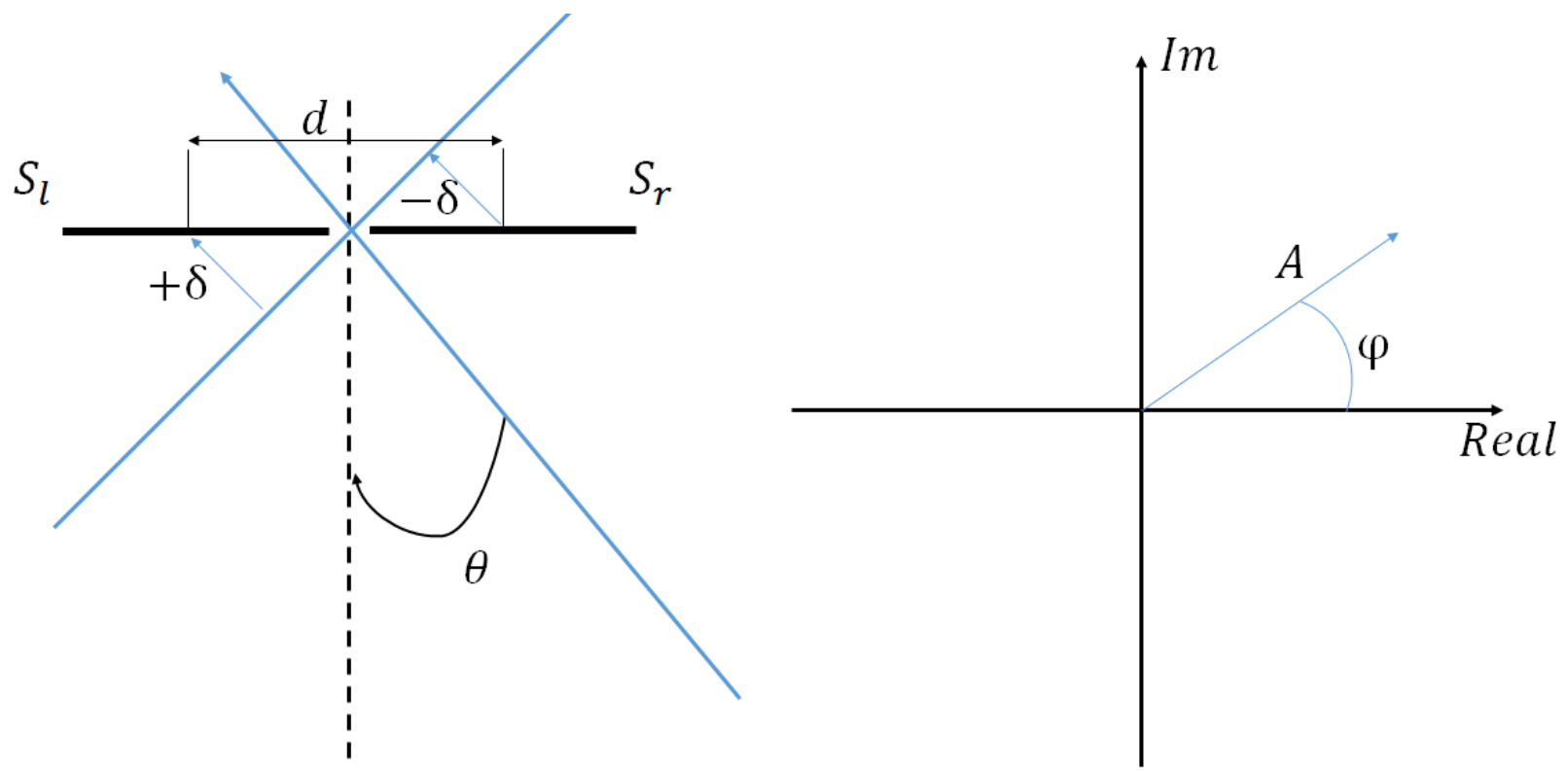

Figure 38. Left image depicts a transducer with split aperture array, with aperture centers separated by distance $d$, a target located in the beam of transducer $\theta$ degrees off center axis, and recorded signals $S_{l}$ and $S_{r}$ separated in space/time by $\delta$, defined below. The right image depicts the complex plane of with amplitude of $A$ and phase angle of $\varphi$.

$$
\begin{gathered}
S_{l}=A e^{-j k(r+\delta)} \\
S_{r}=A e^{-j k(r-\delta)} \\
\delta=\frac{d}{2} \sin (\theta), k=\frac{\omega}{c}=\frac{2 \pi f}{c} \\
S_{r} S_{l}^{*}=A e^{-j k(r-\delta)} A e^{j k(r+\delta)}=A e^{-j k r+j k \delta+j k r+j k \delta}=A e^{2 j k \delta} \\
\frac{i m\left(S_{r} S_{l}{ }^{*}\right)}{r e a l\left(S_{r} S_{l}{ }^{*}\right)}=\frac{\sin (2 k \delta)}{\cos (2 k \delta)}=\tan (2 k \delta)=\tan (\varphi) \\
\tan \left(2 k \frac{d}{2} \sin (\theta)\right)=\tan \left(2 \frac{2 \pi f}{c} \frac{d}{2} \sin (\theta)\right) \\
\tan (\varphi)=\tan \left(\frac{2 \pi f d}{c} \sin (\theta)\right)
\end{gathered}
$$

small angle approximation: $\sin (x) \cong x, \tan (x) \cong x$

$$
\varphi=\frac{2 \pi f d}{c}(\theta)
$$




$$
\theta=\frac{c}{2 \pi f d}(\varphi)
$$

The result of the derivation is an expression relating the electrical phase angle $(\varphi)$ to the mechanical angle $(\theta)$ of a single target off the MRA of the transducer. The mechanical angle can be determined with the electrical phase angle, signal frequencies, and transducer parameters. Furthermore, the frequency dependence of electrical phase angle should be linear (11 and 12).

\section{Analysis of original methodology}

The electrical phase angle of an individual bubble (Figure 39) was calculated from the match filtered broadband data using the methodology applied in the original SWERUS data processing.

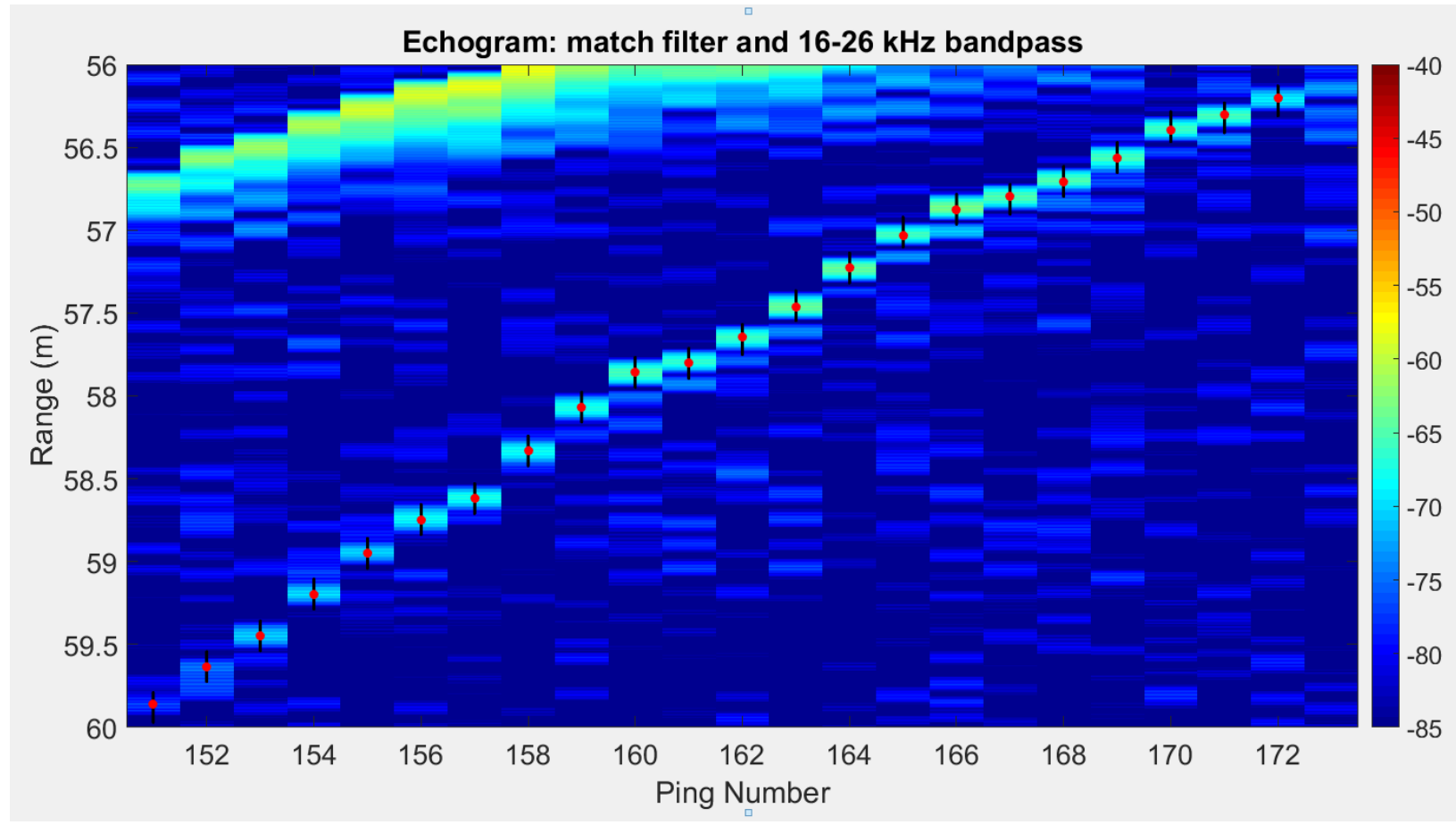

Figure 39. Acoustic response of an individual bubble in an EK80 WBT echogram. An acoustic time series was sampled in each ping over range indicated by the black lines and the electrical phase angle was sampled from the point of maximum amplitude (red marker).

For each record of an individual bubble (series of pings) the electrical phase angle was calculated at the point of maximum acoustic intensity in the bubble's acoustic response, which represents the point of maximum correlation in the match filtering process. The point maximum acoustic 
intensity was identified from the sampled acoustic time series. The electrical phase angle, given by (Eq. 21), was estimated from:

$$
\begin{gathered}
\varphi_{\text {along }}=\tan ^{-1} \frac{\operatorname{im}\left(S_{f} S_{a}{ }^{*}\right)}{\operatorname{real}\left(S_{f} S_{a}{ }^{*}\right)} \\
\varphi_{\text {across }}=\tan ^{-1} \frac{\operatorname{im}\left(S_{s} S_{p}{ }^{*}\right)}{\operatorname{real}\left(S_{s} S_{p}{ }^{*}\right)}
\end{gathered}
$$

Where $S_{f}$ the summation of the acoustic is signal from quadrants 3 and $4 ; S_{a}$ is the summation of the acoustic signal from quadrants 1 and $2 ; S_{S}$ is the summation of the acoustic signal from quadrants 1 and $4 ; S_{p}$ is the summation of the acoustic signal from quadrants 2 and 3.

The estimated electrical phase angle varies between $20^{\circ}$ and $90^{\circ}$ (Figure 41 ). At $90^{\circ}$ the data is cut due to electrical phase angle limitations in the calibration offset values (used for bubble size estimation). The electrical phase angle across the sampled bubble record shows variation on the order of $\pm 10^{\circ}$ (Figure 40 and Figure 41). It is possible that picking the electrical phase angle from a single point (maximum amplitude point) could introduce an error subsequent calculations given the variability in electrical phase angle throughout the bubble record. It is appropriate to use the point of maximum amplitude to define the location of the bubble given the variability of electrical phase angle across the bubble record? The electrical phase angle as determined from the point of maximum amplitude 


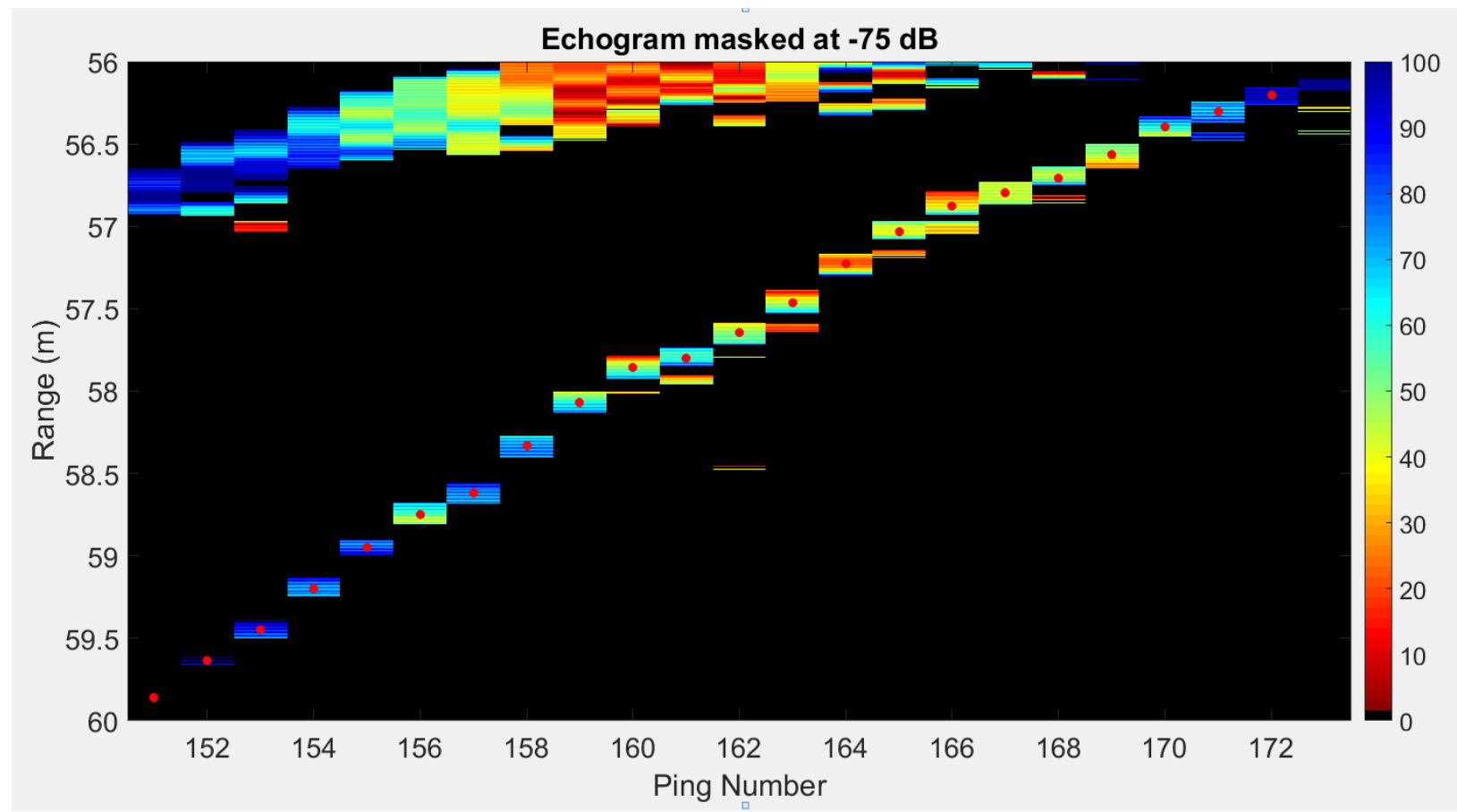

Figure 40. Electrical phase angles of the bubble record calculated from the split aperture processing for an individual bubble record.
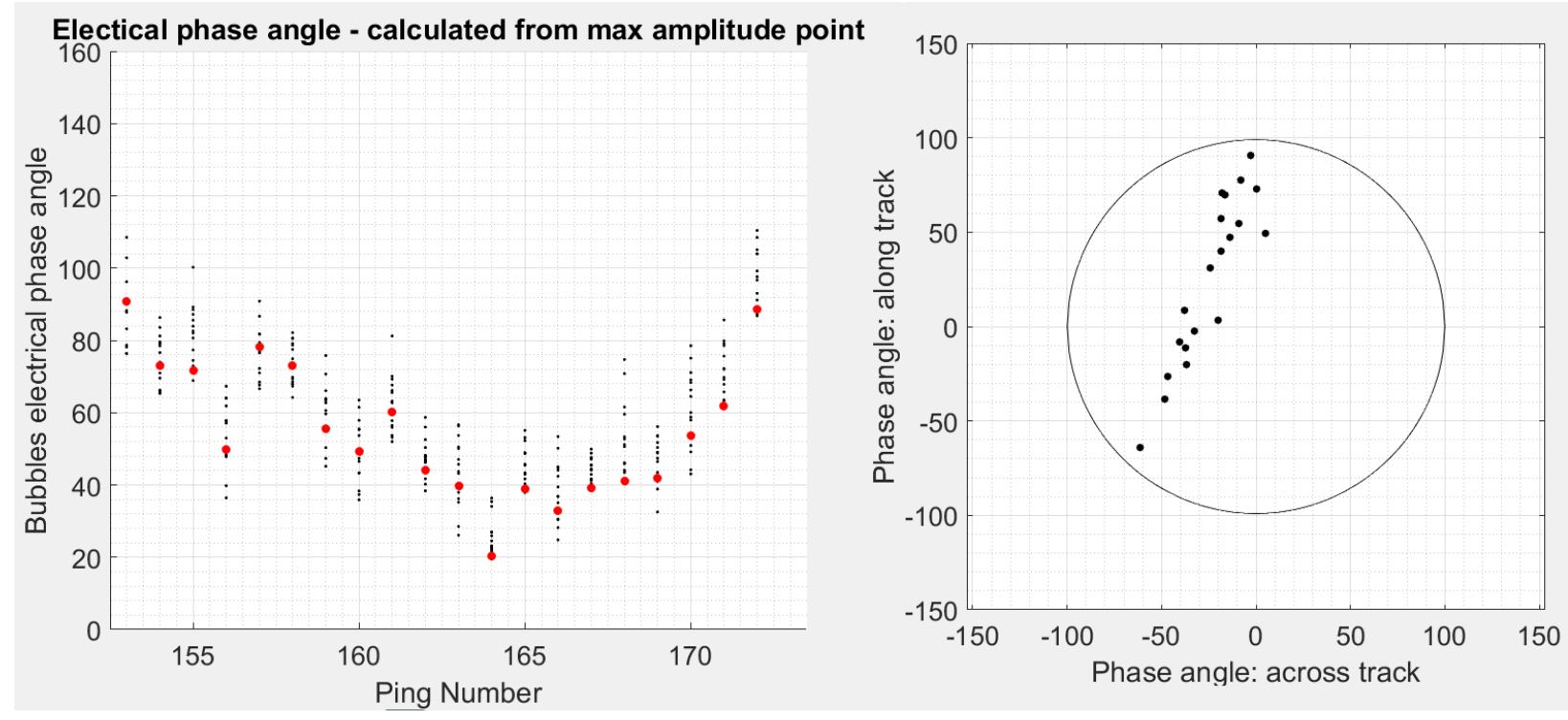

Figure 41. Left panel shows estimated electrical phase angles for the individual bubble (in red), plotted with the electrical phase angles of the rest of the sampled acoustic time series (in black) for each ping. Right panel shows the bubble location (as determined from the maximum amplitude sample) in plane view through the series of pings.

The uncertainty in the estimation of electrical phase angle is given by Burdic (1991) as:

$$
\sigma_{\varphi}^{2}=\frac{E\left[N^{2}\right]}{A^{2}}
$$


where $E\left[N^{2}\right]$ is an estimation of the background noise and $A^{2}$ is the amplitude of the measured signal. Projecting uncertainty in electrical phase angle to uncertainty in mechanical angle is given by:

$$
\sigma_{\theta}^{2}=\frac{\sigma_{\varphi}^{2}}{k d}
$$

where $k d$ is the transducer sensitivity, defined by Simrad as 17.37 and $\sigma_{\varphi}{ }^{2}$ is the uncertainty in the electrical phase angle calculation. Defining electrical phase angle uncertainty by equations 35 and 36 means the lower the SNR, the larger the error in the split-aperture calculation. Low SNR can be a result of a weakly backscattering target and/or increased background noise. The SWERUS methodology defines the minimum SNR to be no less than 10; propagating an SNR of 10 through equations 35 and 36 produces an approximate estimated uncertainty of $0.8^{\circ}$.

The final calculation of bubble rise velocity is made via regression through a series of paired time and depth measurements (Figure 42). The estimation of a bubble's mechanical angle is incorporated into the depth measure via the following equation:

$$
\text { depth }=\text { range } * \cos (\theta)+\text { heave }
$$

Once uncertainity in the mechanical angle is projected through the equation for depth (taking into account cosine of the mechanical angle), the mechanical angle uncertainty is an order of magnitude 
lower than the overall measurement uncertainty (variation ping to ping away from regression line) and is disregarded from the overall rise velocity uncertainty measurment.

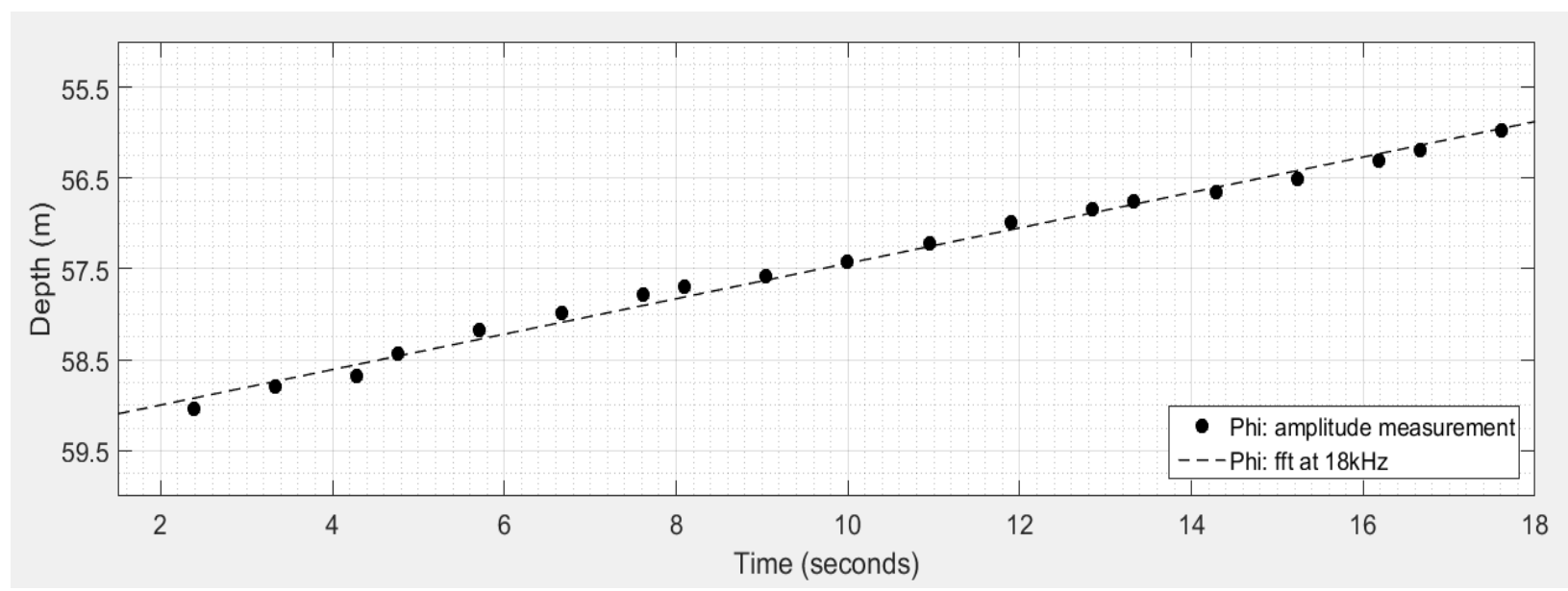

Figure 42. An example of the rise velocity derivation from the paired time and depth values for a bubble record. Average rise velocity is estimated from the slope of the regression and measurement uncertainty is calculated from the deviation of the measurement values from the regression.

Frequency dependence of electrical phase angle

The electrical phase angle of an object ensonified by a broadband signal should show a frequency dependence defined by the physical parameters of the transducer and the frequency range of the signal. This dependence is defined as:

$$
\frac{d \theta}{d f}=\frac{2 \pi f d}{c}
$$

Where $f$ is the frequency range of the signal, $d$ is the distance between the centers of the individual apertures, and $c$ is the speed of sound. If this dependence holds for the SWERUS data set the electrical phase angle should change linearly with increasing frequency.

In order to explore this relationship, the electrical phase angles (along and across track) were calculated using equations 33 and 34. Unlike the SWERUS methodology where $S_{r}$ and $S_{l}$ are defined by a single peak amplitude value of each bubble record, $S_{r}$ and $S_{l}$ were defined by the entire bubble record as a frequency series. The acoustic time series of the bubble record (vertical black 
line - Figure 39) was extracted for all four transducer quadrants and the aperture pairs were calculated by summing the appropriate quadrants:
a. Along track $-y f$ (Fore): quadrants 3 and 4
b. Along track $-y a(\mathrm{Aft})$ : quadrants 1 and 2
c. Across track $-y s$ (Starboard): quadrants 1 and 4
d. Across track $-y p$ (Port): quadrants 2 and 3

The Fourier transform of each time series were taken and the electrical phase angles were calculated from the frequency series:

$$
\begin{aligned}
& Y F=f f t(y f, 375) ; \\
& Y A=f f t(y a, 375) ; \\
& p h i_{\text {Along }}=\tan ^{-1}\left(Y F \times Y A^{*}\right)
\end{aligned}
$$

The resulting vector defines the electrical phase angle as a function of frequency for each record of the bubble as it rises through the watercolumn and moves through the beam of the transducer. The electrical phase angle data only has meaning within the frequency band of the signal (approximately 16-26 kHz), outside of this range there is just noise. Figure 43 shows the frequency dependence of the electrical phase angle for every bubble record (ping) for this individual bubble. There appears to be variation in the frequency dependence on a ping-to-ping basis. Some records (e.g. ping 3 and 10) show a constant linear frequency dependence for both the across and along track electrical phase angles. Other records (e.g. ping 8 and 12) show constant linear frequency dependence in either the along or across track electrical phase angles, but not both. There are also records (e.g. 9 and 14) where there does not appear to be any linear frequency dependence in either the along or across track electrical phase angles. 

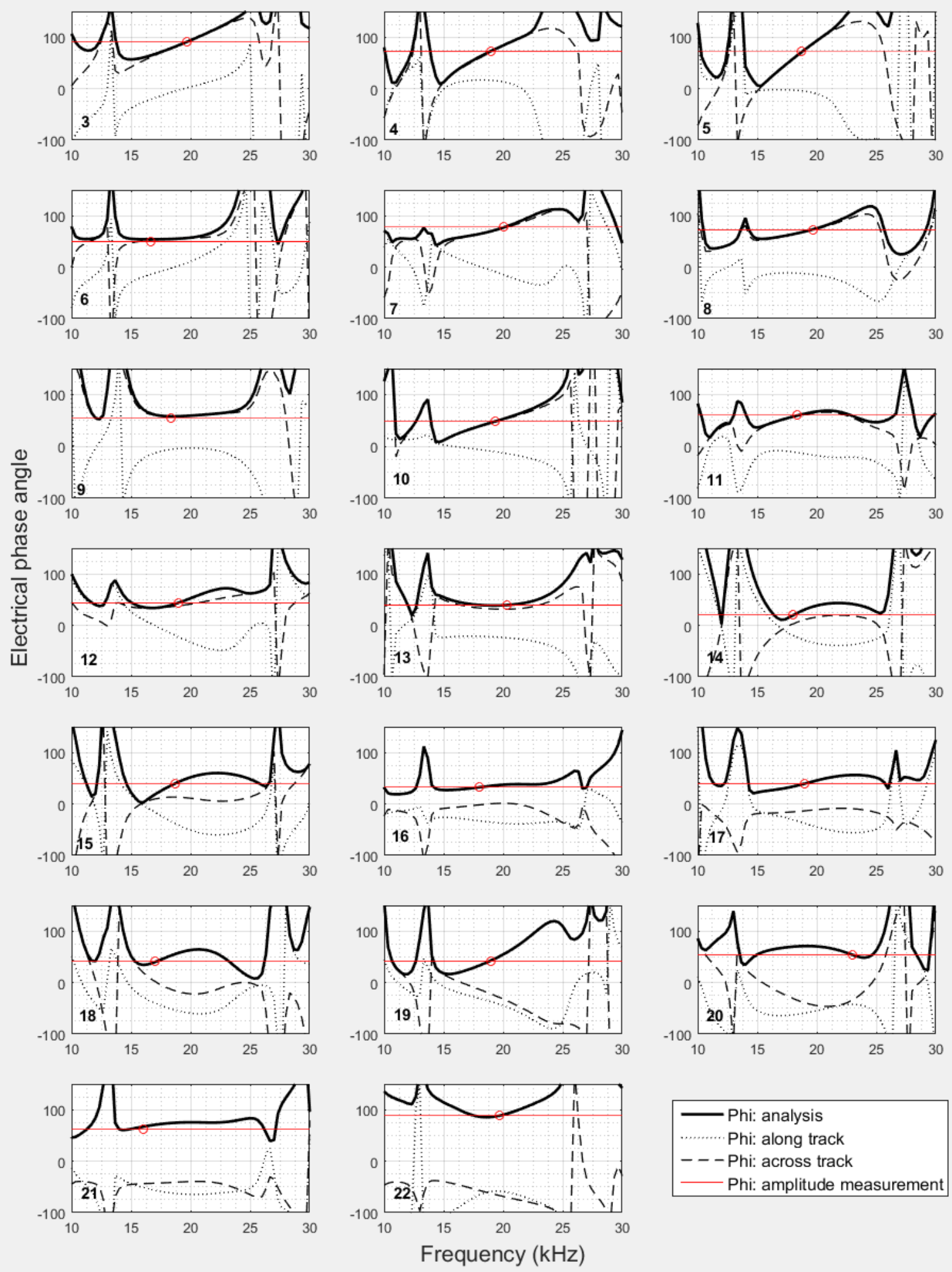

Figure 43. Frequency dependence of bubble electrical phase angle for each ping record. Along track angle is plotted by a dotted line, across track angle is plotted by a dashed ling, analysis angle is plotted by a solid line, and the measurement of electrical phase angle from the single amplitude measurement is plotted by a horizontal red line (no frequency dependence). The location where the amplitude measurement of phase angle crosses the frequency dependent phase angle is marked by a red circle. 
The expected slope of the linear frequency dependence of the electrical phase angle is defined by (Eq. 38). The ES18-11 transducer has approximately $25 \mathrm{~cm}$ separation of the apertures $(d)$. Assuming the speed of sound $(c)$ is $1495 \mathrm{~m} / \mathrm{s}$ and plugging in $d$ to equation 38 , the measured electrical phase angle can be compared to the theoretical frequency dependence (Figure 44 and Figure 45).

In the majority of cases (55\%) there is strong agreement between the theoretical model for frequency dependence and the combined along and across track electrical phase angles (referred to as the "analysis" electrical phase angle). When considering both the along and across track angles, $80 \%$ of the records showed agreement between the theoretical model for frequency dependence in at least one of the electrical phase angle measurements. When observing the combination of the along and across track electrical phase angles in plane-view (Figure 46) there does not appear to be a distinct spatial pattern to agreement between measurements and models. Overall there is a larger range of along track angles $\left(-60^{\circ}\right.$ to $\left.75^{\circ}\right)$ then across track angles $\left(-65^{\circ}\right.$ to $10^{\circ}$ ), but the positions of the non-matching records are not clusters in any quadrant. Additionally, the records where there is strong agreement for both along and across track appear across a range 
of angle values, from "near" to the MRA out to the "edges" of the beam (these measurements are technically measurements of difference in phase, not differences in position).

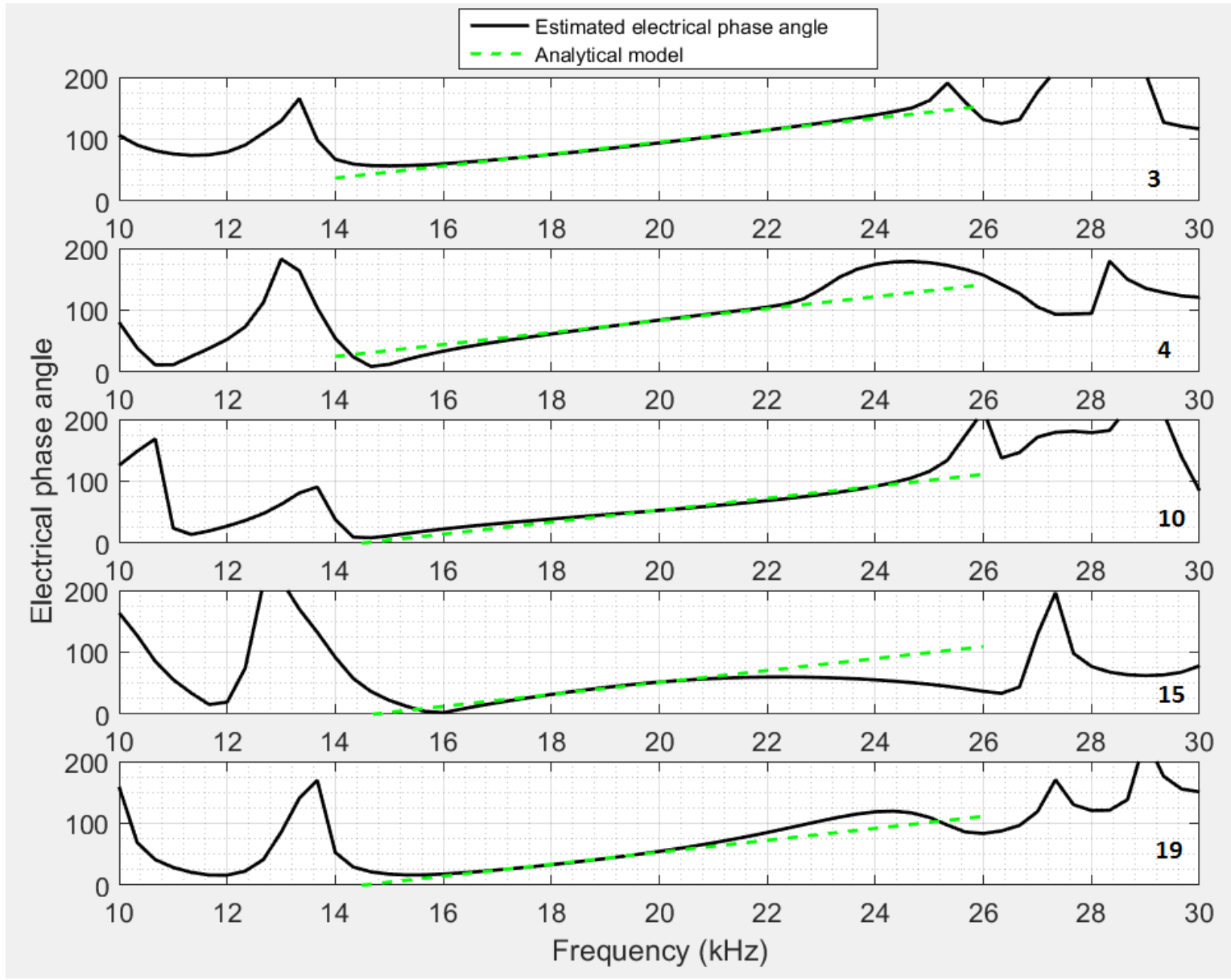

Figure 44. Examples of acoustic records where the measured frequency dependence of electrical phase angle matches to theoretical model for sensitivity well (ping number in lower right corner). 


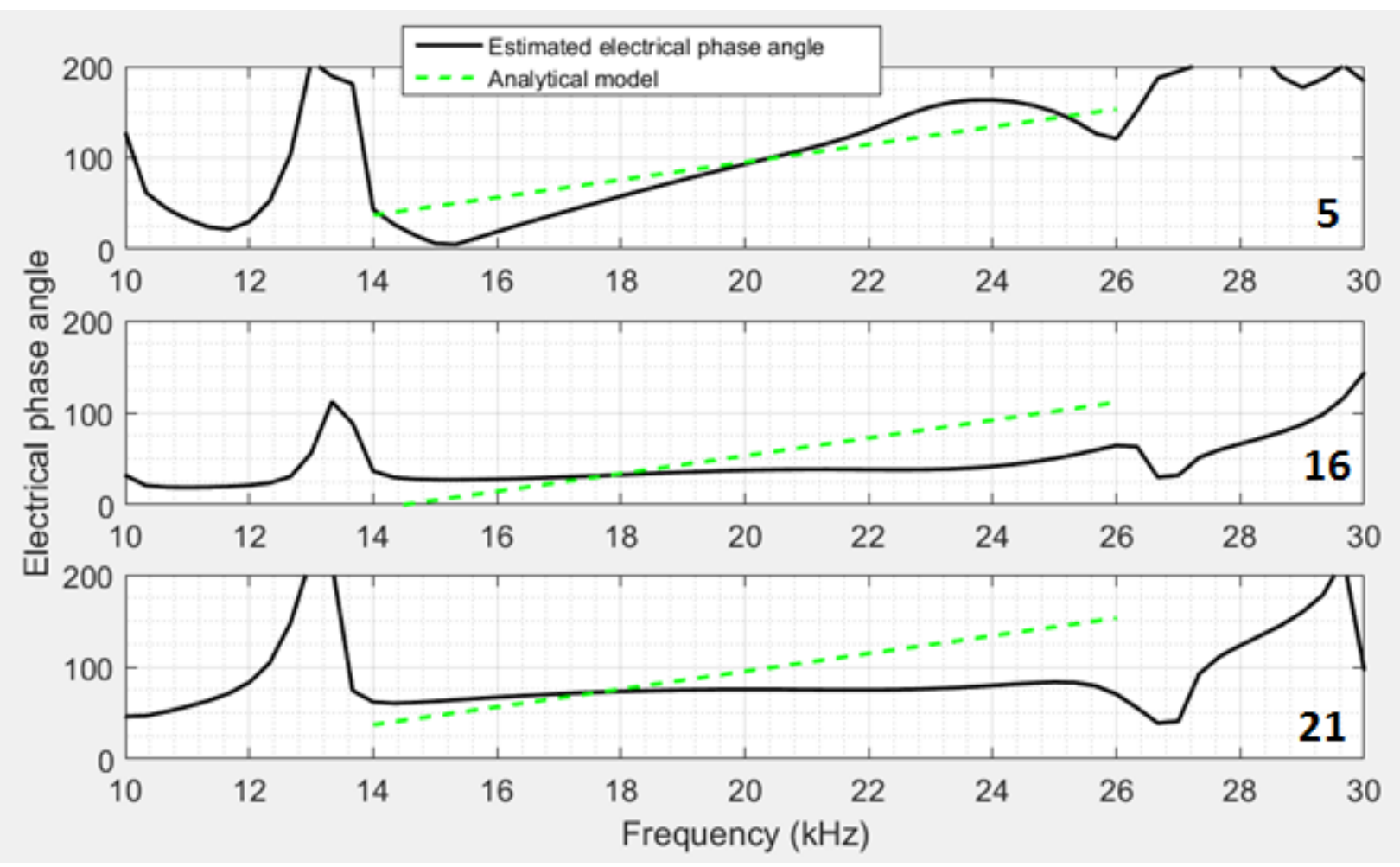

Figure 45. Examples of acoustic records where the measured frequency dependence of electrical phase angle does not match the theoretical model for sensitivity (ping number in lower right corner).

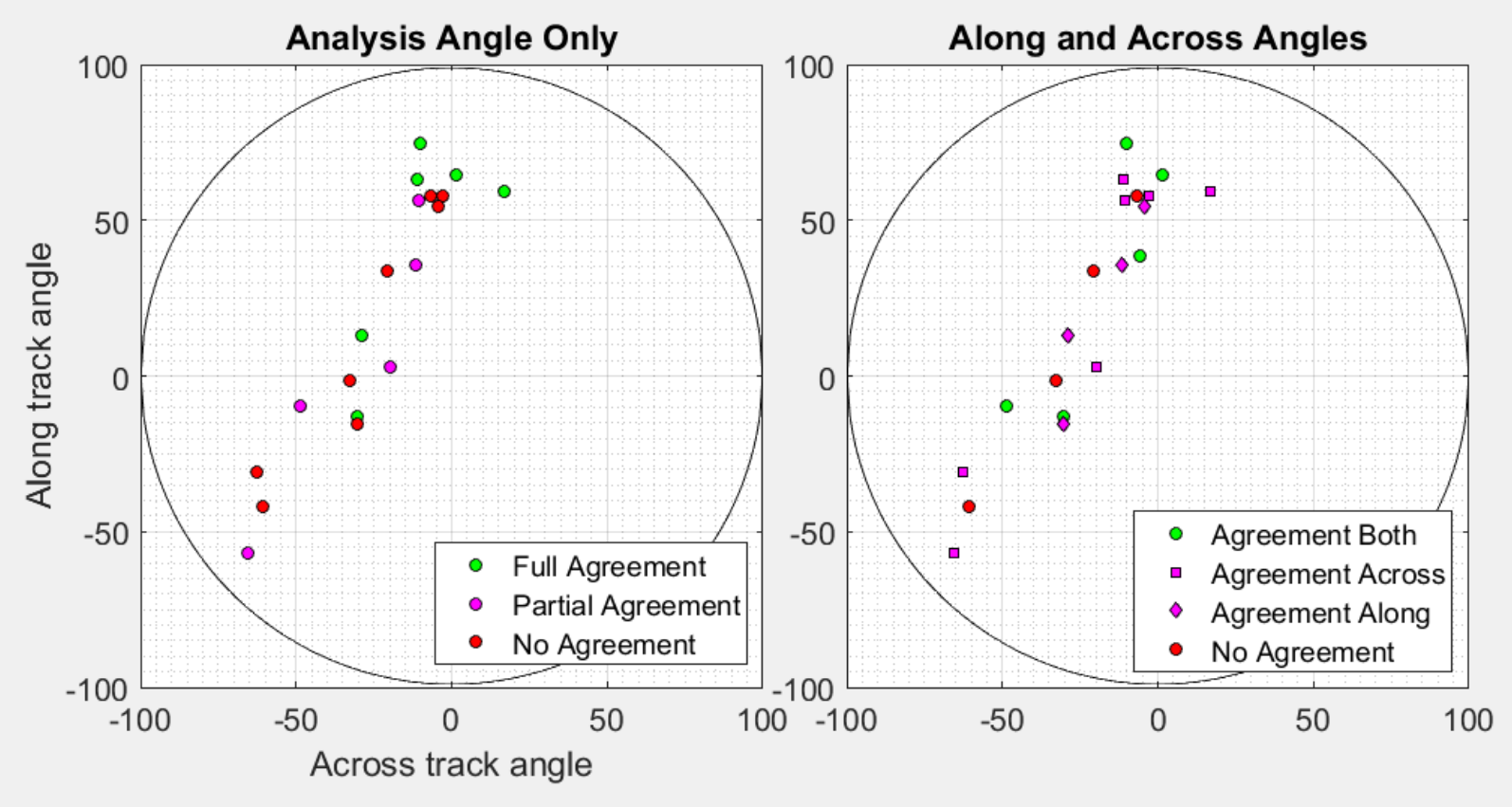

Figure 46. Spatial relationship between $18 \mathrm{kHz}$ bubble phase angles and theoretical model trends. Left figure indicates the level of agreement only considering the final analysis angle (combination of across and along track angles), while the right figure considers the agreement of along and across track angle agreement with the model. Full agreement (left panel) indicates the measured frequency dependency matched the model across the whole frequency range ( 16-26 kHz), partial agreement (both left and right panel) indicates at there was agreement between measurements and model for a portion of the frequency range, and no agreement indicates there was little to no agreement between measurements and model in any part of the frequency range. 


\section{$\underline{\text { Sensitivity test conclusions }}$}

The overarching goal of this analysis has been to investigate the effects of frequency on electrical phase angle and determine if the error (if any) introduced into the mechanical angle calculation can be ignored or if it is necessary to account for such error in final calculations. In has been shown that the change in frequency of the EK80 signal does affect the electrical phase angle; however, the frequency dependence of the electrical phase angle is, at best, linear and, at worst, not existent. There is variability ping-to-ping in the agreement between the theoretical frequency dependence of the electrical phase angle (given by equation 38) and the measured values for electrical phase angle. No clear pattern was determined to explain the variability in agreement with the theoretical model.

We can conclude that we could estimate the electrical phase angle as a function of frequency for some records (where is there good agreement between model and measurements); however, this method would not be acceptable for all bubble records. More investigation must be done into the underlying reasons for measurement deviation from the theoretical acoustic model.

Instead, perhaps we can estimate a new transducer sensitivity value to apply to the SWERUS data to account for the effect of frequency on the electrical phase angle or we could take the electrical phase angle at a frequency of $18 \mathrm{kHz}$ to correctly apply the published transducer sensitivity value. The electrical phase angle at $18 \mathrm{kHz}$ can be directly pulled from the calculated frequency series, the new transducer sensitivity value needs to be estimated using a weighted mean frequency. The weighted mean frequency can be estimated by finding the average intersection point of the original amplitude-based electrical phase angle measurements verses the frequency dependent electrical 
phase angle values (Figure 49, panel 1). The resulting frequency is approximately $18.8 \mathrm{kHz}$ and the new transducer sensitivity value becomes 18.2 .

Comparing all three electrical phase angles (Figure 49, panel 2 and 3), there is overall general agreement in the trend of electrical phase angles from ping-to-ping. When a mechanical angle is estimated from the three electrical phase angles options and rise velocity is calculated (Figure 50), we can see that there is very little difference in the final average rise velocity. Maximum difference between the original SWERUS estimation and the $18 \mathrm{kHz}$-based estimation is $0.4 \mathrm{~cm} / \mathrm{s}$. This value is an order of magnitude lower than the overall uncertainty in rise velocity from the measurement variation, $1.6 \mathrm{~cm} / \mathrm{s}$ and we can conclude that while the EK80 signal's frequency range does have a measurable effect on the electrical phase angle, the overall error introduced into the final rise velocity measurement is small enough to be overlooked in the final calculation. Further tests should be done to investigate the deviation of the measurement from the theoretical model.
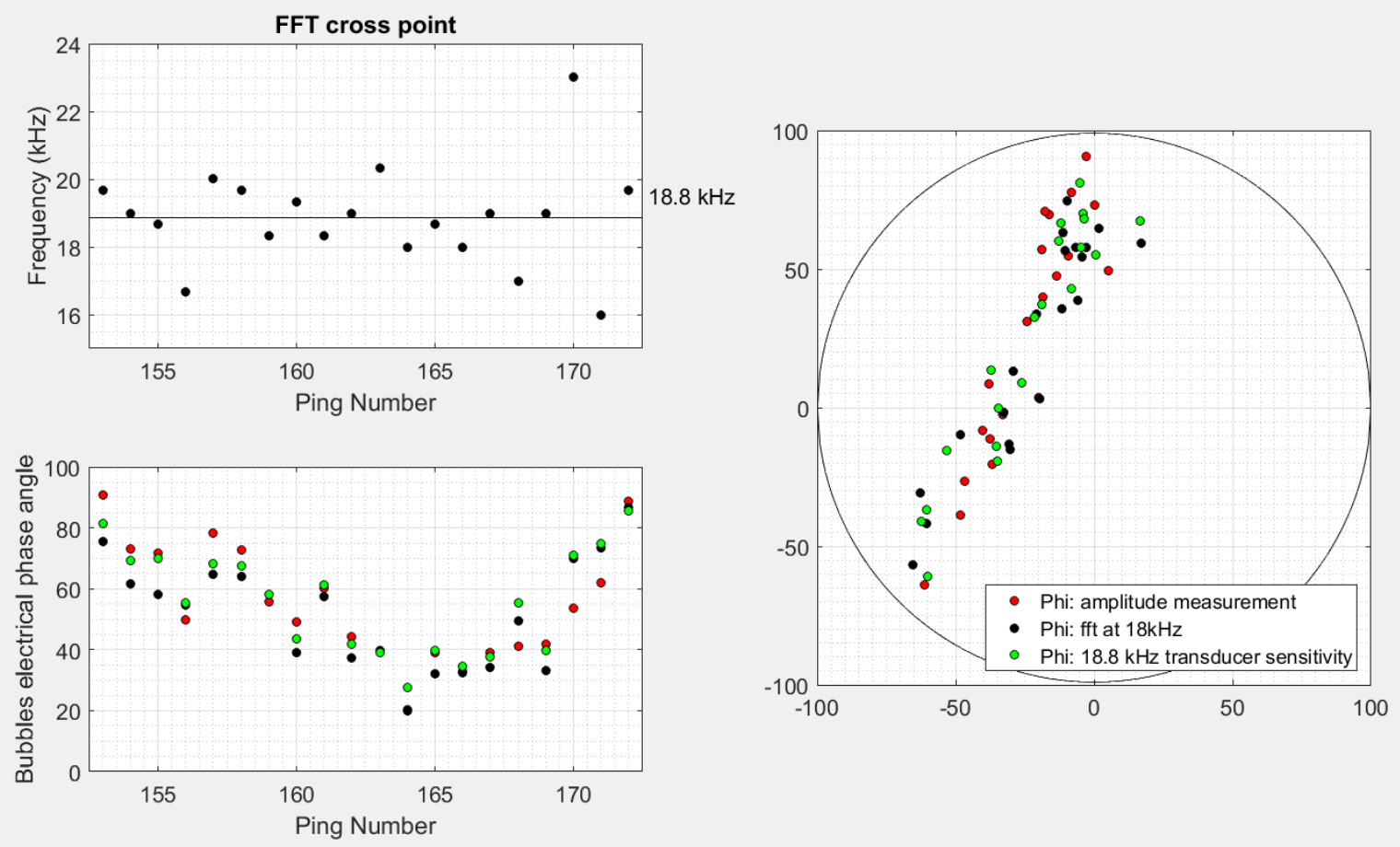

Figure 47. Top left panel shows the frequency where the original electrical phase angle (measured from the max amplitude value) crosses the frequency dependent electrical phase angle measured from the full bubble record. The average frequency crossing 
point is $18.8 \mathrm{kHz}$. The bottom left panel shows three different electrical phase angles calculated via different methodologies: red markers indicate the original electrical phase angle, black are the electrical phase angles at $18 \mathrm{kHz}$, and green are the electrical phase angles at $18.8 \mathrm{kHz}$ (average cross point from first panel). The right panel show the plane view of the electrical phase angles calculated from the three different methods.

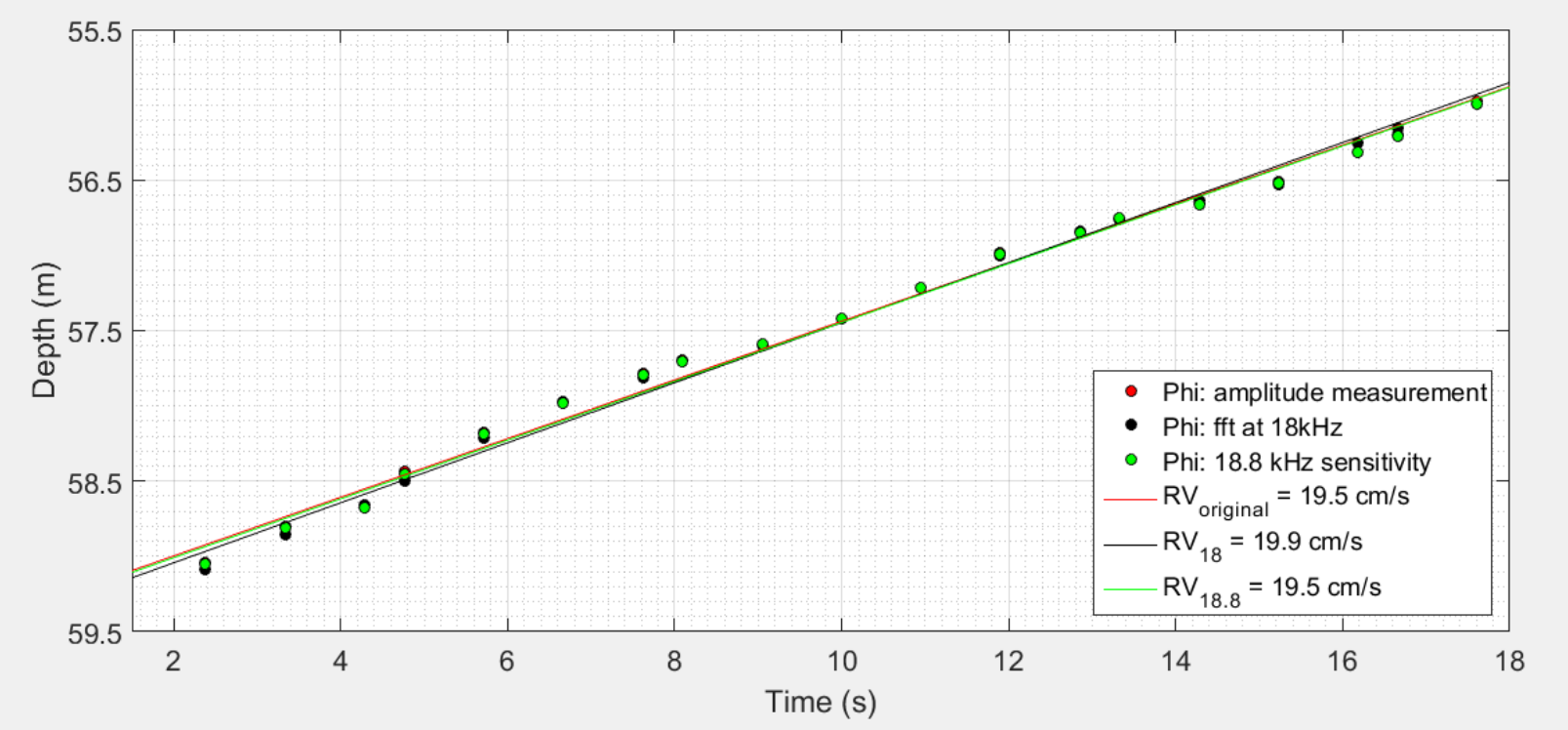

Figure 48. Time and depth data pairs for each ping calculated from the three electrical phase angle options (same as figure 11). Rise velocity is estimated from the slope of the regression through the time and depth pairs. 


\subsection{Acoustic scattering model sensitivity test}

\section{Overview}

This document outlines an investigation into the sensitivity of acoustic scattering of a single bubble to the gas composition of in the bubble, as modeled by the equations defined in Ainslie and Leighton (2009).

Given the geophysical context and published literature bubble ebullating from the seafloor in the Herald Canyon region of the ESAS are likely nearly $100 \%$ methane, originating from a biogenic source. An initial bubble composition of $100 \%$ methane is an assumption made in this research project. During bubble ascent through the water column there is gas transfer between the bubble and the surrounding water. Methane flows out of the bubble and oxygen, nitrogen, and other minor gasses flow into the bubble. The rate of gas transfer is a function of aqueous gas concentrations, temperature, salinity, and pressure. The process of gas transfer results in changing composition of bubbles throughout the water column.

In the calculation of a bubble's equivalent radius the measured frequency modulated target strength is compared to modeled target strength values of bubbles of different sizes; however, the modeled values are calculated with a bubble composition of $100 \%$ methane gas, not a mixture of gas. It is feasible that error could be introduced into the bubble radius values if the modeled for acoustic scattering is sensitive to gas composition.

\section{$\underline{\text { Testing procedure }}$}

To test the sensitivity of acoustic scattering of a bubble to the gas composition of that bubble the acoustic scattering model was altered to take in a variety of bubble gas compositions (mole fraction 
of nitrogen, oxygen, carbon dioxide, and methane). In addition the code takes in environmental parameters (temperature, salinity, and depth), frequency range, and bubble radius.

Several thermodynamic values must be defined for each gas (specific heat at constant volume/pressure, molar mass) and combined depending on the mixture of gases in the modeled bubble. Based on calculated bubble parameters bubble mass, density, thermal conductivity, and ratio of specific heats are calculated. All the information is fed into the single bubble scattering equations to calculate target strength.

Environmental parameters matching the Arctic Ocean and Herald Canyon area were chosen:

- Temperature $=6 \mathrm{C}$

- $\quad$ Salinity $=30 \mathrm{PSU}$

- $\quad$ Depth $=95$ m (maximum SWERUS seep depth)

- $\quad$ Bubble radius = 1-5 mm (typical SWERUS bubble radii)

With these parameters set the model was run for three scenarios:

1) A $100 \%$ methane bubble

2) A bubble with a gas mixture of $25 \%$ oxygen, $25 \%$ nitrogen, $25 \%$ carbon dioxide, and $25 \%$ methane

3) A bubble with gas mixture of $20 \%$ oxygen, $70 \%$ nitrogen, $5 \%$ carbon dioxide 


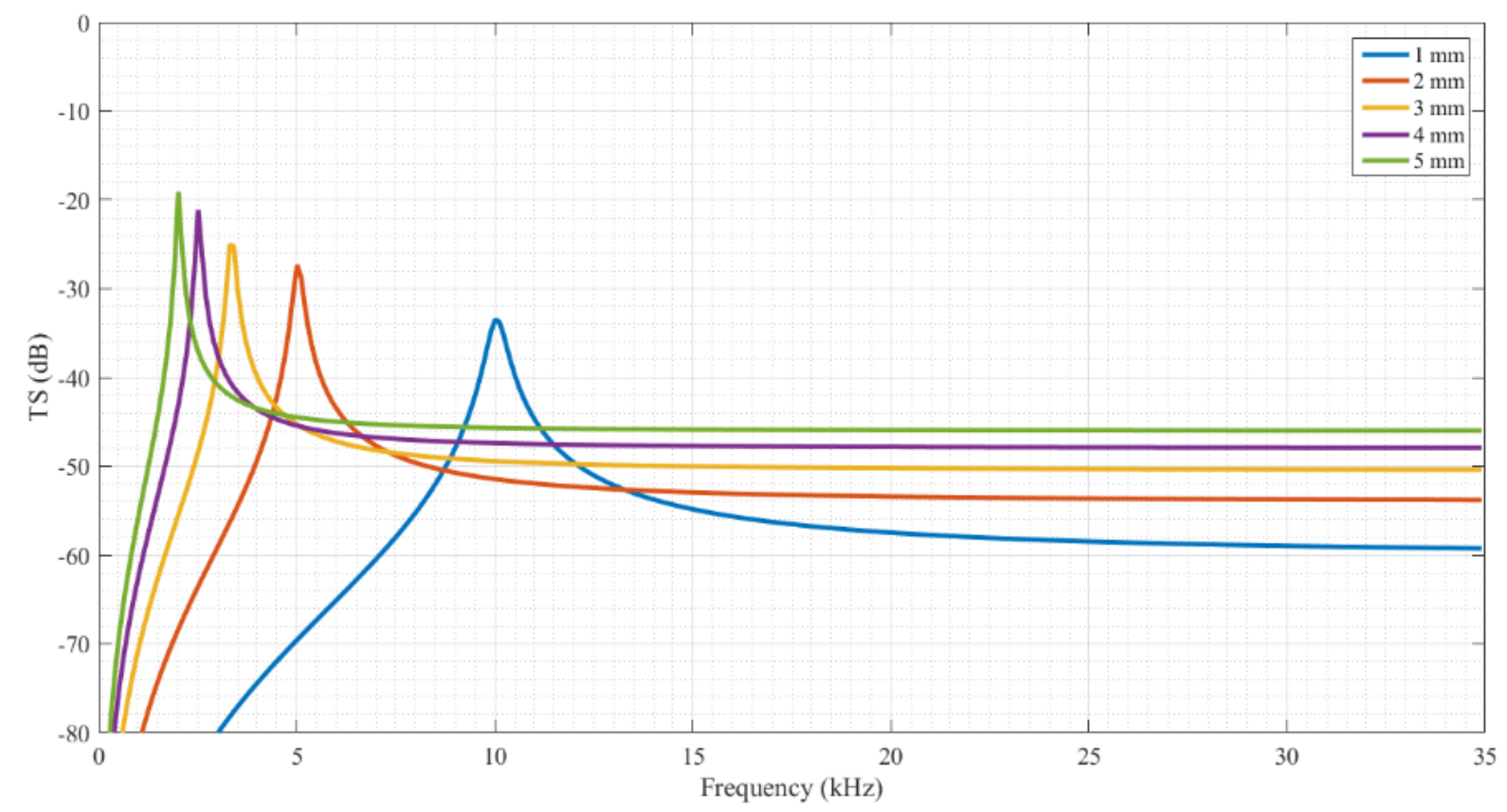

Figure 49. Modeled target strength for $100 \%$ methane bubble with parameters: $z=95 \mathrm{~m}, T=6 C, S=30 P S U$.

\section{$\underline{\text { Sensitivity testing results }}$}

Results of the sensitivity test show very minimal changes in TS curves in bubbles of different gas composition (Figure 52). There appears to be a small frequency dependence to composition sensitivity: TS responses at lower frequencies have larger differences then those at higher frequencies. Smaller bubbles appear to be more sensitive to changes in gas composition than larger bubbles; this is especially clear near resonance where the largest differences in TS are seen. In the target frequency range for this experiment, of approximately $15-30 \mathrm{kHz}$, there is no discernable difference in TS curves for bubbles of different compositions (Figure 53).

The results of this sensitivity test show that the model for single bubble scattering of sound is not sensitive to the composition of bubble gas at the given temperature, pressure, and salinity conditions of the SWERUS seeps. 


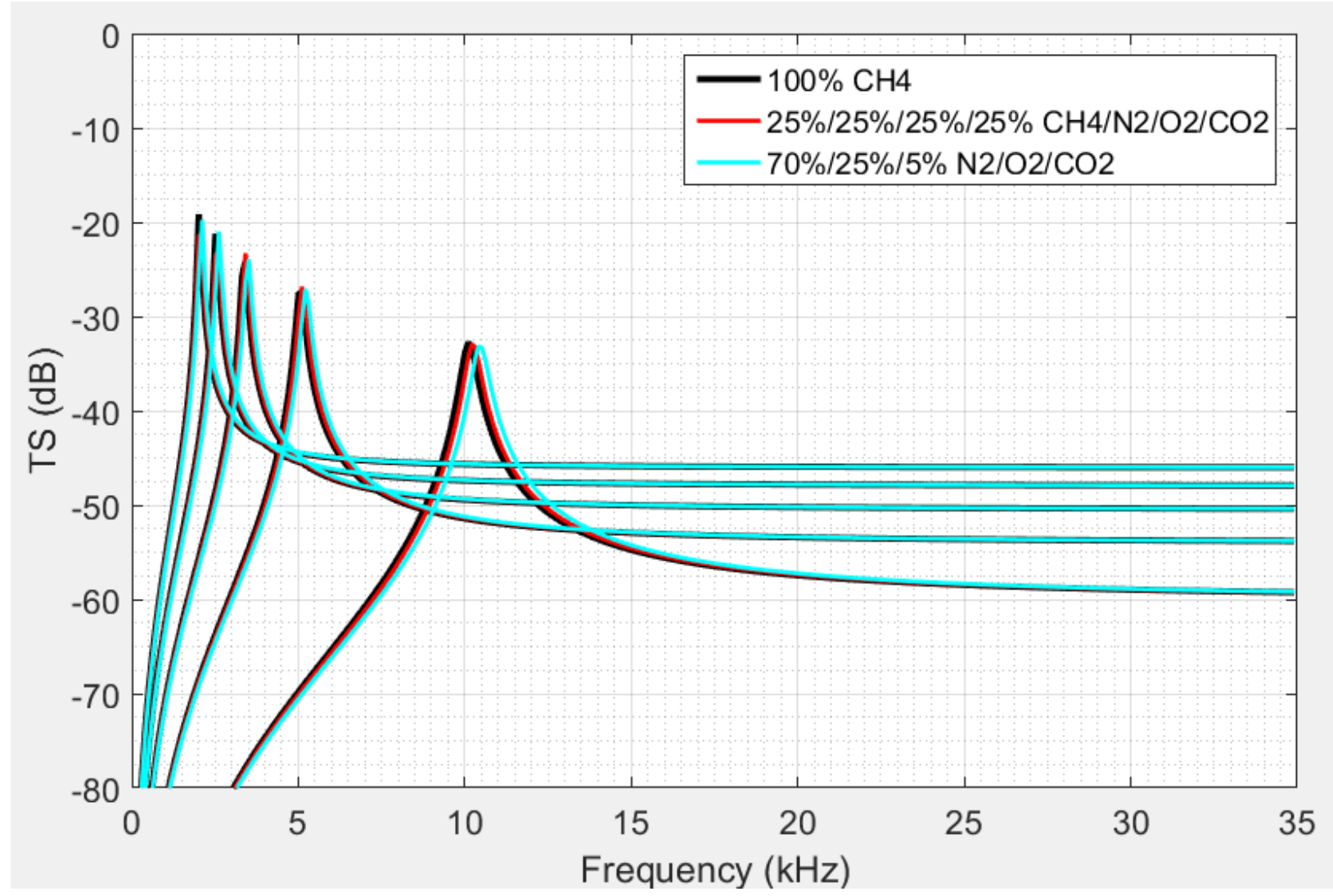

Figure 50. Comparison of modeled target strength of 1-5mm bubbles composed of $100 \%$ methane and two different gas combinations
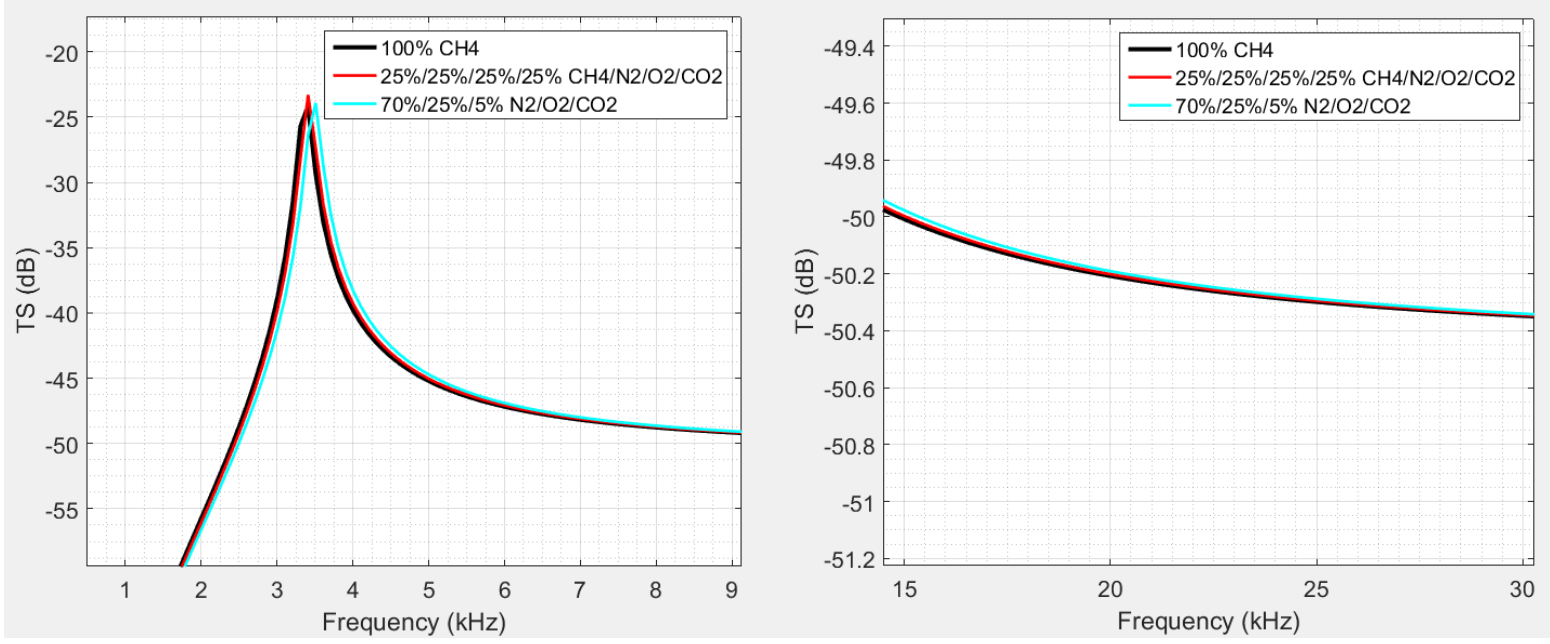

Figure 51. Zoomed view of a $3 \mathrm{~mm}$ bubble target strength value at resonance peak (left) and research target frequency range (right). 
Table 3. Constant parameters calculated in gas mixture function

\begin{tabular}{|c|c|}
\hline \multicolumn{2}{|c|}{ Constants $(\mathrm{z}=95 \mathrm{~m}, \mathrm{~T}=6 \mathrm{C}, \mathrm{S}=30 \mathrm{PSU}, \mathrm{f}=20 \mathrm{kHz}, \mathrm{a}=0.003 \mathrm{~m})$} \\
\hline Bubble surface tension (tau) & 0.075 \\
\hline Density of seawater (rhow) & $1.0242 \mathrm{e} 03$ \\
\hline Ambient pressure $(\mathrm{Pa})$ & $1.0558 \mathrm{e} 06$ \\
\hline Sound speed (c) & $1.4700 \mathrm{e} 03$ \\
\hline \multicolumn{2}{|l|}{ Specific heat (constant pressure) } \\
\hline \begin{tabular}{l|l} 
& Oxygen $\left(\mathrm{Cp} \_\mathrm{O} 2\right)$
\end{tabular} & 0.919 \\
\hline Nitrogen (Cp_N2) & 1.040 \\
\hline Carbon dioxide (Cp_CO2) & 0.844 \\
\hline Methane (Cp_CH4) & 2.220 \\
\hline \multicolumn{2}{|l|}{ Specific heat (constant volume) } \\
\hline \begin{tabular}{|l|l} 
& Oxygen $\left(\mathrm{Cp} \_\mathrm{O} 2\right)$ \\
\end{tabular} & 0.659 \\
\hline Nitrogen $\left(\mathrm{Cp} \_\mathrm{N} 2\right)$ & 0.743 \\
\hline Carbon dioxide (Cp_CO2) & 0.655 \\
\hline Methane (Cp_CH4) & 1.700 \\
\hline \multicolumn{2}{|l|}{ Molar mass } \\
\hline Oxygen $\left(\mathrm{Cp} \_\mathrm{O} 2\right)$ & 0.03199880 \\
\hline Nitrogen (Cp_N2) & 0.02801340 \\
\hline Carbon dioxide (Cp_CO2) & 0.04400954 \\
\hline \begin{tabular}{|l|l|} 
& Methane (Cp_CH4) \\
\end{tabular} & 0.01604246 \\
\hline Volume bubble $(\mathrm{a}=0.003 \mathrm{~m})$ & $1.1310 \mathrm{e}-07$ \\
\hline $\mathrm{Mu}$ & 0.0016 \\
\hline
\end{tabular}

Table 4. Bubble parameters calculated in gas mixture function.

\begin{tabular}{|l|l|l|l|}
\hline \multicolumn{3}{|c|}{ Calculated Bubble Parameters $(\mathrm{z}=95 \mathrm{~m}, \mathrm{~T}=6 \mathrm{C}, \mathrm{S}=30 \mathrm{PSU}, \mathrm{f}=20 \mathrm{kHz}, \mathrm{a}=0.003 \mathrm{~m})$} \\
\hline & \multicolumn{1}{|c|}{$100 \% \mathrm{CH}_{4}$} & $\begin{array}{l}25 \% / 25 \% / 25 \% / 25 \% \\
\mathrm{CH}_{4} / \mathrm{CO}_{2} / \mathrm{N}_{2} / \mathrm{O}_{2}\end{array}$ & $\begin{array}{c}5 \% / 70 \% / 25 \% \\
\mathrm{CO}_{2} / \mathrm{N}_{2} / \mathrm{O}_{2}\end{array}$ \\
\hline Bubble Mass (Mbub) & 1.6042 & 3.0016 & 2.9810 \\
\hline $\begin{array}{l}\text { Specific heat constant } \\
\text { pressure (Cp) }\end{array}$ & 2.2200 & 1.2558 & 1.0000 \\
\hline $\begin{array}{l}\text { Specific heat constant } \\
\text { volume (Cv) }\end{array}$ & 1.7000 & 0.9393 & 0.7176 \\
\hline $\begin{array}{l}\text { Thermal conductivity } \\
\text { (Kg) }\end{array}$ & 0.0309 & 0.0238 & 0.0239 \\
\hline $\begin{array}{l}\text { Ratio of specific } \\
\text { heats (gamma) }\end{array}$ & 1.3059 & 1.3370 & 1.3935 \\
\hline Density of gas (rhog) & $1.4185 \mathrm{e} 07$ & $2.6540 \mathrm{e} 07$ & $2.6357 \mathrm{e} 07$ \\
\hline Intensity (sigmaBS) & $9.5336 \mathrm{e}-06$ & $9.5468 \mathrm{e}-06$ & $95710 \mathrm{e}-06$ \\
\hline
\end{tabular}




\subsection{Distribution fitting}

To define a general bubble size distribution (BSD) for a given morphological area, defined by the seep clustering process, clustered bubble data was binned in 5-meter intervals (Figure 52, Figure 53, Figure 54). The BSD of each cluster was defined at the bin of data with the highest $\mathrm{N}$ :

- Cluster 1: centered at 25.2 meters

- Cluster 2: centered at 16.2 meters

- Cluster 3: centered at 19.0 meters

Binned data were fit to a Rayleigh distribution using the MATLAB 2016a distribution fitting tool (Figure 55). Distribution fitting tool defines the Rayleigh parameter $(\beta)$, the standard error $\left(\sigma_{\beta}\right)$, distribution mean and standard deviation (Table 5).

BSD were then projected down to the seafloor by applying the outputs of the TAMOC model, covered in section 12 (Figure 56). The seafloor distributions have a higher mean and lower standard deviation than the watercolumn distributions (Table 5), due to increase in bubble radius with increasing proximity to the seafloor and non-linear bubble dissolution rate with increasing radius. Mean $(\mu)$ and standard deviation $(\sigma)$ of the seafloor BSD are determined by the following equations:

$$
\mu=\int_{0}^{a_{\max }} a \rho(a) d a \quad \sigma=\int_{0}^{a_{\max }} \rho(a)(a-\mu)^{2} d a
$$



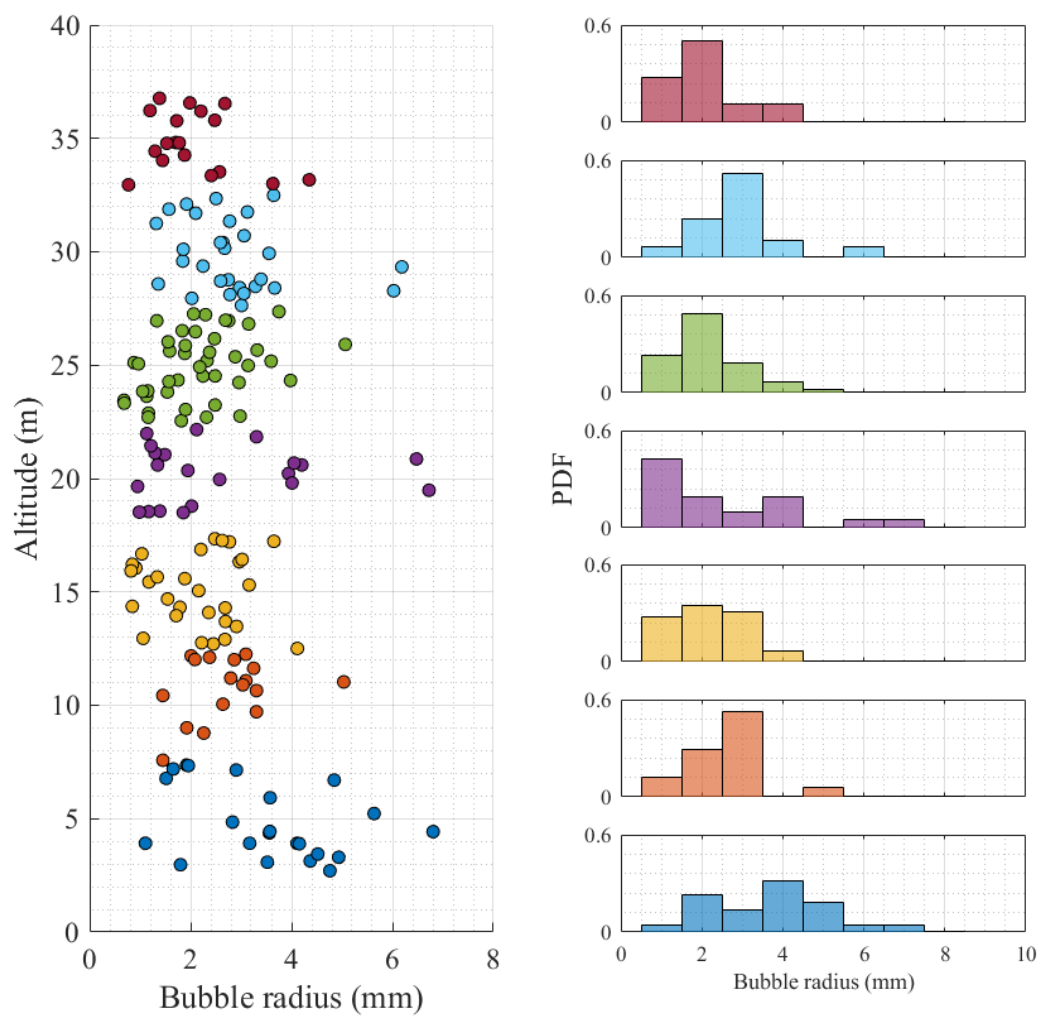

Figure 52. Cluster 1 bubble data binned at $5 \mathrm{~m}$ intervals.
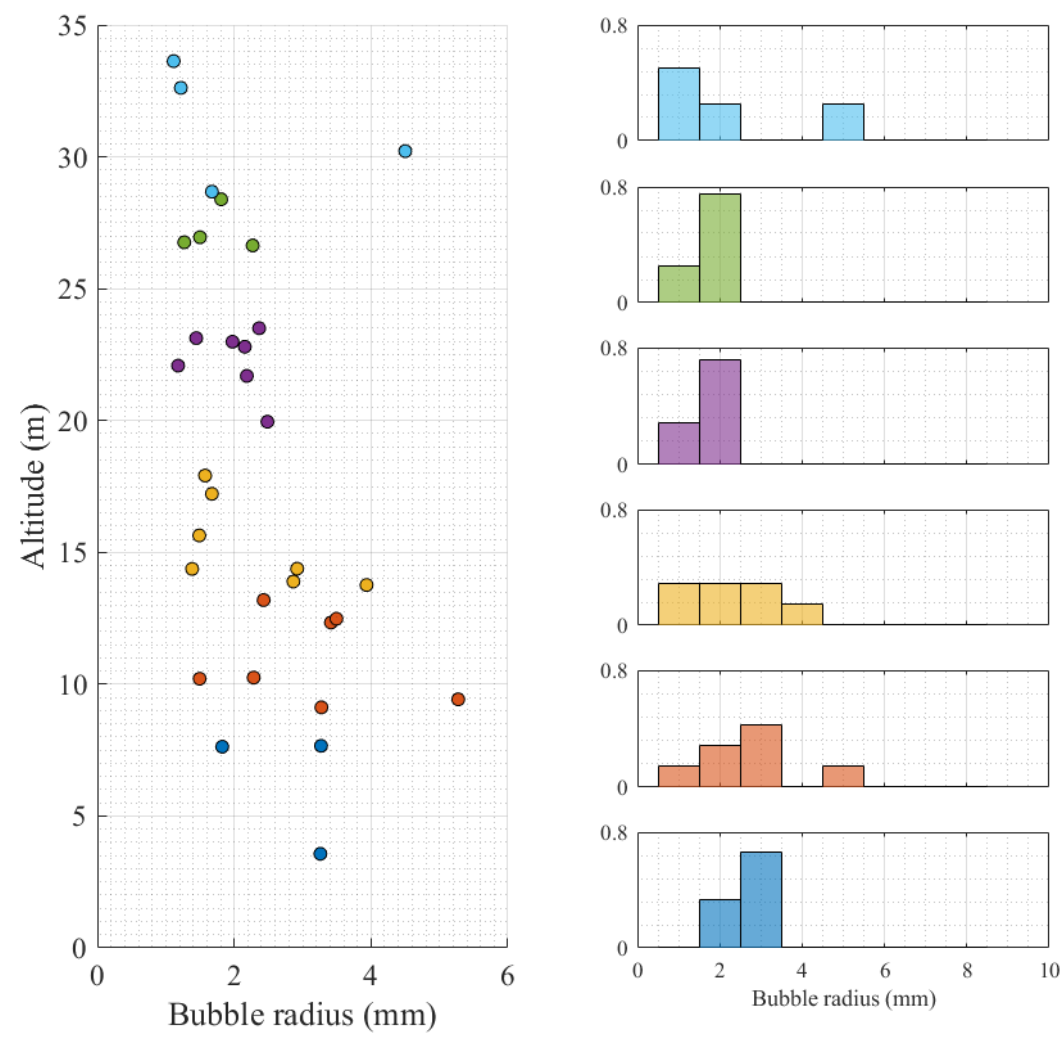

Figure 53. Cluster 2 bubble data binned at $5 \mathrm{~m}$ intervals. 

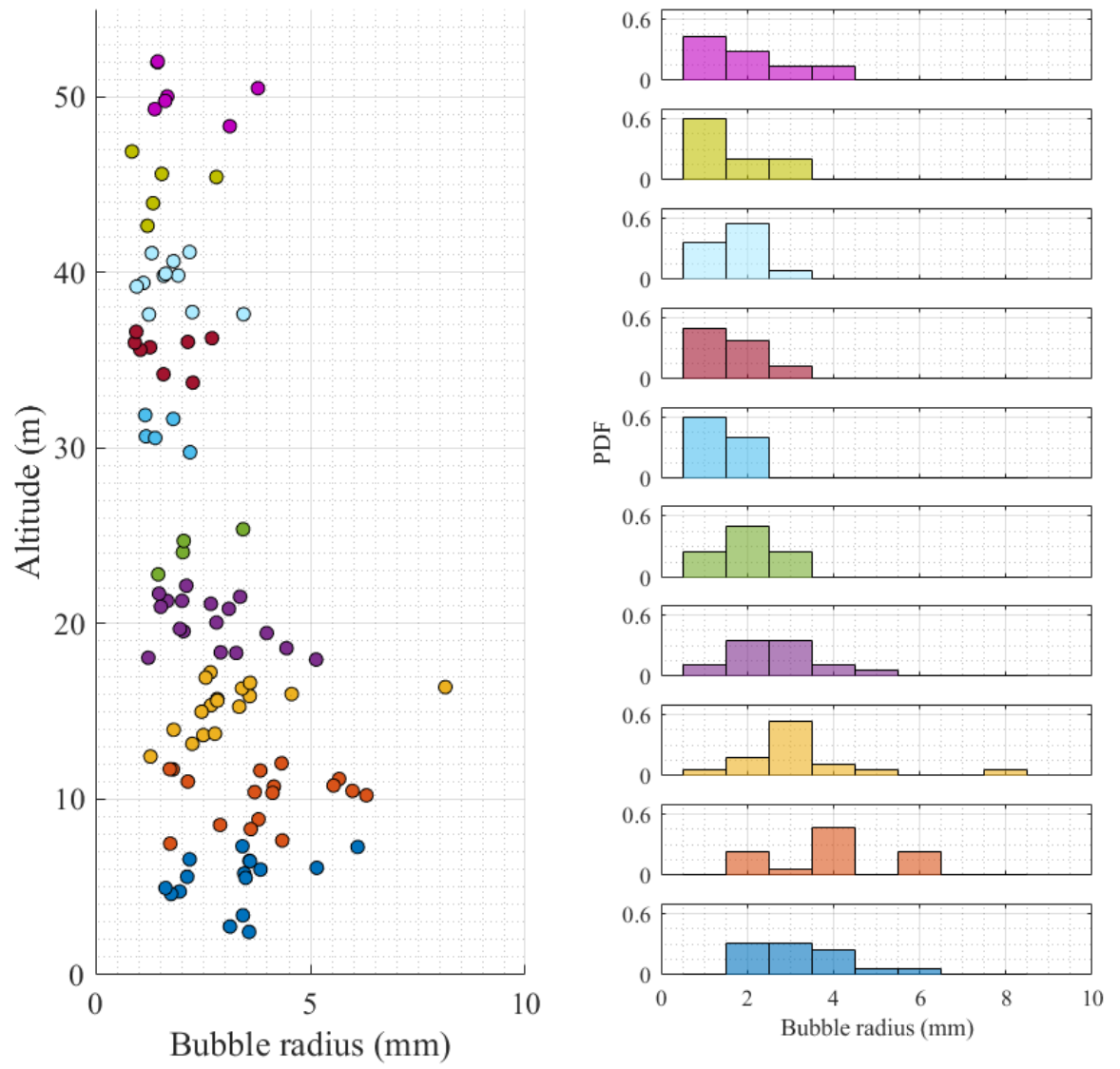

Figure 54. Cluster 3 bubble data binned in $5 \mathrm{~m}$ intervals.
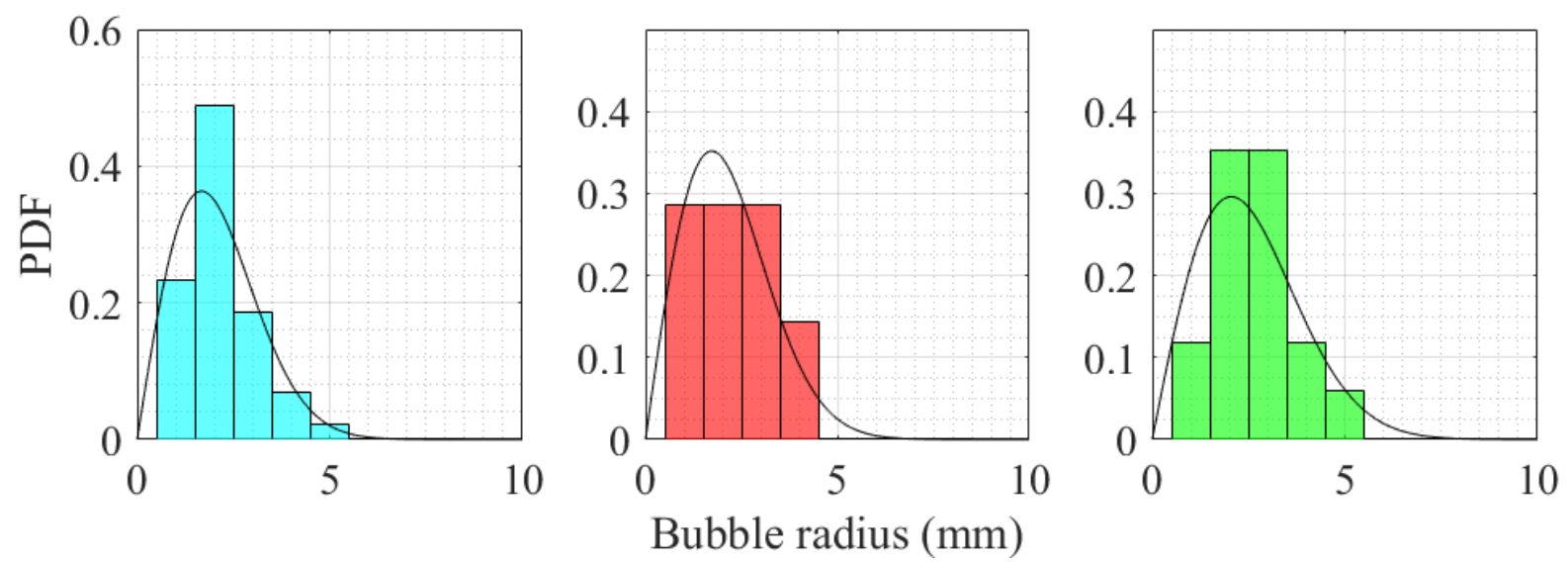

Figure 55.Histograms and fitted Rayleigh PDF of the binned bubble data for cluster 1 (cyan), cluster 2 (red), and cluster 3 (green). 

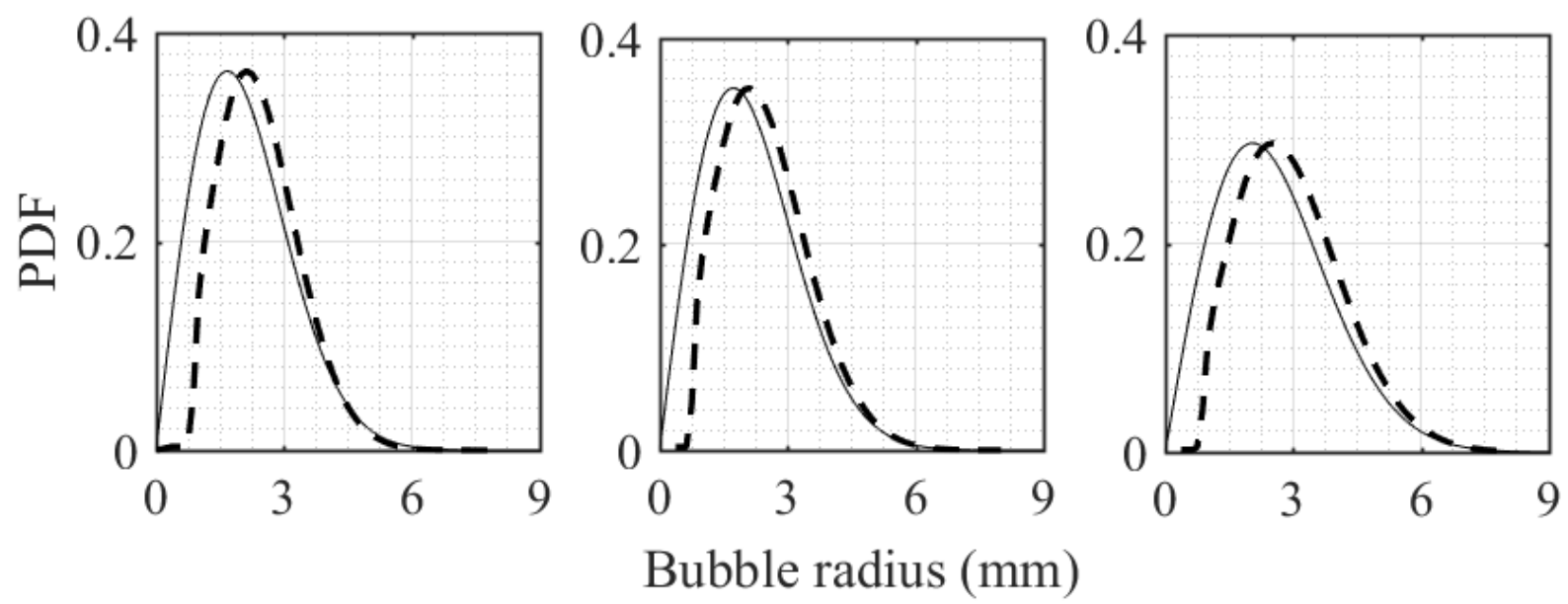

Figure 56. BSD of each cluster in the watercolumn (solid line) and projected to the seafloor (dashed lines). Cluster 1 (left), cluster 2 (center), and cluster 3 (right).

Table 5. Bubble size distribution parameters for the clustered data set.

\begin{tabular}{|c|c|c|c|c|c|c|c|c|}
\hline & \multicolumn{2}{|c|}{ Binned data } & \multicolumn{2}{c|}{ Rayleigh parameters } & \multicolumn{2}{c|}{ WC distribution } & \multicolumn{2}{c|}{ Seafloor distribution } \\
\hline & $\mu$ & $\sigma$ & $\beta$ & $\sigma$ & $\mu$ & $\sigma$ & $\mu$ & $\sigma$ \\
\hline Cluster 1 & 2.17 & 0.95 & 1.67 & 0.13 & 2.09 & 1.19 & 2.14 & 0.90 \\
\hline Cluster 2 & 2.26 & 0.98 & 1.72 & 0.33 & 2.16 & 1.28 & 2.33 & 0.96 \\
\hline Cluster 3 & 2.69 & 1.10 & 2.05 & 0.25 & 2.57 & 1.80 & 2.72 & 1.08 \\
\hline
\end{tabular}




\subsection{Individual seep flux estimates}

\subsubsection{Instantaneous observed volumetric gas flux}

Table 6. Direct flux estimations of Cluster 1 seeps

\begin{tabular}{|c|c|c|}
\hline \multicolumn{3}{|c|}{ Cluster $\mathbf{1}\left(\mathbf{m}^{3} \mathbf{s}\right)$} \\
\hline Seep ID & Q & $\sigma_{Q}$ \\
\hline T010336 & $3.68 \mathrm{E}-09$ & $1.12 \mathrm{E}-09$ \\
\hline T014257 & $4.14 \mathrm{E}-09$ & $5.94 \mathrm{E}-10$ \\
\hline T223620 & $9.02 \mathrm{E}-09$ & $2.26 \mathrm{E}-09$ \\
\hline T224048 & $2.45 \mathrm{E}-07$ & $6.40 \mathrm{E}-08$ \\
\hline T225859 & $1.97 \mathrm{E}-08$ & $4.88 \mathrm{E}-09$ \\
\hline T222721_01 & $4.63 \mathrm{E}-08$ & $1.10 \mathrm{E}-08$ \\
\hline T222721_02 & $7.45 \mathrm{E}-09$ & $1.88 \mathrm{E}-09$ \\
\hline T223151_01 & $4.38 \mathrm{E}-08$ & $8.37 \mathrm{E}-09$ \\
\hline T223151_03 & $2.45 \mathrm{E}-08$ & $5.13 \mathrm{E}-09$ \\
\hline T223151_05 & $6.89 \mathrm{E}-09$ & $1.49 \mathrm{E}-09$ \\
\hline T234343_02 & $1.53 \mathrm{E}-08$ & $4.96 \mathrm{E}-09$ \\
\hline T234343_03 & $6.47 \mathrm{E}-08$ & $1.06 \mathrm{E}-08$ \\
\hline
\end{tabular}

Table 7. Direct flux estimations of Cluster 2 seeps

\begin{tabular}{|c|c|c|}
\hline \multicolumn{3}{|c|}{ Cluster $\mathbf{2}\left(\mathbf{m}^{\mathbf{3}} / \mathbf{s}\right)$} \\
\hline Seep ID & Q & $\sigma_{Q}$ \\
\hline T000559 & $1.13 \mathrm{E}-08$ & $1.78 \mathrm{E}-09$ \\
\hline T071055 & $4.34 \mathrm{E}-08$ & $8.72 \mathrm{E}-09$ \\
\hline T091020_01 & $5.50 \mathrm{E}-09$ & $5.82 \mathrm{E}-10$ \\
\hline T091020_03 & $3.47 \mathrm{E}-08$ & $5.94 \mathrm{E}-09$ \\
\hline T091439_01 & $6.98 \mathrm{E}-10$ & $1.78 \mathrm{E}-10$ \\
\hline T091439_03 & 2.13E-09 & $3.16 \mathrm{E}-10$ \\
\hline T091439_07 & 6.93E-10 & $2.85 \mathrm{E}-10$ \\
\hline T091439_09 & 1.98E-08 & $2.27 \mathrm{E}-09$ \\
\hline T091439_13 & 6.65E-09 & $1.34 \mathrm{E}-09$ \\
\hline
\end{tabular}

Table 8. Direct flux estimations of Cluster 3 seeps

\section{Cluster $3\left(\mathrm{~m}^{3} / \mathrm{s}\right)$}




\begin{tabular}{|c|c|c|c|c|c|}
\hline Seep ID & Q & $\sigma_{Q}$ & Seep ID & Q & $\sigma_{Q}$ \\
\hline T042631_01 & $8.65 \mathrm{E}-08$ & $1.92 \mathrm{E}-08$ & T063136_03 & $4.50 \mathrm{E}-09$ & $1.24 \mathrm{E}-09$ \\
\hline T043037_01 & $1.04 \mathrm{E}-07$ & $2.07 \mathrm{E}-08$ & T065828_01 & $1.68 \mathrm{E}-08$ & $6.92 \mathrm{E}-09$ \\
\hline T063822 & $8.56 \mathrm{E}-08$ & $1.74 \mathrm{E}-08$ & T065828_02 & $4.07 \mathrm{E}-09$ & $9.21 \mathrm{E}-10$ \\
\hline T100624 & $6.78 \mathrm{E}-09$ & $9.03 \mathrm{E}-10$ & T172318_01 & $1.90 \mathrm{E}-09$ & $3.31 \mathrm{E}-10$ \\
\hline T171859 & $2.27 \mathrm{E}-10$ & $6.80 \mathrm{E}-10$ & T172318_03 & $4.29 \mathrm{E}-09$ & $6.01 \mathrm{E}-10$ \\
\hline T173156_01 & $3.30 \mathrm{E}-10$ & $2.28 \mathrm{E}-10$ & T172318_04 & $6.26 \mathrm{E}-09$ & $1.18 \mathrm{E}-09$ \\
\hline T175325 & $2.38 \mathrm{E}-09$ & $4.03 \mathrm{E}-10$ & T174032_01 & $8.17 \mathrm{E}-08$ & $1.32 \mathrm{E}-08$ \\
\hline T063136_01 & $1.43 \mathrm{E}-09$ & $1.64 \mathrm{E}-09$ & T174032_02 & $1.62 \mathrm{E}-08$ & $2.98 \mathrm{E}-09$ \\
\hline T063136_02 & $4.68 \mathrm{E}-09$ & $4.35 \mathrm{E}-10$ & & & \\
\hline
\end{tabular}

Table 9. Direct flux estimations of all seeps from study region

\begin{tabular}{|c|c|c|c|}
\hline \multicolumn{5}{|c|}{ All data $\left(\mathbf{m}^{3} /\right.$ year $)$} \\
\hline Maximum Q & $7.7 \pm 2.0$ & Survey area total Q & $33 \pm 7.1$ \\
\hline Minimum Q & $0.010 \pm 0.0072$ & HC total Q & $5.0 \mathrm{E} 04 \pm 1.1 \mathrm{E} 04$ \\
\hline Mean Q & $0.87 \pm 0.19$ & & \\
\hline
\end{tabular}

\subsubsection{Inferred parameter volumetric gas flux}

Table 10. Flux estimations of Cluster 1 seeps based on the inferred parameter method

\begin{tabular}{|c|c|c|}
\hline \multicolumn{2}{|c|}{ Cluster 1 (m³/s) } \\
\hline Seep ID & Q & $\sigma_{Q}$ \\
\hline T010336 & $8.88 \mathrm{E}-09$ & $4.32 \mathrm{E}-09$ \\
\hline T014257 & $1.46 \mathrm{E}-08$ & $7.10 \mathrm{E}-09$ \\
\hline T223620 & $1.83 \mathrm{E}-08$ & $8.90 \mathrm{E}-09$ \\
\hline T224048 & $6.60 \mathrm{E}-08$ & $3.21 \mathrm{E}-08$ \\
\hline T225859 & $1.76 \mathrm{E}-08$ & $8.56 \mathrm{E}-09$ \\
\hline T222721_01 & $3.42 \mathrm{E}-08$ & $1.66 \mathrm{E}-08$ \\
\hline T222721_02 & $8.85 \mathrm{E}-09$ & $4.30 \mathrm{E}-09$ \\
\hline T223151_01 & $1.87 \mathrm{E}-08$ & $9.10 \mathrm{E}-09$ \\
\hline T223151_03 & $2.02 \mathrm{E}-08$ & $9.82 \mathrm{E}-09$ \\
\hline T223151_05 & $8.53 \mathrm{E}-09$ & $4.14 \mathrm{E}-09$ \\
\hline T234343_02 & $1.01 \mathrm{E}-08$ & $4.91 \mathrm{E}-09$ \\
\hline T234343_03 & $1.43 \mathrm{E}-08$ & $6.97 \mathrm{E}-09$ \\
\hline
\end{tabular}


Table 11. Flux estimations of Cluster 2 seeps based on the inferred parameter method

\begin{tabular}{|c|c|c|}
\hline \multicolumn{3}{|c|}{ Cluster 2 $\left(\mathbf{m}^{\mathbf{3}} / \mathbf{s}\right)$} \\
\hline Seep ID & Q & $\sigma_{Q}$ \\
\hline T000559 & $2.37 \mathrm{E}-08$ & $2.54 \mathrm{E}-08$ \\
\hline T071055 & $2.44 \mathrm{E}-08$ & $2.62 \mathrm{E}-08$ \\
\hline T091020_01 & $3.80 \mathrm{E}-09$ & $4.09 \mathrm{E}-09$ \\
\hline T091020_03 & $8.76 \mathrm{E}-08$ & $9.42 \mathrm{E}-08$ \\
\hline T091439_01 & 6.46E-09 & 6.94E-09 \\
\hline T091439_03 & 5.22E-09 & 5.61E-09 \\
\hline T091439_07 & $9.24 \mathrm{E}-09$ & $9.93 \mathrm{E}-09$ \\
\hline T091439_09 & $1.29 \mathrm{E}-08$ & $1.39 \mathrm{E}-08$ \\
\hline T091439_13 & $9.24 \mathrm{E}-09$ & $9.93 \mathrm{E}-09$ \\
\hline
\end{tabular}

Table 12. Flux estimations of Cluster 3 seeps based on the inferred parameter method

\begin{tabular}{|c|c|c|c|c|c|}
\hline \multicolumn{7}{|c|}{ Cluster 3 $\left(\mathbf{m}^{3} / \mathbf{s}\right)$} \\
\hline Seep ID & Q & $\sigma_{Q}$ & Seep ID & Q & $\sigma_{Q}$ \\
\hline T042631_01 & $6.50 \mathrm{E}-08$ & $4.07 \mathrm{E}-08$ & T063136_03 & $1.01 \mathrm{E}-08$ & $6.33 \mathrm{E}-09$ \\
\hline T043037_01 & $3.26 \mathrm{E}-08$ & $2.04 \mathrm{E}-08$ & T065828_01 & $1.40 \mathrm{E}-08$ & $8.74 \mathrm{E}-09$ \\
\hline T063822 & $3.73 \mathrm{E}-08$ & $2.34 \mathrm{E}-08$ & T065828_02 & $1.82 \mathrm{E}-08$ & $1.14 \mathrm{E}-08$ \\
\hline T100624 & $2.27 \mathrm{E}-08$ & $1.42 \mathrm{E}-08$ & T172318_01 & $6.58 \mathrm{E}-09$ & $4.12 \mathrm{E}-09$ \\
\hline T171859 & $9.50 \mathrm{E}-09$ & $5.94 \mathrm{E}-09$ & T172318_03 & 3.46E-09 & $2.17 \mathrm{E}-09$ \\
\hline T173156_01 & $2.21 \mathrm{E}-08$ & $1.38 \mathrm{E}-08$ & T172318_04 & $1.03 \mathrm{E}-08$ & $6.45 \mathrm{E}-09$ \\
\hline T175325 & $1.50 \mathrm{E}-08$ & $9.39 \mathrm{E}-09$ & T174032_01 & 2.42E-08 & $1.51 \mathrm{E}-08$ \\
\hline T063136_01 & $5.09 \mathrm{E}-08$ & $3.18 \mathrm{E}-08$ & T174032_02 & $3.02 \mathrm{E}-08$ & $1.89 \mathrm{E}-08$ \\
\hline T063136_02 & $4.76 \mathrm{E}-08$ & $2.98 \mathrm{E}-08$ & & & \\
\hline
\end{tabular}

Table 13. Flux estimations of all seeps based on the inferred parameter method

\begin{tabular}{|c|c|c|c|}
\hline \multicolumn{5}{|c|}{ All data $\left(\mathbf{m}^{\mathbf{3}} /\right.$ year $)$} \\
\hline Maximum Q & $2.8 \pm 2.0$ & Survey area total Q & $27 \pm 18$ \\
\hline Minimum Q & $0.11 \pm 0.0068$ & HC total Q & $4.1 \mathrm{E} 04 \pm 290$ \\
\hline Mean Q & $0.70 \pm 0.48$ & & \\
\hline
\end{tabular}




\subsubsection{Methane mass flux}

Table 14. Methane mass flux estimations of Cluster 1 seeps

\begin{tabular}{|c|c|c|}
\hline Cluster 1 & Seafloor & Sea surface \\
\hline Seep ID & Q (g/s) & Q (g/s) \\
\hline T010336 & $4.03 \mathrm{E}-05$ & $7.72 \mathrm{E}-06$ \\
\hline T014257 & $6.63 \mathrm{E}-05$ & $1.27 \mathrm{E}-05$ \\
\hline T223620 & $8.31 \mathrm{E}-05$ & $1.59 \mathrm{E}-05$ \\
\hline T224048 & $3.00 \mathrm{E}-04$ & $5.74 \mathrm{E}-05$ \\
\hline T225859 & $8.00 \mathrm{E}-05$ & $1.53 \mathrm{E}-05$ \\
\hline T222721_01 & $1.55 \mathrm{E}-04$ & $2.97 \mathrm{E}-05$ \\
\hline T222721_02 & $4.01 \mathrm{E}-05$ & $7.69 \mathrm{E}-06$ \\
\hline T223151_01 & $8.50 \mathrm{E}-05$ & $1.63 \mathrm{E}-05$ \\
\hline T223151_03 & $9.17 \mathrm{E}-05$ & $1.76 \mathrm{E}-05$ \\
\hline T223151_05 & $3.87 \mathrm{E}-05$ & $7.41 \mathrm{E}-06$ \\
\hline T234343_02 & $4.58 \mathrm{E}-05$ & $8.78 \mathrm{E}-06$ \\
\hline T234343_03 & $6.51 \mathrm{E}-05$ & $1.25 \mathrm{E}-05$ \\
\hline
\end{tabular}

Table 15. Methane mass flux estimations of Cluster 2 seeps

\begin{tabular}{|c|c|c|}
\hline Cluster 2 & Seafloor & Sea surface \\
\hline Seep ID & $\mathrm{Q}(\mathrm{g} / \mathrm{s})$ & $\mathrm{Q}(\mathrm{g} / \mathrm{s})$ \\
\hline T000559 & $1.34 \mathrm{E}-04$ & $1.70 \mathrm{E}-05$ \\
\hline T071055 & $1.38 \mathrm{E}-04$ & $1.75 \mathrm{E}-05$ \\
\hline T091020_01 & $2.15 \mathrm{E}-05$ & $2.73 \mathrm{E}-06$ \\
\hline T091020_03 & $4.96 \mathrm{E}-04$ & $6.29 \mathrm{E}-05$ \\
\hline T091439_01 & $3.66 \mathrm{E}-05$ & $4.64 \mathrm{E}-06$ \\
\hline T091439_03 & $2.96 \mathrm{E}-05$ & $3.75 \mathrm{E}-06$ \\
\hline T091439_07 & $5.23 \mathrm{E}-05$ & $6.64 \mathrm{E}-06$ \\
\hline T091439_09 & 7.31E-05 & $9.27 \mathrm{E}-06$ \\
\hline T091439_13 & $5.23 \mathrm{E}-05$ & $6.63 \mathrm{E}-06$ \\
\hline
\end{tabular}

Table 16. Methane mass flux estimations of Cluster 3 seeps

\begin{tabular}{|c|c|c|}
\hline Cluster 3 & Seafloor & Sea surface \\
\hline Seep ID & $\mathrm{Q}(\mathrm{g} / \mathrm{s})$ & $\mathrm{Q}(\mathrm{g} / \mathrm{s})$ \\
\hline
\end{tabular}




\begin{tabular}{|c|c|c|}
\hline T042631_01 & $4.76 \mathrm{E}-04$ & $3.97 \mathrm{E}-05$ \\
\hline T043037_01 & $2.39 \mathrm{E}-04$ & $1.99 \mathrm{E}-05$ \\
\hline T063822 & $2.73 \mathrm{E}-04$ & $2.28 \mathrm{E}-05$ \\
\hline T100624 & $1.67 \mathrm{E}-04$ & $1.39 \mathrm{E}-05$ \\
\hline T171859 & $6.95 \mathrm{E}-05$ & $5.80 \mathrm{E}-06$ \\
\hline T173156_01 & $1.62 \mathrm{E}-04$ & $1.35 \mathrm{E}-05$ \\
\hline T175325 & $1.10 \mathrm{E}-04$ & $9.17 \mathrm{E}-06$ \\
\hline T063136_01 & $3.73 \mathrm{E}-04$ & $3.11 \mathrm{E}-05$ \\
\hline T063136_02 & $3.49 \mathrm{E}-04$ & $2.91 \mathrm{E}-05$ \\
\hline T063136_03 & $7.40 \mathrm{E}-05$ & $6.18 \mathrm{E}-06$ \\
\hline T065828_01 & $1.02 \mathrm{E}-04$ & $8.54 \mathrm{E}-06$ \\
\hline T065828_02 & $1.33 \mathrm{E}-04$ & $1.11 \mathrm{E}-05$ \\
\hline T172318_01 & $4.82 \mathrm{E}-05$ & $4.03 \mathrm{E}-06$ \\
\hline T172318_03 & $2.54 \mathrm{E}-05$ & $2.12 \mathrm{E}-06$ \\
\hline T172318_04 & $7.54 \mathrm{E}-05$ & $6.30 \mathrm{E}-06$ \\
\hline T174032_01 & $1.77 \mathrm{E}-04$ & $1.48 \mathrm{E}-05$ \\
\hline T174032_02 & $2.21 \mathrm{E}-04$ & $1.85 \mathrm{E}-05$ \\
\hline
\end{tabular}

Table 17. Methane mass flux estimations of all seeps

\begin{tabular}{|c|c|c|c|}
\hline \multicolumn{5}{|c|}{ Seafloor flux: all data (kg/year) } \\
\hline Maximum Q & 16.0 & Survey area total Q & 160 \\
\hline Minimum Q & 0.68 & HC total Q & $2.4 \mathrm{E} 05$ \\
\hline Mean Q & 4.3 & & 19 \\
\hline \multicolumn{4}{|c|}{ Sea surface flux: all data (kg/year) } \\
\hline Maximum Q & 2.0 & Survey area total Q & $2.9 \mathrm{E} 04$ \\
\hline Minimum Q & 0.067 & HC total Q & \\
\hline Mean Q & 0.50 & & \\
\hline
\end{tabular}




\subsection{Herald Canyon oceanographic measurements}

Oceanographic parameters of temperature, salinity, and oxygen were defined by CTD casts taken during survey operations of SWERUS (Figure 57). Dissolved watercolumn methane concentrations were estimated during SWERUS-C3 onboard operations (Figure 58).

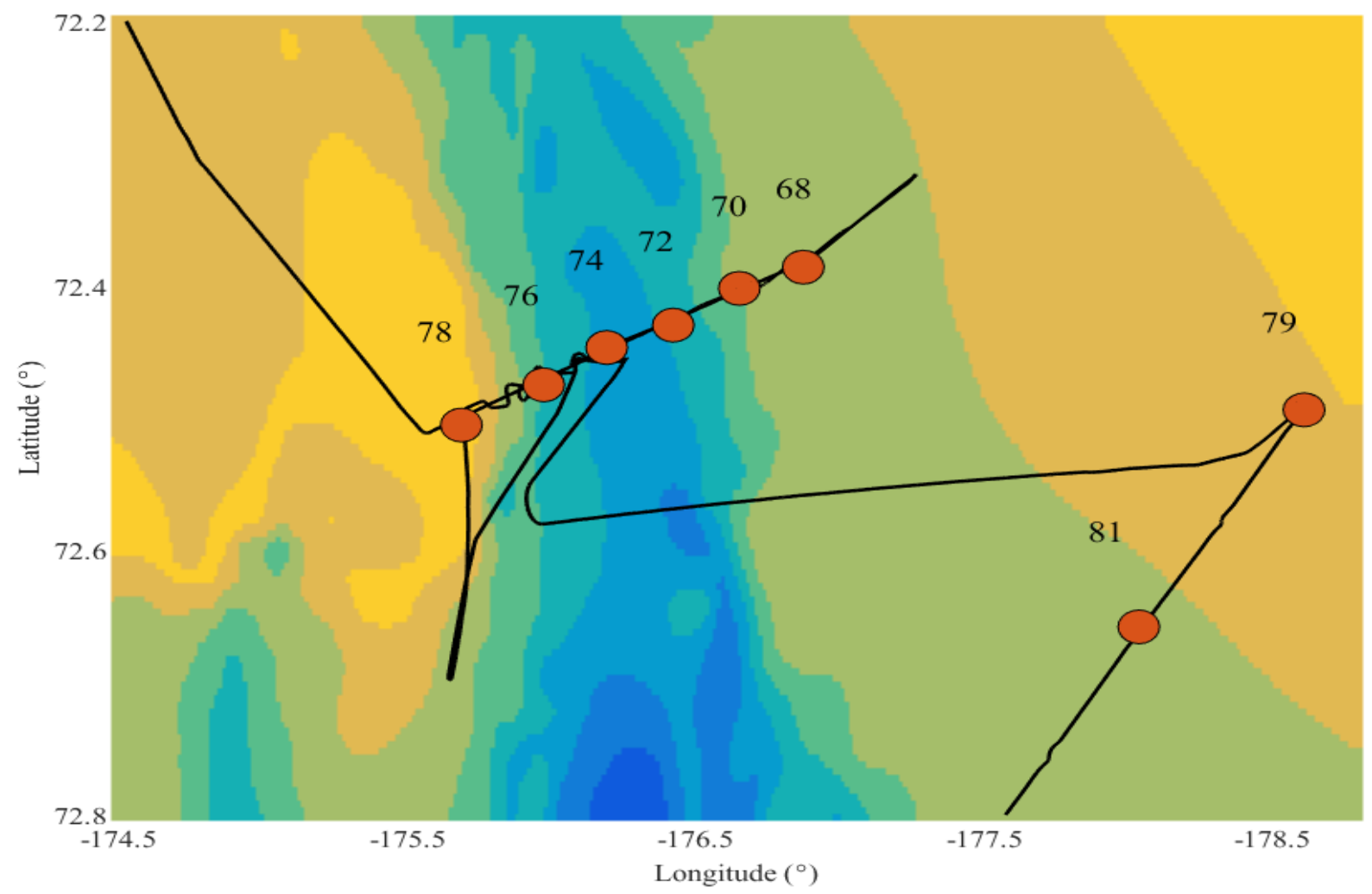

Figure 57.CTD cast locations in Herald Canyon during SWERUS-C3 operations.
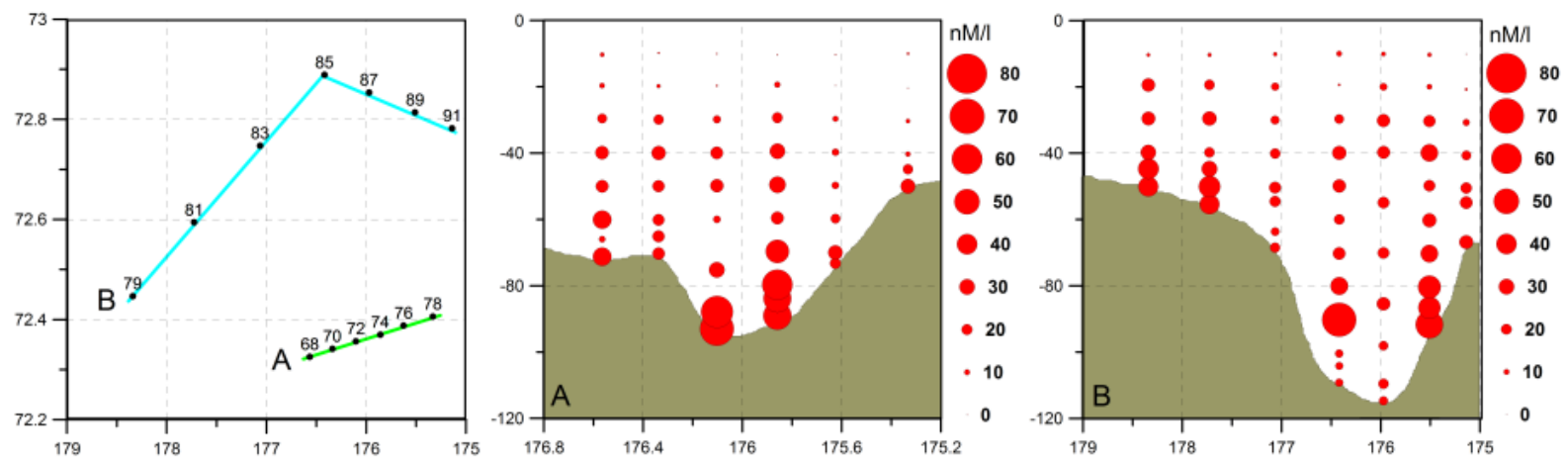

Figure 58. Methane distribution in Herald Canyon - transects A, B (box 1). From SWERUS-C3 cruise report 
The TAMOC model was seeded with oceanographic profiles from CTD station \#74 (Figure 59). Station \#74 was sampled from approximately the center of the Herald Canyon survey area, at depths as deep as the deepest seeps.
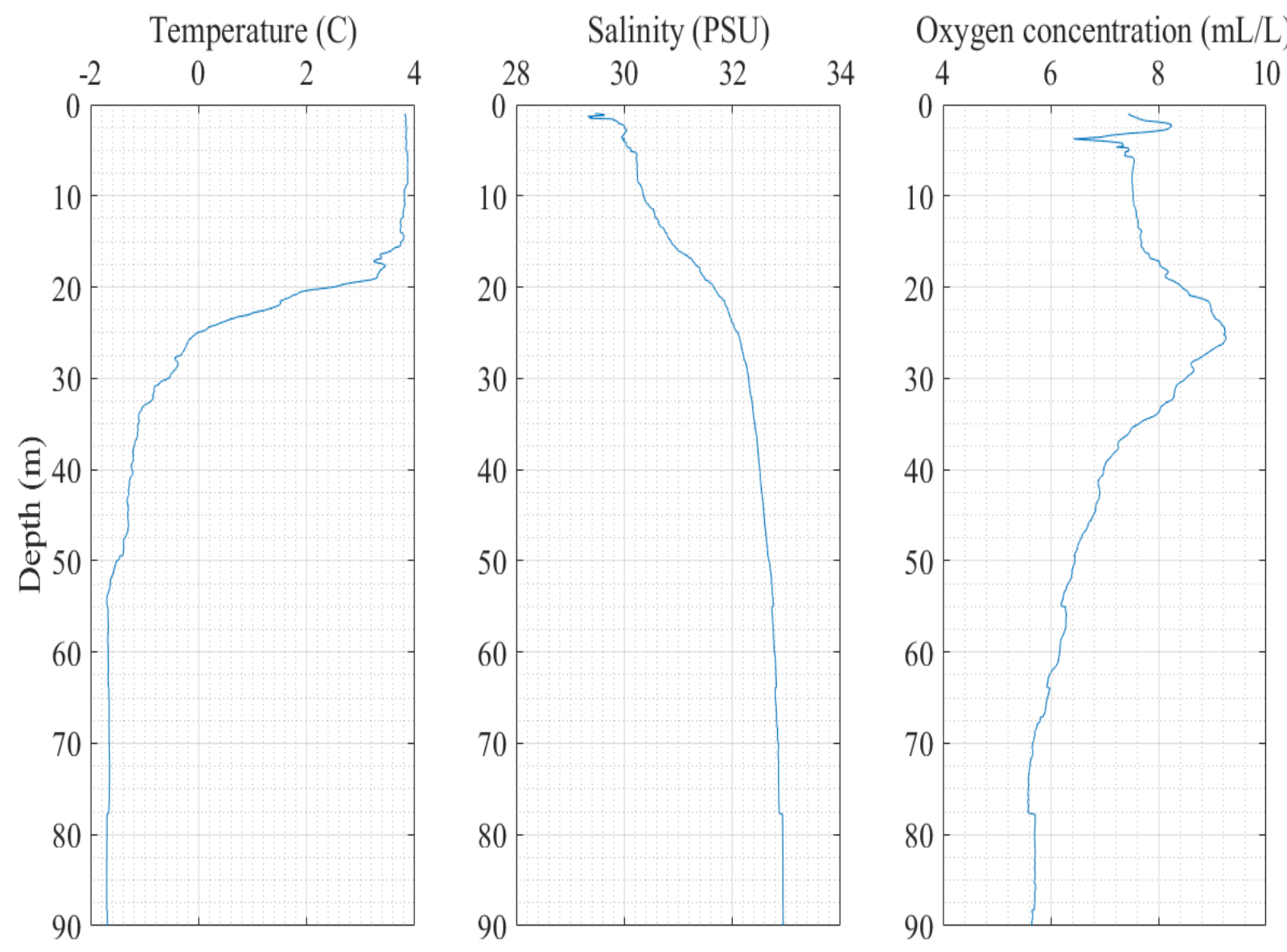

Figure 59. Oceanography parameter profiles measured at CTD station \#74 during SWERUS survey operations. 


\subsection{TAMOC model output}

The Texas A\&M Oilspill Calculator (TAMOC) bubble dissolution and transport model published by [Socolofsky et al., 2015] was employed to quantify bubble fate and transport in Herald Canyon. The TAMOC model was run with oceanographic parameters measured at CTD station \#74 (Figure 57), bubble diameters of 0.75 to $16.0 \mathrm{~mm}$ at $0.25 \mathrm{~mm}$ increments, at three depths (as defined by the seep clusters): $52 \mathrm{~m}, 67 \mathrm{~m}$, and $89 \mathrm{~m}$. The model was run for clean bubbles with a composition of $100 \%$ methane gas at release.

The TAMOC model output provides bubble size as a function of depth, as well as bubble composition as a function of depth. After release from the seafloor, bubble sizes generally decreased with increasing altitude until either full dissolution or a critical point in which they increased in size until they reached the sea surface (Figure 60). With deeper starting depth increasingly larger bubbles fully dissolved and there was a larger difference in size between bubbles released at the seafloor and those at the surface.
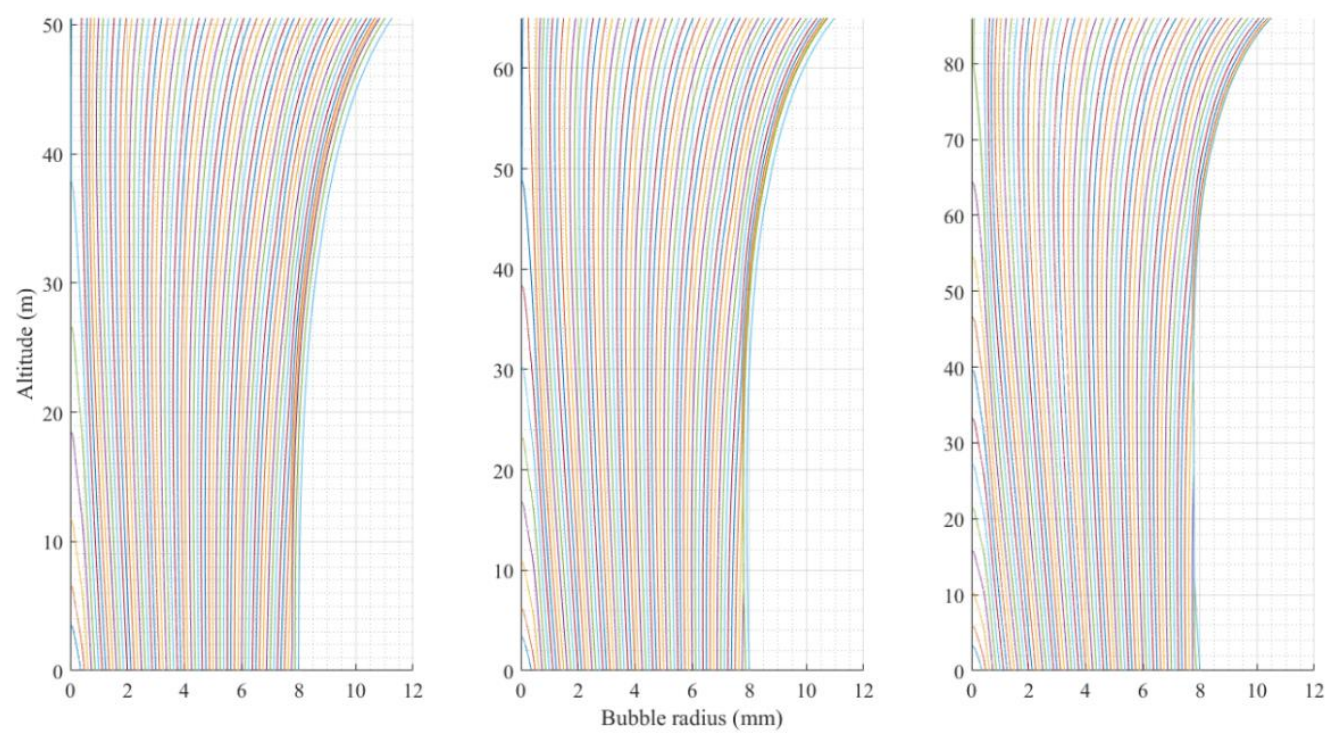

Figure 60. TAMOC model output of bubble radius as a function of altitude for the seep cluster starting depths: cluster 1 @ 52 m, cluster $2 @ 67$ m, and cluster $3 @ 89 m$. 
Methane mass transport is output in the form of moles of methane in each bubble as a function of bubble altitude (Figure 61). Bubbles are 100\% methane at release and are assumed to be spherical in shape throughout their ascent.
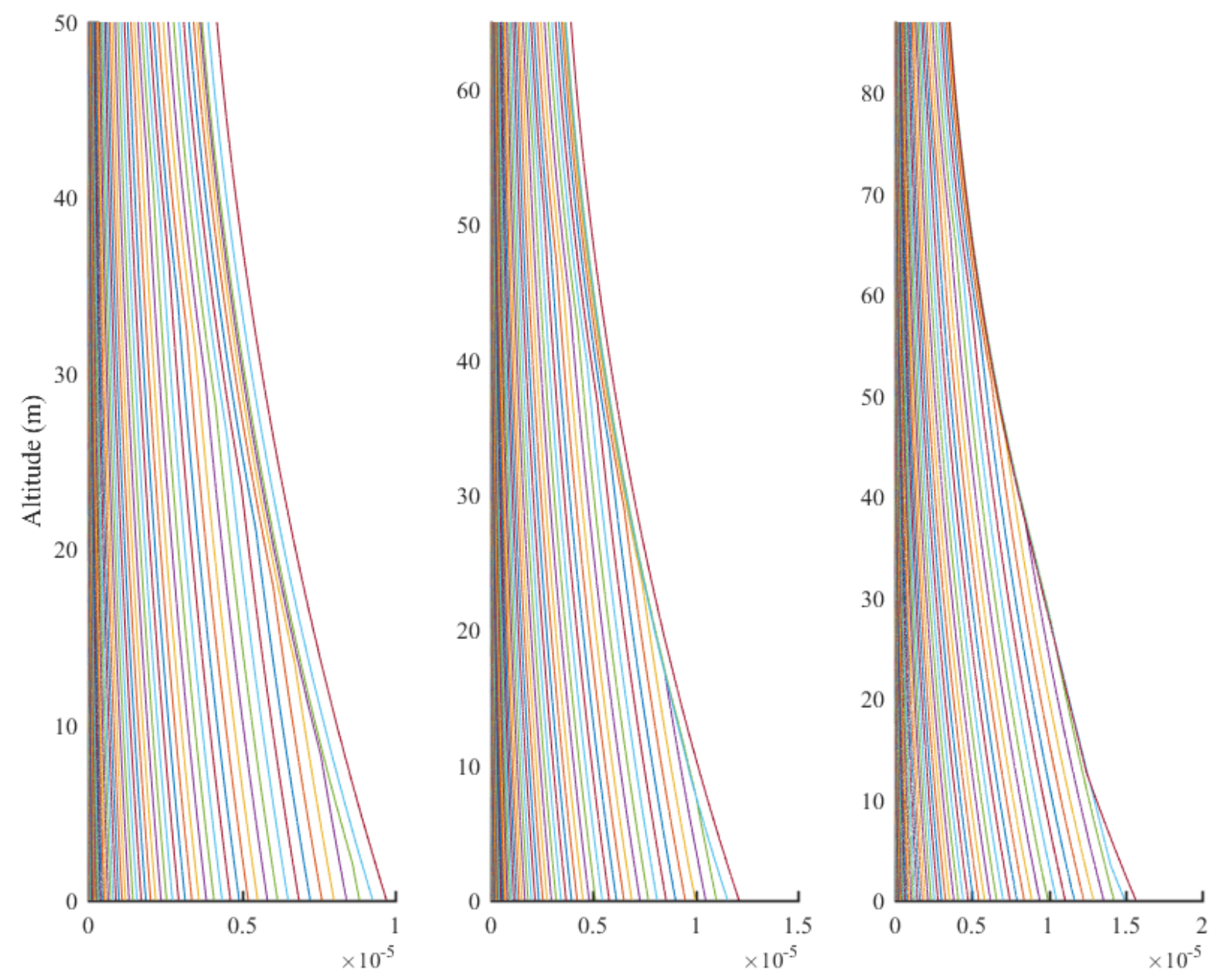

Moles methane

Figure 61. TAMOC model output of methane mass (moles) for each bubble size as a function of altitude: cluster $1 @ 52$ m, cluster $2 @ 67 \mathrm{~m}$, and cluster $3 @ 89 \mathrm{~m}$. 


\section{REFERENCES}

Ainslie, M. A. and T. G. Leighton (2009), Near resonant bubble acoustic cross-section corrections, including examples from oceanography, volcanology, and biomedical ultrasound, J. Acoust. Soc. Am., 126(5), 2163-2175, doi:10.1121/1.3180130.

AMAP Assessment 2015: Methane as an Arctic climate forcer, Arctic Monitoring and Assessment Programme (AMAP), Oslo, Norway, 139 pp.

Anderson, V. C. (1950), Sound scattering from a fluid sphere, J. Acoust. Soc. Am., 22(4), 426-431

Burdic, W. S. (1991), Underwater Acoustic System Analysis, 2nd ed., pp. 328-331, Prentice Hall, Upper Saddle River, N. J.

Clay, C., and H. Medwin (1977), Acoustical Oceanography: Principles and Applications, pp. 194201 and 236-241, New York: John Wiley \& Sons.

Clift, R., J. R. Grace, and M. E. Weber (1978), Bubbles, Drops and Particles, pp. 172, Academic, New York.

Demer, D. A., L. Berger, M. Bernasconi, E. Bethke, K. Boswell, D. Chu, R. Domokos, A. Dunford, S. Fäaaler, S. Gauthier, L. T. Hufnagle, J. M. Jech, N. Bouffant, A. Lebouges-Dhaussy, X. Lurton, G. J. Macaulay, Y. Perrot, T. Ryan, S. Parker-Stetter, S. Stienessen, T. Weber, and N. Williamson (2015), Calibration of acoustic instruments, ICES Cooperative Research Report No. 326, 133 pp. 
Foote, K. G., H. P. Knudsen, and G. Vestnes (1987), Calibration of Acoustic Instruments for Fish Density Estimation: A Practical Guide, International Council for the Exploration of the Sea, Copenhagen.

Francois, R. E., and G. R. Garrison (1982), Sound absorption based on ocean measurements: Part I: Pure water and magnesium sulfate contributions, J. Acoust. Soc. Am., 72, 896.

Greinert, J., Y. Artemov, V. Egorov. M. De Batist, and D. McGinnis (2006), 1300-m-high rising bubbles from mud volcanoes at 2080m in the Black Sea: Hydroacoustic characteristics and temporal variability, Earth Planet. Sci. Lett., 244, 1-15.

Greinert, J. (2008), Monitoring temporal variability of bubble release at seeps: The hydroacoustic swath system GasQuant, J. Geophys. Res., 113, C07048, doi:10.1029/2007JC004704.

Greinert, J., D. F. Mcginnis, L. Naudts, P. Linke, and M. De Batist (2010), Atmospheric methane flux from bubbling seeps: Spatially extrapolated quantification from a Black Sea shelf area, $J$. Geophys. Res: Oceans, 115, doi:10.1029/2009JC005381.

Gros, J., C. M. Reddy, R. K. Nelson, S. A. Socolofsky, and J. S. Arey (2016), Simulating GasLiquid-Water Partitioning and Fluid Properties of Petroleum under Pressure: Implications for Deep-Sea Blowouts, Environ. Sci. Technol., 50(14), 7397-7408, doi:10.1021/acs.est.5b04617.

Gros, J., S. A. Socolofsky, A. L. Dissanayake, I. Jun, L. Zhao, M. C. Boufadel, C. M. Reddy, and J. S. Arey (2017), Petroleum dynamics in the sea and influence of subsea dispersant injection during Deepwater Horizon, Proceedings of the National Academy of Sciences, doi:10.1073/pnas.1612518114. 
Heeschen, K., A. Trehu, R. Collier, E. Suess, and G. Rehder (2003), Distribution and height of methane bubble plumes on the Cascadia Margin characterized by acoustic imaging, Geophys. Res. Lett., 30(12), 1643, doi:10.1029/2003GL016974.

Jakobsson, M., Nilsson, J., Anderson, L., Backman, J., Björk, G., Cronin, T.M., Kirchner, N., Koshurnikov, A., Mayer, L., Noormets, R., O’Regan, M., Stranne, C., Ananiev, R., Macho, N.B., Cherniykh, D., Coxall, H., Eriksson, B., Flodén, T., Gemery, L., Gustafsson, Ö., Jerram, K., Johansson, C., Khortov, A., Mohammad, R. and Semiletov, I., 2015, Evidence for an ice shelf covering the central Arctic Ocean during the penultimate glaciation, Nat. Com., 7, 10365, doi:10.1038/ncomms10365

Jech, J. M., J. K. Horne, C. Dezhang, D. A. Demer, D. T. I. Francis, N. Gorska, B. Jones, A. C. Lavery, T. K. Stanton, G. J. Macaulay, D. B. Reeder, and K. Sawada (2015), Comparisons among ten models of acoustic backscattering used in aquatic ecosystem research, J. Acoust. Soc. Am. 136(6), 3742-3764.

Jerram, K., T. C. Weber, J. Beaudoin (2015), Split-beam echosounder observations of natural methane seep variability in the northern Gulf of Mexico, Geochem., Geophys., Geosyst., 15, doi:10.1002/2014GC005429.

Judd, A. G. (2004), Natural seabed gas seeps as sources of atmospheric methane. Environ. Geol., 46, 988-996, doi:10.1007/s00254-004-1083-3.

Kannberg, P. K., A. M. Trehu, S. D. Pierce, C. K. Paull, and D. W. Caress (2013), Temporal variation of methane flares in the ocean above Hydrate Ridge, Oregon, Earth Planet. Sci. Lett., $368,33-42$. 
Kirschke, S., P. Bousquet, P. Ciais, M. Saunois, J. G. Canadell, E. J. Dlugokencky, P. Bergamaschi, D. Bergmann, D. R. Blake, L. Bruhwiler, P. Cameron-Smith, S. Castaldi, F. Chevallier, L. Feng, A. Fraser, M. Heimann, E. L. Hodson, S. Houweling, B. Josse, P. J. Fraser, P. B. Krummel, J. Lamarque, R. L. Langenfelds, C. Le Quéré, V. Naik, S. O'Doherty, P. I. Palmer, I. Pison, D. Plummer, B. Poulter, R. G. Prinn, M. Rigby, B. Ringeval, M. Santini, M. Schmidt, D. T. Shindell, I. J. Simpson, R. Spahni, L. Paul Steele, Sarah A. Strode, K. Sudo, S. Szopa, G. R. van der Werf, A. Voulgarakis, M. van Weele, R. F. Weiss, J. E. Williams, and G. Zeng (2013), Three decades of global methane sources and sinks. Nat. Geosci., 6, 813-823, doi:10.1038/ngeo1955.

Lammers, R. B., A. I. Shiklomanov, C. J. Vörösmarty, B. M. Fekete, and B. J. Peterson (2001), Assessment of contemporary Arctic river runoff based on observational discharge records, $J$. Geophys. Res., 106, 3321-3334, doi:10.1029/20000JD900444.

Leifer, I., and K. Wilson (2004), Quantified oil emissions with a video-monitored, oil seep-tent, Marine Technology Society Journal, 38(3): 44-53.

Lavery, A. C., D. Chu, and J. N. Moum (2010a), Measurements of acoustic scattering from zooplankton and oceanic microstructure using a broadband echosounder, ICES J. Mar. Sci., 67: 379-394.

Lavery, A. C., D. Chu, J. N. Moum (2010b), Observations of broadband acoustic backscattering from nonlinear internal waves: assessing the contribution from microstructure, IEEE J. Ocean Engin., 35(4): 695-709.

Leifer, I. and D. Cullings (2010), Formation of seep bubble plumes in the Coal Oil Point seep field, Geo. Mar. Lett., 30, 339-353, doi:10.1016/S0278-4343(02)00065-1. 
Leifer, I. and R. K. Patro (2002), The bubble mechanism for methane transport from the shallow sea bed to the surface: A review and sensitivity study, Contin. S. Res., 22, 2409-2428.

Leifer, I., and I. R. MacDonald (2003), Dynamics of the gas flux from shallow gas hydrate deposits: Interaction between oily hydrate bubbles and the oceanic environment, Earth Planet. Sci. Lett., 210(3-4), 411-424, doi:10.1016/S0012-821X(03)00173-0

Leifer, I, D. Chernykh, N. Shakhova, and I. Semiletov (2017), Sonar gas flux estimation by bubble insonification: application to methane bubble flux from seep areas in the outer Laptev Sea, The Cyrosphere, 11: 1333-1350, doi.org/10.5194/tc-11-1333-2017

MacDonald, I. R., I. Leifer, R. Sassen, P. Stine, R. Mitchell, and N. Guinasso (2002), Transfer of hydrocarbons from natural seeps to water column and atmosphere, Geofluids, 2, 95-107.

Maslanik, J. A., C. Fowler, J. Stroeve, S. Drobot, J. Zwally, D. Yi, and W. Emery (2007), A younger, thinner Arctic ice cover: Increased potential for rapid, extensive, sea-ice loss, Geophys. Res. Lett., 34: L24501, doi:10.1029/2007GL032043.

McGinnis, D. F., J. Greinert, Y. Artemov, S. E. Beaubien, and A. Wüest (2006), Fate of rising methane bubbles in stratified waters: How much methane reaches the atmosphere? J. Geophys. Res., 111, C09007, doi:10.1029/2005/JC003183.

Merewether, R., M. S. Olsson, and P. Lonsdale (1985), Acoustically detected hydrocarbon plumes rising from 2-km depths in the Guayamas Basin, Gulf of California, J. Geophys. Res., 90, 3075-3085. 
Nikolovska, A., H. Sahling, and G. Bohrmann (2008), Hydroacoustic methodology for detection, localization, and quantification of gas bubbles rising from the seafloor at gas seeps from the eastern Black Sea, Geochem. Geophy. Geosy., 9, doi:10.1029/2008GC002118.

Padilla, A., K. Rychert, and T. C. Weber (2017), Experimental observations of acoustic backscattering from spherical and wobbly bubbles, Paper presented at the $173^{\text {rd }}$ Meeting of the Acoustical Society of America, Boston, Ma.

Ostrovsky, I., D. F. McGinnis, L. Lapidus, and W. Eckert (2008), Quantifying gas ebullition with echosounder: The role of methane transport by bubbles in a medium- sized lake, Limnol. Oceanogr. Methods, 6, 105-118, doi:10.4319/lom.2008.6.105.

Reeburgh, W. S. (2007), Oceanic methane biogeochemistry, Chem. Rev., 107(2), 486-513.

Rehder, G., I. Leifer, P. G. Bewer, G. Friederich, and E. T. Peltzer (2009), Controls on methane bubble dissolution inside and outside the hydrate stability field from open ocean field experiments and numerical modeleing, Mar. Chem., 114, 19-30, doi:10.1016/j.marchem.2009.03.004.

Romanovskii, N. N., H. W. Hubberten, A.V. Gavrilov, A. A. Eliseeva, and G. S. Tipenko (2005), Offshore permafrost and gas hydrate stability zone on the shelf of East Siberian Seas, Geo. Mar. Lett., 25, 167-182.

Römer, M., H. Sahling, T. Pape, A. Bahr, T. Feseker, P. Wintersteller, G. Bohrmann (2012a) Geological controls and magnitude of methane ebullition for a high-flux seep area in the Black Sea - the Kerch seep area, Mar. Geo., 319-322, 57-74, doi:10.1016/j.margeo.2012.07.005. 
Römer, M., H. Sahling, T. Pape, G. Bohrmann, and V. Spieß (2012b), Quantification of gas bubble emissions from submarine hydrocarbon seeps at the Makran continental margin (offshore Pakistan), J. Geophys. Res. Oceans, 117, doi:10.1029/2011JC007424.

Römer, M., M. Riedel, M. Scherwath, M. Heesemann, and G. D. Spence (2016a), Tidally controlled gas bubble emissions: A comprehensive study using long-term monitoring data from the NEPTUNE cabled observatory offshore Vancouver Island, Geochem. Geophys. Geosyst. 17, doi:10.1002/2016GC006528.

Ruppel, C. D. and J. D. Kessler (2016), The interactions of climate change and methane hydrates, Rev. Geophys,55:126-168, doi:10.1002/2016RG000534.

Sapart, C. J., N. Shakhova, I. Semiletov, J. Jansen, S. Szidat, D. Kosmach, O. Dudarev, C. van der Veen, M. Egger, V. Sergienko, A. Salyuk, V. Tumskoy, J. Tison, and T. Rockmann (2017), The origin of methane in the East Siberian Arctic Shelf unraveled with triple isotope analysis, Biogeoscin., 14, 2283-2292, doi:10.5194/bg-14-2283-2017.

Schneider von Deimling, J., G. Rehder, J. Greinert, D. F. McGinnnis, A. Boetius, and P. Linke (2011), Quantification of seep-related methane gas emissions at Tommeliten, North Sea, Cont. Shelf Res., 31(7), 867-878.

Semiletov, I. P. (1999), Aquatic sources and sinks of $\mathrm{CO} 2$ and CH4 in the polar regions, J. Atmo. Sci., vol. 56(2), pp. 286-306.

Semiletov, I. P., N. E. Shakhova, V. I. Sergienko, I. I. Pipko, and O. V. Dudarev (2012), On carbon transport and fate in the East Siberian Arctic land-shelf-atmosphere system, Environ. Res. Lett., 7, doi:10.1088/1748-9326/7/1/015201. 
Shakhova, N., I. Semiletov, and G. Panteleev (2005), The distribution of methane on the Siberian Arctic shelves: Implications for the marine methane cycle, Geophys. Res. Lett., 32, doi:10.1029/2005GL022751.

Shakhova, N., I. Semiletov, A. Salyu, V. Yusupov, D. Kosmach, and O. Gustafsson (2010), Extensive methane venting to the atmosphere from sediments of the East Siberian Arctic Shelf, Science, 327, 1246-1250, doi:10.1126/science.1182221.

Shakhova, N., I. Semiletov, I. Leifer, V. Sergienko, A. Salyuk, D. Kosmach, D. Chernykh, C. Stubbs, D. Nicolsky, V. Tumskoy, and Ö. Gustafsson (2014), Ebullition and storm-induced methane release from the East Siberian Arctic Shelf, Nat. Geosci., 7, 64-70, doi:10.1038/ngeo2007.

Socolofsky, S. A., A. L. Dissanayake, I. Jun, J. Gros, J. S. Arey, and C. M. Reddy (2015), Texas A\&M Oilspill Calculator (TAMOC): Modeling Suite for Subsea Spills, $38^{\text {th }}$ AMOP Technical Seminar on Environmental Contamination and Response, Vancouver, B. C., Canada, June 24.

Stanton, T. K., D. Chu, J. M. Jech, and J. D. Irish (2010), New broadband methods for resonance classification and high-resolution imagery of fish with swimbladders using a modified commercial broadband echosounder, ICES Journal of Marine Science, 67(2): 365-378.

Stanton, T. K. and D. Chu (2008), Calibration of broadband active acoustic systems using a single standard spherical target, Oceans 2008 - MTS/IEEE Kobe Techno-Ocean, Vol. 1-3: 144-146.

Turin, G. L. (1960). "An introduction to matched filters". IRE Transactions on Information Theory. 6 (3): 311-329. doi:10.1109/TIT.1960.1057571. 
Veloso, M., J. Geinert, J. Mienert, and M. De Batist (2015), A new methodology for quantifying bubble flow rates in deep water using splitbeam echosounders: Examples from Arctic offshore NW-Svalbard, Limnol. Oceanogr. Methods, 13, 267-287, doi:10.1002/lom3.10024.

Walczowski, W. and J. Piechura (2006), New evidence of warming propagating toward the Arctic Ocean, Geophys. Res. Lett., 33, L12601, doi:10.1029/2006GL025872.

Wang, B. and S. Socolofsky (2015), A deep-sea, high-speed, stereoscopic imaging system for in situ measurements of natural seep bubble and droplet characteristics, Deep Sea Res. Part I Oceanogr. Res. Pap., 104, 134-148.

Wang, B., S. A. Socolofsky, J. A. Breier, and J. S. Seewald (2016), Observations of bubbles in natural seep flares at GC 600 and MC 118 using in situ quantitative imaging. JGR: Oceans, 121, doi:10.1002/2015JC011452.

Weber, T. C., L. Mayer, K. Jerram, J. Beaudoin, Y. Rzhanov, and D. Lovalvo (2014), Acoustic estimates of methane gas flux from the seabed in a $6000 \mathrm{~km}^{2}$ region in the Northern Gulf of Mexico, Geochem. Geophys. Geosyst., 15, 1911-1925, doi:10.1002/2014GC005271.

Woodgate, R. A., K. Aagaard, and T. J. Weingartner (2006), Interannual changes in the Bering Strait fluxes of volume, heat, and freshwater between 1991 and 2004, Geophys. Res. Lett., 33, L15609, doi:10.1029/2006GL026931. 